San Jose State University

SJSU ScholarWorks

Master's Theses

Master's Theses and Graduate Research

1995

\title{
Fecundity and embryonic development of Octopus rubescens Berry from Monterey Bay, California
}

Steven A. Osborn

San Jose State University

Follow this and additional works at: https://scholarworks.sjsu.edu/etd_theses

\section{Recommended Citation}

Osborn, Steven A., "Fecundity and embryonic development of Octopus rubescens Berry from Monterey Bay, California" (1995). Master's Theses. 1170.

DOI: https://doi.org/10.31979/etd.7xt8-yjr2

https://scholarworks.sjsu.edu/etd_theses/1170

This Thesis is brought to you for free and open access by the Master's Theses and Graduate Research at SJSU ScholarWorks. It has been accepted for inclusion in Master's Theses by an authorized administrator of SJSU ScholarWorks. For more information, please contact scholarworks@sjsu.edu. 


\section{INFORMATION TO USERS}

This manuscript has been reproduced from the microfilm master. UMI films the text directly from the original or copy submitted. Thus, some thesis and dissertation copies are in typewriter face, while others may be from any type of computer printer.

The quality of this reproduction is dependent upon the quality of the copy submitted. Broken or indistinct print, colored or poor quality illustrations and photographs, print bleedthrough, substandard margins, and improper alignment can adversely affect reproduction.

In the unlikely event that the author did not send UMI a complete manuscript and there are missing pages, these will be noted. Also, if unauthorized copyright material had to be removed, a note will indicate the deletion.

Oversize materials (e.g., maps, drawings, charts) are reproduced by sectioning the original, beginning at the upper left-hand corner and contimuing from left to right in equal sections with small overlaps. Each original is also photographed in one exposure and is included in reduced form at the back of the book.

Photographs included in the original manuscript have been reproduced xerographically in this copy. Higher quality $6^{n} \times 9^{n}$ black and white photographic prints are available for any photographs or illustrations appearing in this copy for an additional charge. Contact UMI directly to order.

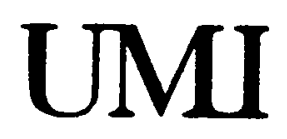

A Bell \& Howell intormation Company 



\title{
FECUNDITY AND EMBRYONIC DEVELOPMENT OF OCTOPUS RUBESCENS BERRY FROM MONTEREY BAY, CALIFORNIA
}

\author{
A Thesis \\ Presented to \\ The Faculty of Moss Landing Marine Laboratories \\ San Jose State University \\ In Partial Fulfillment \\ of the Requirements for the Degree \\ Master of Science
}

by

Steven A. Osborn

December, 1995 
UMI Number: 1377261

OMI Microform 1377261

Copyright 1996, by UMI Company. All rights reserved.

This microform edition is protected against unauthorized copying under Title 17, United States Code.

\section{UMI}

300 North Zeeb Road

Ann Arbor, MI 48103 
(C) 1995

Steven A. Osborn

ALL RIGHTS RESERVED 
APPROVED FOR THE DEPARTMENT OF MOSS LANDING MARINE LABORATORIES

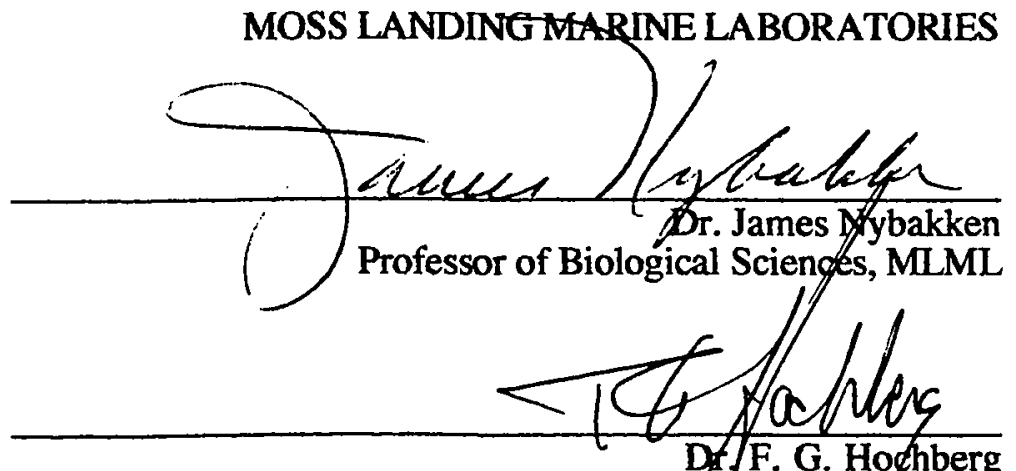

Curator, Department of Invertebrate Zoology Santa Barbara Museum of Natural History

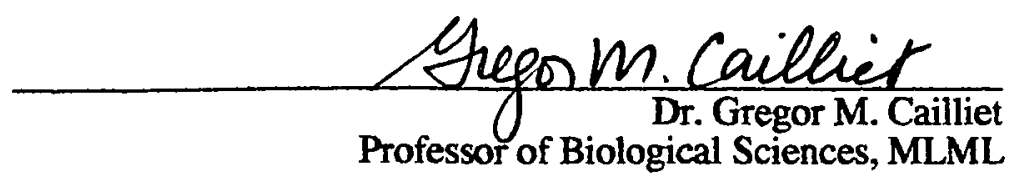

APPROVED FOR THE UNIVERSITY

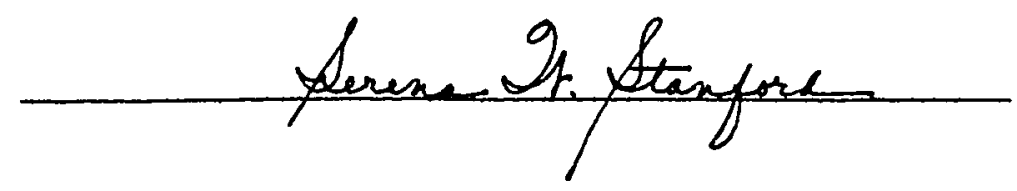




\section{ABSTRACT \\ FECUNDITY AND EMBRYONIC DEVELOPMENT OF OCTOPUS RUBESCENS BERRY FROM MONTEREY BAY, CALIFORNIA \\ by Steven A. Osborn}

Fecundity and embryonic analyses were conducted on the common red octopus, Octopus rubescens Berry, 1953, from Monterey Bay, California during the years 1989 through 1993. Relatively constant fecundities (117-140 eggs/g) and brood weights (2530\%) were recorded for all females weighing 35-140 g (maximum size: $150 \mathrm{~g}$ ). Although variable, females weighing less than $35 \mathrm{~g}$ were significantly less fecund. On an absolute basis, larger females laid more and longer festoons containing greater egg densities. Festoon length, however, was consistently recorded at approximately $45-60 \%$ female mantle length. Gravimetric techniques proved approximately four times more accurate and precise than volumetric techniques. Although individual festoons accurately assessed fecundity ( $<10 \%$ error), increasing the number of festoons per subsample to four incieased accuracy by $50 \%$ and precision by $60 \%$.

Stages of embryonic development in Octopus rubescens were identified and described from embryos reared in the laboratory. Development times ranged from 52-91 days at mean temperatures of $17.7^{\circ} \mathrm{C}$ and $14.8^{\circ} \mathrm{C}$, respectively. A dichotomous key to the stages of development was produced. Chromatophore patterns of the most common California octopus paralarvae were compared. 


\section{ACKNOWLEDGEMENTS}

I owe many thanks to my committee members Dr. James Nybakken, Dr. Eric Hochberg, and Dr. Gregor Cailliet for their guidance, encouragement, patience, and wisdom, and for critically reviewing this manuscript. I have enjoyed working with them immensely, and hope for continued interaction in the future.

Many people helped in this research, however, I cannot mention all of them. Suffice it to say that I am indebted to all of them. Many thanks to Hopkins Field Station for providing valuable water table space following the Loma Prieta earthquake.

Many thanks to the faculty, staff, and students of Moss Landing Marine Laboratories. Their help and encouragement have been extraordinary. Special thanks to Michelle Hester, Gail Johnston, and Sandy Yarborough for their friendship and support over the years.

This work is the result of research sponsored in part by the David and Lucille Packard Foundation, the Earl and Ethyl Myers Oceanographic and Marine Biology Trust, the California Sea Grant Graduate Research Fellowship, the Western Society of Malacologists, and the Conchologists of America. 
TABLE OF CONTENTS

Page

Abstract

Acknowledgments

iv

List of Tables

List of Figures

List of Appendices

v

vii

viii

ix

I. GENERAL INTRODUCTION 1

II. FECUNDITY

Introduction

Materials and Methods

Results

Discussion

III. EMBRYONIC DEVELOPMENT

Introduction

19

$\begin{array}{ll}\text { Materials and Methods } & 20\end{array}$

Results

Embryonic Stages of Octopus rubescens $\quad 22$

Key to Stages of Embryonic Development of Octopus rubescens 30

Discussion

IV. MISCELLANEOUS

Post-Hatching Behavior

Rearing of Paralarvae

Ectoparasite

$\begin{array}{ll}\text { LITERATURE CITED } & 38\end{array}$

$\begin{array}{ll}\text { TABLES } & 44\end{array}$

FIGURES 50

$\begin{array}{ll}\text { APPENDICES } & 68\end{array}$ 


\section{LIST OF TABLES}

Table 1. Comparisons of accuracy and precision of egg counts between readers. $\quad 44$

Table 2. Summarized data for fecundity and brood characteristics. 45

Table 3. Statistical comparisons of the relationship between mean egg density per size class of festoon length and festoon length within each brood. $\quad 46$

Table 4. Comparisons of fecundity between species of octopuses. 47

Table 5. Chromatophore development in embryos of Octopus rubescens. 48

Table 6. Distinguishing characteristics of planktonic paralarvae found along the eastern Pacific. 


\section{LIST OF FIGURES}

Figure 1. Photograph of Octopus rubescens during copulation. 50

Figure 2. Photograph of female Octopus rubescens with brood of eggs. 51

Figure 3. Photograph of festoon viewed through dissecting scope. 51

Figure 4. Methods for quantifying accuracy and precision. 52

Figure 5. Frequency of differences in egg numbers between readers. 53

Figure 6. Chronology of festoon production. 54

Figure 7. Effects of female wet weight on fecundity. 55

Figure 8. Effects of female wet weight on brood weight. 56

Figure 9. Effects of laboratory time on fecundity and female wet weight. 57

Figure 10. Effects of female size on festoon length and numbers of festoons laid. 58

Figure 11. Effects of female wet weight on egg density. 59

Figure 12. Percent deviation from true fecundity using individual festoons for estimates.

Figure 13. Effects of cumulative numbers of subsamples and cumulative numbers of festoons per subsample on the accuracy and precision of fecundity estimates.

Figure 14. Effects of numbers of subsamples and numbers of festoons per subsample on the accuracy and precision of fecundity estimates.

Figure 15. Synthesis of brood characteristics and their theoretical relationship to increasing female size and increasing festoon length.

Figure 16. Photographs of three stages of embryonic development in Octopus rubescens.

Figure 17. Chromatophore development in embryos of Octopus rubescens.

Figure 18. Typical sequence of embryonic development in Octopus rubescens recorded at three temperature ranges.

Figure 19. Photograph of ectoparasites on an egg of Qctopus rubescens. 


\section{LIST OF APPENDICES}

Page

Appendix 1. Recorded festoon parameters used for fecundity analyses.

68

Appendix 2. Effects of numbers of subsamples and numbers of festoons per subsample on the accuracy and precision of fecundity estimates. 


\section{GENERAL INTRODUCTION}

Octopus rubescens Berry, 1953 is the most common shallow-water octopus of the eastern North Pacific Ocean (Hochberg and Fields 1980). This species has a latitudinal distribution from the Gulf of Alaska to southern Baja California, Mexico and occurs from intertidal areas to depths of $200 \mathrm{~m}$ (Hochberg 1987). It inhabits numerous substrate types ranging from inshore rocky areas to offshore soft mud bottoms (Hochberg and Fields 1980; pers. obs.).

Octopus rubescens of ten constitutes the dominant prey species in the diets of marine mammals and seabirds. Oxman (1995) reported that $\underline{\text { O. }}$ rubescens dominated harbor seal diets in Monterey Bay. Octopus rubescens comprised up to $20 \%$ of the prey of Pigeon Guillemonts throughout California (Ainley and Boekelheide 1990) and is an alternative prey during warm water years for other seabird species (Sydeman, Point Reyes Bird Observatory, pers. comm.). ROV observations in Monterey Bay identified it as the most abundant taxon at a depth of $200 \mathrm{~m}$ (Butler 1992) with densities of $300,000 / \mathrm{km}^{2}$. The fisheries potential of $\underline{\mathrm{O}}$. rubescens was recently assessed in southern California waters (Rasmussen and Kronman 1990).

Octopus rubescens has been the subject of numerous studies. Ballering et al. (1972) developed evenomation techniques for this species. The ultrastructure of its Kolliker bundles was described by Brocco et al. (1974). Dicyemid mesozoan parasites within the kidneys of $\underline{\mathrm{O}}$. rubescens were described (McConnaughey 1941, 1949) with species-specific assemblages noted (Hochberg 1990). Using $\underline{O}$. rubescens as a model, Packard and Hochberg (1977) described skin patterning in Octopus, and Warren et al. (1974) described its color changes during attacks on prey. Individual and social behaviors of this species were described by Mather and Anderson (1993) and Dorsey (1976), respectively. 
Little information, however, exists on the life history of Octopus rubescens. The reasons for this appear to be three-fold: It has long been considered hard to maintain in aquaria; it is venomous and has a tendency to bite (Halstead 1949; Berry and Halstead 1954; Oglesby 1972); and it has small planktonic hatchlings, which have never been reared beyond the planktonic stage. Nevertheless, some life history information does exist. In Monterey Bay, this species attains a maximum size of approximately $150 \mathrm{~g}$ (Osbom, unpubl. data) and is reported to undergo seasonal depth migrations moving into shallow water during summer months (Hochberg 1980). Various aspects of its reproduction were reported by Fisher $(1923,1925)$ and fecundities of $20,000-50,000$ eggs were reported by MacGinitie and MacGinitie (1968). Planktonic hatchlings of $\underline{\mathrm{O}}$. rubescens often have been collected in midwater trawls (McGowan 1967; Young 1972; Green 1973; Mills 1983) and were described by Hochberg et al. (1992).

Some of the information on the life history of Octopus rubescens is contradictory. Dorsey (1976) stated that this species has a life cycle of two years and an embryonic development time of ten months. In contrast, Hochberg and Fields (1980) stated that $\underline{\mathrm{O}}$. rubescens has an annual life cycle, with juveniles hatching after only six to eight weeks. Although Dorsey's and Hochberg's studies were conducted at $7^{\circ} \mathrm{C}$ and $14^{\circ} \mathrm{C}$ respectively, estimates of their integrated time-temperature values do not coincide (Yamashita 1974; Strathman 1987).

Numerous questions remain regarding the life history of Octopus rubescens, an important species in marine and estuarine ecosystems in the eastern North Pacific Ocean. The objectives of this research were to develop techniques to describe the fecundity and embryonic development of laboratory-reared $\underline{\mathrm{O}}$ rubescens. This resulted in the development of models for describing fecundity and embryonic development which can be applied to other small-egg species of benthic octopuses. 


\section{FECUNDITY OF OCTOPUS RUBESCENS}

\section{INTRODUCTION}

Knowledge of cephalopod life histories is required to prevent over-exploitation of commercial stocks. High-intensity fisheries methods are relatively recent to the cephalopod industry (Amaratunga 1987). High-intensity fisheries are known to cause ecological perturbations (Caddy 1983) and often lead to over-exploitation of the resource. Todarodes pacificus Steenstrup, 1880 was the most extensively exploited resource in cephalopod fisheries until stocks were depleted in the 1970's (Rathjen and Voss 1987).

Fisheries dynamics are well understood in regards to fish stocks (Beverton and Holt 1957; Ricker 1958). However, conventional fish stocks are long-lived and multi-aged whereas cephalopods typically are short-lived with one generation completely replacing the next (Amaratunga 1987). Populations of such short-lived species may not recover from even brief periods of over-exploitation. Thus, population dynamics of cephalopods must be understood for current and potential fisheries assessment and proper resource utilization. This requires a full understanding of cephalopod life histories, including fecundities.

Few studies have analyzed fecundity in cephalopods. Much of the information on cephalopod fecundities has been obtained from commercially important species, composed mainly of teuthoid squids (for review see Mangold 1987). Although octopods comprise nearly $25 \%$ of all major species of commercial cephalopods (Rathjen and Voss 1987), even less information exists on the fecundities of these cephalopods.

Existing data on octopus fecundities provide limited information. Benthic, littoral octopuses can be divided into three (non-taxonomic) groups: (1) species that produce large eggs (>10 mm) and benthic young; (2) species that produce small eggs ( $<6 \mathrm{~mm}$ ) and long duration planktonic young (Boletzky 1974); and (3) species that produce medium-sized eggs $(6-10 \mathrm{~mm})$ and short duration planktonic young. Information on octopus fecundities 
has been derived primarily from trawl data of large-egg species (Macalaster 1976; Boyle et al. 1988; Kuehl 1988; Perez and Haimovici 1991). Gonadal indices from numerous trawlcollected specimens can provide fecundity data from a large size range of the species. However, accuracy of these data is unclear because a female may not lay all of the eggs found within her ovary and it often cannot be determined if spawning had already begun. Most fecundity data for octopuses have been obtained from laboratory observations of eggs laid by specimens of either small-egg species (Yamashita 1974; Van Heukelem 1976; Forsythe and Hanlon 1985) or large-egg species (Pickford and McConnaughey 1949; Tait 1980). Where known, the majority of octopuses are semelparous, laying all eggs in one brood at the end of the life cycle. Therefore, these data would provide accurate values for fecundity. Unfortunately, such studies have noted fecundities of few animals (i.e., 1-3 females of a species) and, for logistical considerations of counting large numbers of eggs, have employed gravimetric and/or volumetric estimation techniques. Such information says little about the fecundity of the species, because it provides only estimates of fecundity without regard to potential effects of female size.

The goal of this part of the study was to determine the fecundity of Octopus rubescens over a wide size range based on actual, not estimated, numbers of eggs on each festoon, or string of eggs, laid. Such data will allow us to better understand the effect of body size on octopus fecundities and how body size affects physical characteristics of the brood itself (e.g., number of festoons laid, mean festoon length, egg densities, etc.). Also, knowing the actual number of eggs per festoon will allow us to determine the accuracy of gravimetric and volumetric estimation techniques and to determine the effect sample size and replication may have on improving the accuracy of fecundity estimates.

\section{MATERIALS AND METHODS}

Fecundities were determined from 20 female Octopus rubescens ( 10 females per 
breeding season from two consecutive breedings seasons) that were maintained in the laboratory. Octopuses were collected with bottom trawls at depths of $15-60 \mathrm{~m}$ within Monterey Bay, California in the vicinity of Moss Landing Harbor ( $36^{\circ} 48^{\prime} \mathrm{N}, 121^{\circ} 47^{\prime} \mathrm{W}$ ). All octopuses were collected in 1991 and 1992 at the beginning of the breeding season during the months of April through July. A wide variety of gonad maturity stages was observed at time of collection. Attempts were made to utilize females that were either undergoing maturation (i.e., in the process of developing mature ova) or fully mature at the time of collection. All octopuses were transferred to Moss Landing Marine Laboratories where each octopus was isolated in a $21 \times 21 \times 16 \mathrm{~cm}$ plexiglass aquarium . Each aquarium was lined with astroturf to prevent escape. Sand-filtered seawater was provided at a rate of $2.5 \mathrm{~L} / \mathrm{min}$. Mean seawater temperatures in the laboratory were $16.3 \pm 0.3{ }^{\circ} \mathrm{C}$ and $17.7 \pm 0.1^{\circ} \mathrm{C}$ for years 1991 and 1992 , respectively. Octopuses were fed Hemigrapsus oregonensis and Pachygrapsus crassipes (10-12 mm carapace width) ad libitum and all aquaria received only natural indirect sunlight.

On several occasions during maturation, females were paired with males in aquaria (Fig. 1). This ensured viable sperm within the female's reproductive tract, thus preventing any delays in egg-laying. Upon maturation, females were blotted dry and weighed. Wet weights were measured to the nearest $0.01 \mathrm{~g}$. Mantle lengths, defined as the distance from the posterior end of the mantle to the midpoint of the eye, were recorded to the nearest 0.1 $\mathrm{mm}$. Attempts were made to record wet weights and mantle lengths within 1-3 d prior to the onset of egg-laying.

Female Octopus rubescens lay eggs by intertwining and cementing the long chorion stalks of the egg capsules together to form a string, or festoon, of eggs. Each festoon is cemented at one end to the substrate (Fig. 2). For this study, festoons were removed from the substrate within $24 \mathrm{hr}$ of being laid, which permitted observations and data acquisition on eggs at the same stage of embryonic development. Care was taken to remove each 
festoon at the point of attachment to the substrate. Upon removal of each festoon, four parameters were measured: festoon length, festoon wet weight, festoon wet volume, and number of eggs per festoon. Festoon length is defined as the distance from the point of substrate attachment to the most distal portion of the most distal egg. Wet weights were recorded using a standard toploader balance (0-200 g). Wet volumes were recorded using a $25 \mathrm{ml}$ graduated cylinder. All festoons were blotted dry prior to recording wet weights and wet volumes. Recorded measurements for festoon length, festoon wet weight, and festoon wet volume were rounded to the nearest $0.1 \mathrm{~mm}, 0.01 \mathrm{~g}, 0.01 \mathrm{ml}$, respectively. Stereo dissecting microscopes (10-64X) were used to count the number of eggs on each festoon. All recorded values for numbers of eggs per festoon were the average of three separate counts and rounded to the nearest integer. Brood weights and brood volumes were recorded as the total weight and total volume of all festoons laid by the same female, respectively. An Olympus image analysis system (Cue II) was employed for all linear measurements. Upon death of each female, ovaries were observed and any remaining eggs were enumerated.

Immediately following all measurements, festoons were placed into labeled fingerbowls for later analysis of embryonic development. These fingerbowls were partially submerged in water baths at ambient seawater temperatures. Fingerbowls of eggs received flowing ambient seawater at a rate of $0.4 \mathrm{~L} / \mathrm{min}$ and were not aerated.

To ensure data quality, comparisons of egg counts between readers were conducted. Five readers were involved with data acquisition. Eggs were often seen overlapping one another when viewed through the microscope (Fig. 3). Thus, the potential existed for inaccurate egg counts and between reader variation. To test for reader bias, 20 festoons were randomly selected and each festoon was enumerated three times by two readers. (No more than two readers, one being this author, were ever involved with data acquisition at any one time). Based on actual numbers of eggs, average percent errors 
(Beamish and Fournier 1981) were calculated for each festoon enumerated by each reader. Mean average percent error was then calculated for each reader to determine if reader accuracies were within acceptable limits (i.e., within $2 \%$ APE). Student's T-tests (t tests) were also conducted to determine if average percent errors were significantly different between readers. Precision was calculated as indices of precision and coefficients of variation (Chang 1982). To ascertain whether logarithmic transformations were required for fecundity values, a one-way analysis of variance (ANOVA) was used to determine if the precision among categories of varying numbers of eggs per festoon was significantly different (i.e., determine if the standard deviation was proportional to the mean). All data, expressed as percentages, were arcsine square root transformed before analysis (Zar 1984). Frequency distributions were used to determine deviation from normality. Homogeneity of variance was tested using Bartlett's test (Zar 1984). A confidence level of $95 \%$ was used when testing the null hypothesis for all statistical tests.

Egg-laying chronology was monitored daily in a total of eight females from two consecutive breeding seasons. An ANOVA was used to determine if the number of eggs laid per night was significantly different among females. A t-test was used to determine if the numbers of eggs laid per night was significantly different between years.

Egg size was recorded and compared within and between broods. Egg length, egg width, and egg wet weight were recorded from ten randomly chosen freshly laid eggs from each of five randomly chosen females. An ANOVA was used to determine if mean egg length, mean egg width, and mean egg wet weight significantly differed among broods. A Tukey's test was used for a posteriori multiple comparisons (Zar 1984). Regression analysis was used to describe the relationship of egg length and egg width to female wet weight.

Four parameters were used to determine the effects of female body size on various brood characteristics. Mean festoon length per brood, numbers of eggs per brood, number 
of festoons per brood, and mean egg density per brood were quantified for each female. Regression analysis was used to describe the relationship of each of these parameters to female wet weight. Regression analysis also was used to determine if mean egg densities varied among $10 \mathrm{~mm}$ festoon length size classes within broods. This information, in conjunction with egg size data, was used to determine if all festoons within a brood were similar enough to allow random sampling of festoons when estimating fecundity.

Laboratory conditions may produce unrealistic and biased fecundity data. To elucidate the effects of laboratory time on fecundities, regression analysis was used to describe the relationship of laboratory time to female wet weight and fecundity.

The effects of gravimetric and volumetric techniques on fecundity estimates were compared using data from 18 females. Three festoons were chosen randomly from a female's brood. Numbers of eggs, wet weights, and wet volumes were summed for all three festoons. These data, in conjunction with brood weight and brood volume, were then used to estimate the total number of eggs within the brood. This procedure was conducted three times, thus producing three fecundity estimates. As actual numbers of eggs laid by the female were known, percent deviations from true fecundities were calculated. Based on these percent deviations, measures of accuracy and precision were calculated and presented as a mean average percent error and a mean index of precision, respectively. Detailed methods for determining accuracy and precision of fecundity estimates (i.e., calculating average percent errors, coefficients of variation, and indices of precision) are presented in Figure 4. The aforementioned procedure was conducted for each of 18 females. All data, expressed as percentages, were arcsine square root transformed (Zar 1984). T-tests were then conducted between average percent errors and coefficients of variation and indices of precision to determine if one technique provided significantly more accurate and/or precise fecundity estimates than the other.

The effects of sample size and replication on fecundity estimates also were 
investigated. Prior to this study is was unclear which method, or a combination thereof, would provide the most accurate and/or precise fecundity estimates: 1) subsampling numerous festoons on only one occasion; or 2) subsampling relatively fewer numbers of festoons on numerous occasions (i.e., numerous distinct subsamples) and then taking a mean of those estimates. To answer this, the effects of cumulative numbers of festoons on the percent deviation from the true fecundity was first investigated. The results determined, under best and worst conditions, the maximum number of festoons necessary to achieve the most accurate fecundity estimates. Three distinct subsamples of one through ten randomly chosen festoons from nine randomly chosen females were used for this analysis. Once an approximate optimal number of festoons per subsample was determined, a similar analysis was conducted to determine the proper number of subsamples needed to achieve the most accurate and precise fecundity estimates. To do this, the effects of using one through ten cumulative subsamples, containing one to five festoons per subsample, were assessed using randomly chosen festoons from the brood of one randomly chosen female. To confirm these results and to investigate the inter-relationship between the number of subsamples and the number of festoons per subsample on the accuracy and precision of fecundity estimates, a two-factor ANOVA was used incorporating data from all 18 females. All data, expressed as percentages, were arcsine square root transformed before analysis (Zar 1984).

\section{RESULTS}

Egg counts between readers were similar, with all readers recording very accurate and precise data. Seventy-nine festoons, containing 29-144 eggs each, were used for comparisons. Egg counts between readers were within one egg $71 \%$ of the time and within two eggs $90 \%$ of the time (Fig. 5). These differences in egg counts resulted in a less than $5 \%$ deviation from the actual number of eggs per festoon. Accuracy was high, with all 
readers having average percent errors of less than $2 \%$ (Table 1). Precision was also high for all readers, with coefficients of variation and indices of precision less than $2 \%$ and $1 \%$, respectively. Although egg counts were significantly different between one set of readers, all data fell within acceptable levels of accuracy and precision and were pooled for analysis. Based on mean coefficients of variation derived from each of the five readers, no significant differences in precision existed among categories of varying numbers of eggs per festoon (ANOVA; $\mathrm{n}=5, \mathrm{~F}=1.02, \mathrm{p}=0.389$ ). Thus, precision was not affected by the numbers of eggs on a festoon and no logarithmic transformations of fecundity data were required prior to further analysis.

All broods were laid during early Spring to late Summer, during the months of March through October, with a peak of egg-laying from June through July. Festoons were produced only during the early morning hours. Egg-laying time ranged from 4-13 d, with approximately $80 \%$ of all festoons laid within the first $5 \mathrm{~d}$ (Fig. 6). The number of festoons produced per day steadily decreased following the fifth day of egg-laying. No more than $55 \%$ of a brood was ever laid in one night. When laying eggs, all females laid significantly similar numbers per night (ANOVA; $n=8, F=1.09, p=0.387$ ). No significant difference in numbers of eggs laid per night occurred between the two years/temperatures (t-test; $\mathrm{n}=8, \mathrm{t}=-1.93, \mathrm{p}=0.059$ ).

Fecundities were obtained from a large size range (Table 2). Female wet weight at time of egg-laying ranged from 23.5-137.5 g, which represents the size range for this species at this latitude (Osborn, unpubl. data). Fecundities ranged from approximately 1,000-19,000 eggs and from approximately $41-140 \mathrm{eggs} / \mathrm{g}$ of female wet weight. Data recorded from all festoons laid by each female are presented in Appendix 1.

A maximum fecundity may exist for this species. A significant positive relationship existed between female wet weight and absolute fecundity ( $t$-test; $n=20, t=24.77$, $p=0.0001)$ and was best represented by the linear equation: $y=-1811.8+140.6 \times\left(r^{2}=0.972\right.$; 
Fig. 7a). No significant relationship (i.e., no significant slope) existed between fecundity (egg/g) and female size for females greater than $35 \mathrm{~g}\left(\mathrm{t}\right.$-test; $\mathrm{n}=10, \mathrm{r}^{2}=0.338, \mathrm{t}=2.02$, $\mathrm{p}=0.0779$, Fig. $7 \mathrm{~b}$ ). Thus, all females with wet weights greater than $35 \mathrm{~g}$ had a fecundity of approximately $117 \pm 8 \mathrm{eggs} / \mathrm{g}$, potentially the maximum fecundity for the species. The relationship between female wet weight and fecundity (eggs/g) for females weighing less than $35 \mathrm{~g}$ was best represented by the linear equation: $y=-40.13+3.903 x\left(r^{2}=0.589\right)$. All eggs laid were fertilized and all females died within two weeks post-hatching. Upon death, no more than five mature eggs remained in the ovary of any female.

In regard to female size, brood weight followed trends similar to fecundity (Fig. 8). No significant relationship (i.e., no significant slope) existed between brood weight (presented as percent female wet weight) and female size for females greater than $35 \mathrm{~g}$ ( $t$-test; $n=9, r^{2}=0.376, t=2.053, p=0.0792$ ). Thus, all females with wet weights greater than $35 \mathrm{~g}$ had broods which comprised $25.7 \pm 3.5 \%$ of the female's weight, potentially the maximum brood weight for the species. The relationship between brood weight and female wet weight for females weighing less than $35 \mathrm{~g}$ was not adequately described (i.e., $\mathrm{r}^{2}>0.5$ ) by linear or curvilinear analyses.

The effects of laboratory time on fecundity appear to be minimal (Fig. 9). A significant positive relationship existed between the amount of time a female was held in the laboratory prior to egg-laying and female wet weight at time of egg-laying (t-test; $n=14$, $t=10.06, p<0.001$ ) and was best described by the linear equation: $y=16.0+0.689 x$ ( $\mathbf{r}^{2}=0.894$; Fig. 9a). A slight but significant positive relationship existed between fecundity (eggs/g) and laboratory time ( $\mathrm{t}$-test; $\mathrm{n}=14, \mathrm{r}^{2}=0.402, \mathrm{t}=2.84, \mathrm{p}=0.015$, Fig. 9b). Females $(n=10)$ maintained in the laboratory for relatively short periods (i.e., 10-50 d) had wide ranging fecundities. Five of these females had fecundities that were not significantly different from females maintained in the laboratory for $130-180 \mathrm{~d}$ ( $\mathrm{t}$-test; $\mathrm{N}=9, \mathrm{t}=-2.112$, $\mathrm{p}=0.073$ ). 
A maximum brood weight, in conjunction with a maximum number of eggs/g of female wet weight, suggested similar egg sizes between females. Egg size was nearly identical within broods. Ten randomly selected eggs from each of five females (23-89 $\mathrm{g})$ rendered mean egg lengths, mean egg widths, and mean wet weights of $2.99 \pm 0.23 \mathrm{~mm}$, $1.05 \pm 0.04 \mathrm{~mm}$, and $2.56 \pm 0.50 \mathrm{mg}$, respectively. Highly precise data revealed significantly different egg lengths (ANOVA; $n=5, F=835.45, p<0.001$ ) and egg widths (ANOVA; $n=5, F=54.27, p<0.001$ ) among all broods. Although trends suggested a slight positive relationship, egg length ( $t$-test; $n=5, r^{2}=0.759, t=3.07, .05<p<.10$ ) and egg width ( $t$-test; $n=5, r^{2}=0.64, t=2.30, .10<p<.20$ ) were not significantly related to female wet weight. Egg wet weights were not significantly different among broods (ANOVA; $n=5$, $\mathrm{F}=0.57, \mathrm{p}=0.6877)$.

On an absolute basis, larger females laid more and longer festoons (Fig. 10). Mean festoon length per female ( $t$-test; $n=18, r^{2}=0.790, t=10.67, p<0.001 ;$ Fig. 10a) and the number of festoons laid by each female ( $t$-test; $n=18, r^{2}=0.733, t=6.61, p<0.001$; Fig. 10b) were significantly and positiveiy related to female wet weight. Plotting the number of festoons laid by each female and female wet weight (Fig. 10b) suggested that regardless of female size a maximum of 80-100 festoons may be laid. Although highly precise data revealed significantly different mean festoon lengths among females (ANOVA; $n=17$, $F=9.91, p<0.0002$ ), an apparent peak in festoon length existed among all females, regardless of size, as two-thirds of all festoons laid $(n=867)$ were within $40-75 \%$ of the female's mantle length (Fig. 10c).

Egg densities differed among broods but were similar within broods. Although mean egg density per female and female wet weight were significantly and positively related ( $\mathrm{t}$-test; $\left.\mathrm{n}=18, \mathrm{r}^{2}=0.548, \mathrm{t}=4.40, \mathrm{p}<0.001\right)$, data were not adequately described (i.e., $\mathrm{r}^{2}>0.6$ ) by linear or curvilinear analyses (Fig. 11). Within a brood, mean egg density per size class of festoon length was not correlated with festoon length (Table 3). Thus, egg 
density within a brood remained constant regardless of festoon length.

Gravimetric techniques provided significantly more accurate and precise fecundity estimates than volumetric techniques. Since all festoons within each brood had constant egg densities, egg sizes, and amounts of cement material, increasing the number of eggs on each festoon should have increased the weight and/or volume of each festoon in direct proportion. Results rendered significantly higher $r$-squared values for wet weights

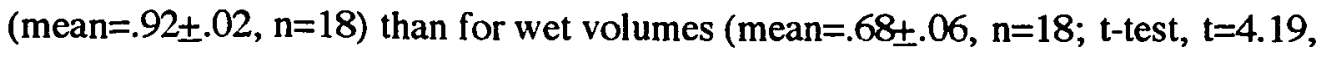
$\mathrm{p}<0.0001$ ), suggesting gravimetric techniques provide more accurate estimates of the number of eggs on each festoon and, ultimately, the fecundity of the female. Based on average percent errors, gravimetric techniques (mean $=4.6 \pm 2.5 \%, \mathrm{n}=18)$ rendered significantly more accurate estimates of fecundity than volumetric techniques (mean $=15.4 \pm 10.6 \%, n=18 ; t$-test, $t=4.20, p<0.0001$ ). Based on indices of precision, gravimetric techniques (mean $=2.0 \pm 1.3 \%, \mathrm{n}=18$ ) rendered significantly more precise estimates of fecundity than volumetric techniques (mean $=8.2 \pm 4.4 \%, n=18 ; t-t e s t, t=-5.74$, $\mathrm{p}<0.0001)$.

The accuracy of fecundity estimates was consistently good with no regard to numbers of subsamples or subsample size (Fig. 12). Each festoon was individually used to gravimetrically estimate fecundity. Results indicated that $89.5 \%$ of all fecundity estimates ( $n=907)$ were within $\pm 12.5 \%$ of the true fecundity. Over $72 \%$ of all fecundity estimates were within $\pm 7.5 \%$ of the true fecundity. The greatest deviations in fecundity estimates were based on festoons of less than average lengths.

Initial investigations revealed that the accuracy and precision of fecundity estimates could be increased by increasing the number of subsamples and subsample sizes (Fig. 13). Without replicating numbers of subsamples, it was only necessary to use approximately five festoons to render accurate estimates of fecundity (Fig. 13a). Based on data from one female, it was only necessary to use approximately five subsamples to render accurate 
(Fig. 13b) and precise (Fig. 13c) estimates of fecundity, regardless of the number of festoons per subsarıple.

Based on data from all 18 females, both accuracy and precision were maximized by increasing the number of festoons per subsample rather than increasing the number of subsamples (Fig. 14). The number of festoons per subsample significantly increased the accuracy (ANOVA; $n=18, F=12.42, p<0.0002$ ) and precision (ANOVA; $n=18, F=15.59$, $\mathrm{p}<0.0002$ ) of fecundity estimates (see Appendix 2 for errors). Although trends suggested slight increases in precision, the number of subsamples used for fecundity estimates did not significantly effect the accuracy (ANOVA; $\mathrm{n}=18, \mathrm{~F}=0.56, \mathrm{p}=0.654$ ) or precision (ANOVA; $\mathrm{n}=18, \mathrm{~F}=1.26, \mathrm{p}=0.320$ ) of fecundity estimates. No significant interaction occurred between the number of subsamples and the number of festoons per subsample in regard to accuracy $(n=18, F=0.31, p=0.881)$ or precision $(n=18, F=1.30, p=0.226)$.

\section{DISCUSSION}

Laboratory conditions c.uld bias fecundity. Optimal laboratory conditions, including near ad libitum diets, were continuously maintained and all females underwent significant growth while in the laboratory (Fig. 8a). It is not clear, however, if such growth is normal for this species. Near ad libitum diets may have increased the amount of energy available for egg production and ultimately may have increased fecundities. However, $50 \%$ of all females maintained in the laboratory for short durations prior to egglaying had fecundities (eggs/g) nearly equal to those of females maintained in the laboratory for the longest durations (Fig. 9b). Although fecundity data may have been slightly biased towards the optimum, recorded fecundities were not unrealistic as to what may be found in the natural environment.

Rates of festoon production may have been similar between all females. Females of slightly different size and from separate breeding seasons laid similar numbers per night. 
Data also show females that had three times the fecundity took three times as long to lay the brood. If one assumes all females spend approximately equal numbers of hours laying eggs per night, then these data suggest all females of Octopus rubescens - regardless of size, temperature, and time of egg-laying - have similar rates of festoon production.

Although sample size was small $(n=20)$, several relationships between fecundity and body size were apparent. Simple linear regressions provided maximum fecundity estimates of $141 \mathrm{eggs} / \mathrm{g}$ of female body weight. Actual measurements revealed a maximum fecundity of approximately $117 \mathrm{eggs} / \mathrm{g}$. Although no significant slope (i.e., no significant increase in fecundity) existed for females greater than $35 \mathrm{~g}$, it was closely approached $(\mathrm{p}=0.0779)$. It would be safe to assume, therefore, that the maximum fecundity for the species lies somewhere between 117-141 eggs/g. These data also suggest that females with wet weights of less than $35 \mathrm{~g}$ could not allocate the maximum amount of energy into egg production, with much energy still possibly going towards growth.

The fecundity data of Octopus rubescens are similar to the fecundities reported for other small-egg species of octopus (Table 4). Although absolute fecundities among smallegg species of octopus differ by orders of magnitude, fecundities relative to body size are similar. As expected, $\underline{\text { O. }}$ rubescens is significantly more fecund than any large-egg species of octopus.

The large size range of reproductively mature females suggests two cohorts may exist within a single breeding season. Seasonal reproduction (i.e., spring-summer) of variously-sized females suggest females are responding to environmental cues, most probably changes in light intensity and/or duration. These cues stimulate the optic glands to produce a hormone which triggers gonad maturation (Wells and Wells 1959). Gonads will not respond to this hormone, however, until they have achieved a minimum stage of development (Richard 1970). Unsynchronized growth rates within a recruiting population could produce juveniles with varying degrees of gonad development. When environmental 
cues induce hormone production, larger juveniles could begin to mature during the winter and reproduce the following spring as one of the relatively smaller reproductive females. Slower growing juveniles would again overwinter as immature adults and contribute to the spawning population the following spring as one of the relatively larger reproductive females. Such a reproductive strategy results in a cohort less susceptible to adverse environmental conditions and poor prey recruitment, thus promoting population stability.

The effects of female body size on various brood characteristics are not completely clear. Figure 15 shows various brood characteristics in theoretical relation to female body size depicted as rates of change. As reported above, a linear relationship existed between female size and absolute fecundity. Fecundity, relative to female size, did not increase or decrease significantly. It also was reported above that festoon length increased absolutely with increasing female size (Fig. 10a). However, the rate of increase in festoon length relative to body size was actually decreasing. No rate of change (i.e., no relative increases or decreases in festoon length) was observed for festoon length relative to female mantle length. Thus, on a relative basis, larger females lay similar numbers of eggs on shorter festoons. This can be accomplished by either increasing the density of eggs on these shorter festoons or by increasing the total number of festoons laid. The number of festoons laid appeared to level off at approximately 90 festoons for females greater than $90 \mathrm{~g}$ (Fig. 10b). This, coupled with a slight but continuous increase in egg densities with increasing female size (Fig. 11), suggested, albeit inconclusively, that females may increase the number of eggs on festoons more so than increasing the numbers of festoons they lay.

Brood characteristics can be explained by a combination of both behavioral and physical constraints. A constant festoon length of approximately $45-60 \%$ fernale mantle length was recorded for all festoons. Observations made during the egg-laying procedure help explain this consistency. Immediately prior to egg-laying, females position the mouth 
region flat against the substrate. The distal two-thirds of all suckers on each arm are then firmly adhered to the substrate (i.e., aquarium glass). This limits the distance a female can extend dorsally, away from the substrate, which is required as the female intertwines more eggs onto the end of the festoon. When the female no longer can extend away from the substrate without relinquishing suction, she releases the festoon, repositions herself flat on the substrate, and starts producing another festoon. Such a procedure is analogous to having an open hand placed on a flat object and then trying to lift the palm of the hand away from a flat surface without lifting any part of the fingers; the palm of the hand is going to move away from the object approximately the same distance every time. Similar egg laying procedures have been recorded for other species of octopuses (Gravely 1908). For those species I would theorize that festoon length is very consistent within a brood.

Additionally, I predict that regardless of size all species that lay eggs in long festoons and that have body proportions (i.e., ratio of arm length to mantle length) similar to Qctopus rubescens lay festoons approximately $45-60 \%$ of the female's mantle length.

Additional brood characteristics were noted. Larger females laid relatively shorter festoons. This seems appropriate since weight varies as the cube of linear dimensions and festoon length is directly related to the linear dimension of mantle length which, in turn, is in proportion to the length of the arms, which define a female's ability to extend from the substrate during egg-laying. Larger females also laid more eggs while producing relatively shorter festoons. To accomplish this by increasing the number of eggs on each festoon as opposed to increasing the total number of festoons laid suggests that the area of substrate used for festoon attachment is limited by the area the female can successfully brood.

Gravimetric techniques proved nearly four times more accurate and precise than volumetric techniques. I therefore advocate the use of gravimetric techniques for estimating fecundities in octopuses. The increased accuracy of gravimetric techniques may be due to differences in detectable resolutions of instruments and analysts. Although the smallest 
diameter graduated cylinder that would allow the passage of festoons was used for all volume measurements, the analyst's ability to accurately detect changes in volume was less than the ability of the analytical balance to accurately detect changes in weight. Such results may differ for larger species which lay small eggs (e.g., Octopus cyanea). Compared to $\underline{\mathrm{O}}$. rubescens, these octopuses lay longer festoons of similar diameters, thus allowing a greater volume change to be measured with proportionately less error.

Results indicated additional techniques may further increase the accuracy and precision of fecundity estimates. For Octopus rubescens festoons may be subsampled randomly since egg size and egg densities were similar on all festoons within each brood. Results also suggest one should avoid subsampling festoons of relatively shorter lengths. Although individual festoons fairly accurately estimated fecundity ( $<10 \% \mathrm{APE})$, increasing the number of festoons per subsample to four increased accuracy by $50 \%$ and precision by $60 \%$. Such procedures are recommended, since little additional time and effort are required.

Conclusions ascertained in this study regarding fecundity estimation techniques will not apply to all octopuses. Since all fecundity estimation techniques require subsampling of festoons, the greater the similarities of all festoons, the greater the accuracy of fecundity estimates. The high accuracy and precision achieved in this study seem appropriate since all festoons within each brood of $\underline{\text { O}}$. rubescens had similar lengths, egg densities, and egg sizes. Similar studies need to be conducted on other species which lay small eggs in festoons, such as $\underline{\mathrm{O}}$. bimaculatus, $\underline{\mathrm{O}}$. vulgaris, and $\underline{\mathrm{O}}$. cyanea. Similar studies conducted on other species having dissimilar egg-laying procedures may yield different conclusions. 


\section{EMBRYONIC DEVELOPMENT OF OCTOPUS RUBESCENS}

\section{INTRODUCTION}

Methods for describing the embryonic development of cephalopods have changed over time. Embryonic development initially was reported in time intervals (e.g., $42 \mathrm{~d}$ post-laying). Researchers recognized the inadequacy of defining stages of embryonic development in time-intervals, because development time may be dependent upon various environmental conditions, especially temperature. More recently many researchers have described morphologically distinct developmental stages, thus allowing interspecies comparisons (Naef 1923, 1928; Amold 1965; Lemaire 1970; Yamamoto 1982; Segawa 1987; Hun Baeg et al. 1992).

The embryonic development of numerous species of octopuses have been described (for reviews see Fioroni 1978; Boletzky 1989). Detailed embryonic development has been reported for many large-egg species of octopus, including Octopus joubini (Boletzky 1969; Boletzky and Boletzky 1969; Opresko and Thomas 1975), Octopus briareus (Boletzky 1969), Eledone moschata (Boletzky 1975), and Hapalochlaena maculosa (Dew 1959). In addition, detailed embryonic development has been reported for many small-egg species of octopus, including Octopus vulgaris (Naef 1928; Fioroni 1965; Fioroni 1970; Boletzky 1971), Octopus dofleini (Gabe 1975), Octopus cyanea (Dew 1959), Octopus tetricus (Joll 1976, 1978), Octopus bimaculatus (Ambrose 1981), Octopus burryi (Forsythe and Hanlon 1985), Scaeurgus unicirrhus (Boletzky 1977, 1984) and Eledone cirrhosa (Mangold et al. 1971; Fuchs 1973; Bradbury 1974).

The staging system currently used in studies of octopod embryology is subject to interpretation. All aforementioned studies of octopod embryology used a staging system developed by Naef (1928) for Octopus vulgaris. This staging system excludes features of the internal anatomy. The stages of embryonic development are based entirely on surface 
morphology recognizable in preserved specimens. Researchers have found Naef's stages adequate for describing embryonic development in most octopuses. However, many heterochronies have been noted which of ten have prevented objective assignments to specific stages. Researcher interpretation currently plays an important role in defining embryonic development of octopuses.

Naef (1928) realized heterochronies would exist between species in the development of various organ systems, but no attempt was made to reduce their effects. Heterochronies will always exist between species. Thus, emphasis should be placed on choosing diagnostic characters with the least amount of intraspecific and interspecific variability. Naef's stages are based on diagnostic characters having high degrees of interspecific variability. By selecting diagnostic characters containing low intraspecific and interspecific variability, much of the subjectiveness in deciphering stages of embryonic development in octopuses may be reduced. A staging system based on such diagnostic characters would promote embryological studies and interspecies comparisons.

The specific objectives of this part of the study were to: (1) identify distinct stages of development in laboratory-reared embryos of Octopus rubescens; (2) list the state of development of all potential diagnostic characters throughout each stage; (3) select diagnostic characters specific for each stage which have low intraspecific variability and no overlap into adjacent stages; and (4) using the most easily observed, dependable, least subjective, and temperature-independent diagnostic characters, form a key to the embryonic stages of Octopus rubescens.

\section{MATERIALS AND METHODS}

The embryonic development of eggs from 21 females of Octopus rubescens (from five annual breeding seasons) was monitored in the laboratory. Animals and festoons were collected and reared as described in the Materials and Methods section of the preceding 
chapter. Temperature ranges were recorded weekly. All festoons were supplied with flowing ambient seawater. Local seawater temperatures varied during the course of this study, due to seasonal changes and El Nino influences. This allowed embryonic development to be described under the following five temperature ranges: 1) $13.5-15.5^{\circ} \mathrm{C}$, Spring 1989 ; 2) $13.5-15.5^{\circ} \mathrm{C}$, Spring-Summer 1990 ; 3) $16.0-16.5^{\circ} \mathrm{C}$, Summer 1991 ; 4) 17.3-17.9 ${ }^{\circ} \mathrm{C}$, Spring-Summer 1992; and 5) 13.5-15.5 ${ }^{\circ} \mathrm{C}$, Spring 1993.

State of embryonic development was determined daily using standard dissecting microscopes (10-64X), still-photography, and/or video. Embryonic nomenclature of Naef (1928) was used in all descriptions. The color, location, and time of development of each chromatophore were ascertained from 10 embryos per female, from three females per breeding season, from four annual breeding seasons. The chromatophore nomenclature of Young et al. (1989) and Hochberg et al. (1992) was used in all descriptions. An Olympus image analysis system (CUE II) was employed for all measurements.

Stages of embryonic development for Octopus rubescens were identified and are described in detail. All diagnostic characters may be taken literally (e.g. branchial hearts at least partially covered by anteriorly extending ventral mantle). Diagnostic characters were chosen only if they were observed in all embryos examined from five breeding seasons and reared at three different temperature ranges and whether or not any of these embryos were removed from their chorion capsules (outer egg case). Also, all diagnostic characters states had to occur as listed only within the noted stage. Only the most easily observed, dependable, and least subjective characters were used. No temperature-dependent characters were used in hopes of providing a key which could be used throughout this species' wide latitudinal range.

It is believed development time does not change with season, but may change with temperature. To test this, a one-way analysis of variance (ANOVA) was used to determine whether development time (number of days from first egg-laying to first hatching) differed 
among breeding seasons of similar temperature (e.g., $13.5-15.5^{\circ} \mathrm{C}$ ). Also, regression analysis was used to determine if development time was related to temperature. Frequency distributions were used to first determine deviation from normality, and homogeneity of variance was tested using Bartlett's test (Zar 1984). A confidence level of $95 \%$ was used when testing the null hypothesis for both statistical tests.

\section{RESULTS}

Embryonic Stages of Octopus rubescens

Embryonic development was best described by 31 distinct stages ( 30 developmental stages and 1 hatching stage). Blastulation comprised Stages 1 through 10 , which occurred approximately within the first $2 \mathrm{~d}$ of development (at $17.7^{\circ} \mathrm{C}$ ). Gastrulation occurred from Stage 11 through Stage 15. Organogenesis was first evident during Stage 16 and occurred through Stage 25. The character states listed for each stage below were prioritized, with the most reliable, least subjective diagnostic characters presented first. Development time and stages advocated by Naef (1928) are indicated in parentheses. Development time was based on embryos developing in a mean seawater temperature of $17.7^{\circ} \mathrm{C}$, with a range of $17.3-17.9^{\circ} \mathrm{C}$.

Stage $1(0 \mathrm{hr}, \mathrm{N}=0)$ ): (Figure 16a). Freshly laid egg. Micropyle still attached to yolk at animal pole.

Stage 2 ( $3 \mathrm{hr}, \mathbf{N}=0)$ : Fertilization. Distance between animal pole yolk and chorion increases.

Stage 3 ( $20 \mathrm{hr}, \mathrm{N}=0$ ): Blastodisc elevated. Polar bodies evident.

Stage 4 (25 hr, N=0): First cleavage. Furrow arising in center of blastodisc. Twocell stage.

Stage $5(30 \mathrm{hr}, \mathrm{N}=0)$ : Second cleavage. Second furrow forms at right angle to first 
furrow. Four-cell stage.

Stage 6 (35 hr, N=0): Third cleavage. Division unequal. Eight-cell stage.

Stage 7 (40 hr, N=0): Fourth cleavage. Sixteen-cell stage.

Stage 8 (45 hr, N=0): Fif th cleavage. 32-cell stage.

Stage 9 (50 hr, $\mathrm{N}=0$ ): Sixth cleavage. 64-cell stage.

Stage 10 ( 3 days, $\mathbf{N}=1$ ): Discoblastula complete. Approximately 1,000 cells.

Stage 11 (5 days, N=2): Gastrulation begins. Peripheral blastomeres covered by the adjacent cells of the central blastodisc (ectoderm), thus producing the second germinal cell layer (mesendoderm). Perivetilline membrane (continuous yolk syncytium) spreads rapidly over the yolk towards the vegetal pole.

Stage 12 ( 7 days, $N=3$ ): Complete formation of three germinal cell layers. Blastodisc large and elevated.

Stage 13 (9 days, $\mathbf{N}=4$ ): Blastoderm (yolk sac) covers $15 \%$ of egg surface.

Stage 14 (11 days, $N=5$ ): Blastoderm covers $30 \%$ of egg surface.

Stage 15 (13 days, $N=6$ ): Blastoderm covers $50 \%$ of egg surface.

Stage 16 (14 days, $N=7$ ): Blastoderm covers $60 \%$ of egg surface. Rotation begins. Slight invagination of mouth occasionally seen. Organogenesis begins.

Stage 17 (15 days, N=7-8): Blastoderm nearly covers entire egg surface. Mouth distinct as depression on dorsal surface. Optic vesicle primordia seen as placodes. Statocyst primordia seen as small depressions on the lateral edge of ventral surface. Shell gland primordium visible at animal pole.

Stage 18 (16 days, $N=8-9$ ): Post-first inversion. Blastoderm covers entire yolk. Eye primordia being covered by ring folds. Slight elevation of thickened arm band (appears as slight equatorial constriction) designates area of future separation between external yolk and developing embryo. Statocyst primordia distinct. Peripheral elevation of mouth begins although not distinct yet. Mouth invagination increases. Individual arm 
primordia not distinct yet. Mantle primordium, anal primordium, and branchial heart primordia present. Primordia of anterior and posterior funnel folds apparent as placodes. Pulsation of external yolk begins.

Stage 19 (18 days, $\mathbf{N}=9$ ): Eye vesicles nearly closed. Faint retinal pigmentation (light orange) around closing edges. All eight arm primordia distinct. Mouth very large and crescent-shaped. Small, bulbous pharyngeal mass visible. Distinct salivary pit in mouth. Fin visible. Anal primordium, branchial heart primordia, and anterior and posterior funnel folds bulbous and distinct. Mantle enlarges both anteriorly and posteriorly. Statocysts, which move toward midline throughout development, now lie lateral to mantle.

Stage 20 (19 days, $\mathbf{N}=10$ ): Retinal pigmentation very faint over entire surface (darkest at posterior edge). Mouth opening still large. Mantle not rounded yet, appears like bilobed cap. Pharyngeal mass large and bulbous. Right and left anterior and posterior funnel folds fuse on their respective sides and elevate. Gill primordia present. Statocysts between lateral edge of mantle and distal edge of gill primordia. Eye lens primordia visible. Stage 21 (20 days, N=11): Distal edges of anterior end of right and left funnel folds raise and bend toward midline. Mouth opening very small. Mantle rounded but does not cover branchial hearts. Gills elongate. Eyes do not extend laterally out of optic vesicles. Pharyngeal mass smooth and large. Eye lens evident. Retina flat to only slightly cupshaped and light orange over entire surface. Statocysts visible anterior to distal edge of gills.

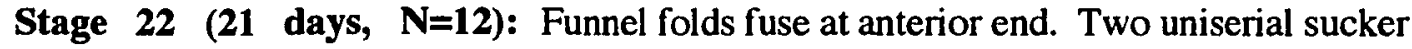
primordia develop on each arm by end of stage (appear on ventral arms first). No statoliths. Branchial hearts partially covered by anteriorly extending ventral mantle. Gills completely exposed. Retina orange. Branchial hearts begin to beat irregularly. Eyes extend laterally out of optic vesicles (appear to bulge from head). Statocysts enlarge 
medially with $50 \%$ of each lying beneath funnel fold. Last stage of development in which removal of embryo from the chorion does not change its morphological orientation (i.e., positioning of organ systems in relation to one another).

Stage 23 (25 days, N=13): Statoliths visible at anterior end of statocysts. Third sucker primordium evident. Median and posterior portions of funnel folds have fused. Systemic heart activity first observed. Rotation ends. Branchial hearts covered by ventral mantle. Gills partially covered by mantle. Distal (outer) side of retina orange. Proximal (inner) side of retina red. Iris curved, pigmentation absent. Mouth opening still posterior to bases of arms I. Two gill leaflets present plus end bulb. Dorsal arm bases I and II and ventral arm bases III and IV fuse, respectively, and begin to extend both laterally and posteriorly. Posterior edge of both dorsal and ventral arm base folds cover about $50 \%$ of dorsal and ventral head. Retina may (w/ chorion removed) or may not (w/o chorion removed) be fully cup-shaped.

Stage 24 (28 days, N=14): Statoliths first touch one another at midline. Fourth sucker present. Gills and lateral edges of funnel covered by ventral mantle. Ventral mantle does not cover anal opening. Three gill leaflets present plus end bulb. Light pigmentation (faint red) of iris. Distal side of retina red, proximal side red-black. Retina fully cupshaped. Dorsal arm base fold extends mainly posteriorly to dorsal mantle edge. Ventral arm base fold extends laterally to cover about $50 \%$ of optic ganglion. Ventral head chromatophores visible on $50 \%$ of the embryos observed by end of stage.

Stage 25 (30 days, $\mathbf{N}=15$ ): (Figure 16b). Olfactory tubercles appear in head/mantle region posterior to ventral edge of retina. Mouth opening still visible on dorsal surface of head in lateral view of embryo. All hearts beating regularly. Entire lateral portions of funnel covered by ventral mantle (medial portion of funnel and anal opening may or may not be covered by mantle). Four gill leaflets present plus end bulb. Iris brick-red. Retina red-black. Mantle undulations visible, although not common. Independent funnel 
movement. Dorsal arm base fold extends laterally to cover about $50 \%$ of retina (dorsal view). Ventral arm base fold extends posteriorly to olfactory tubercles. Dorsal head chromatophores begin to appear on some embryos by end of stage.

Stage 26 (32 days, $\mathbf{N}=16$ ): Ventral mantle chromatophores (light orange) visible along ventral mantle edge of all embryos. Mouth opening no longer visible in lateral view of embryo, but still visible from dorsal view lying anterior and oral to arm bases. Funnel tip clearly closer to statoliths than to arm bases. Dorsal and ventral arm base folds connect by thin extensions on posterio-lateral side of head just in front of olfactory tubercles. Olfactory tubercles, slightly obscured by arm base folds, move dorsally to lie behind ventral half of retina. Medial portion of funnel covered by ventral mantle (this may change after this stage as funnel begins to "grow" and "reposition" more anteriorly). A few very faint viscera chromatophores seen on some embryos by end of stage. Arm web developing between arms I and its distal edge lies posterior to mouth opening. Bases of arms I remain farther apart from each other than from bases of arms II. Iris red. Retina near black on both sides. Arm movement seen. Five gill leaflets present plus end bulb. Postorganogenetic phase begins.

Stage 27 (35 days, $\mathbf{N}=17$ ): Arm base chromatophores visible on all embryos (appear on ventral arms IV first). Bases of arms I equidistant from each other as to bases of arms II. Statocysts enlarge dramatically extending from anterior edge of ventral head chromatophores to posterior edge of optic ganglion. Olfactory tubercles again distinct and large and directly posterior to iris. Primary lid primordia begins to develop on posterior lateral region of eye vesicle immediately anterior to widening arm base fold connection and quickly covers nearly all of eye (by mid-Stage 27, primary lid covers all of eye vesicle except for a circle the size of the iris located posterior to the iris). Arm web between arms I complete. Mid-gut and caecum faintly visible. Five gill leaflets present plus end bulb. Iris dark brick red. Retina black. Anterior tip of funnel located mid-way between statoliths 
and ventral arm base chromatophores. Dorsal mantle chromatophores visible on most embryos by end of stage. Mouth opening below (oral to) distal edge of web of arms I, although still visible in dorsal view. Medial portion of funnel may or may not be covered by ventral mantle. Arms begin to extend and wrap around external yolk sac.

Stage 28 (37 days, N=18): Arm chromatophores visible on all embryos. Funnel tip clearly closer to arm base chromatophores than to statoliths. Primary lid covers entire eye. Arms wrap around 50\% of external yolk sac. Midgut and caecum distinct. No ink visible. Six gill leaflets present plus end bulb. Iris red-black. Retina black. Funnel chromatophores seen on some embryos by end of stage. Mouth opening no longer visible in dorsal view of embryo.

Stage 29 (42 days, $\mathrm{N}=19$ ): Ink quickly fills ink sac. Arms approximately equal in length to external yolk sac. Second inversion has occurred on $50 \%$ of all embryos. Eight gill leaflets present plus end bulb. Olfactory tubercles remain located directly behind iris, but larger.

Stage 30 (49 days, N=20): (Figure 16c). No external yolk sac visible; 8-10 gill leaflets present plus end bulb.

H (52 days, $\mathbf{N = 2 0 ) : ~ T i m e ~ o f ~ h a t c h i n g . ~ M a y ~ o c c u r ~ p r e m a t u r e l y ~ p r i o r ~ t o ~ S t a g e ~} 30$.

Additional information was recorded on the embryonic development of Octopus rubescens. Upon egg-laying, embryos were oriented with the animal pole towards the micropyle end of the chorion. Embryos reverse their position twice during development, thus returning to their original orientation. The first inversion occurred at Stage 17-18. The second inversion occurred at Stage 29-30.

Embryo rotation, which was in a clockwise direction when viewed from the micropyle end of the chorion, began at Stage 16 and required $1-1.5 \mathrm{~min}$ to travel through $360^{\circ}$. Rotational velocities decreased following Stage 16 (Stage $17=2.0 \mathrm{~min} / 360^{\circ}$ 
rotation; Stage 18=2.5 min; Stage $19=6.5 \mathrm{~min}$; Stage $20=7.0 \mathrm{~min}$; stage $21=8.33 \mathrm{~min}$; early Stage $22=10.0 \mathrm{~min}$; late Stage $22=20.0 \mathrm{~min}$ ), stopping by Stage 23 . If embryos at Stage 16 were left under a lighted microscope for $2 \mathrm{~min}$, the rotational velocity reduced to approximately $6.0 \mathrm{~min} / 360^{\circ}$ rotation. Observations on embryo rotation had to be made quickly before water temperatures increased.

Rudimentary yolk sacs were seen first at Stage 19 when a constriction, due to the presence of arm bud primordia, began to divide the yolk into an inner and outer yolk sac. Distinct inner and outer yolk sacs werc apparent by late Stage 23. The internal yolk sac became distinctly bi-lobed at Stage 22 , becoming again spherical by Stage 25 . The internal yolk sac decreased in size from Stage 19 (maximum width $=0.750 \mathrm{~mm}$ ) until Stage 24 (maximum width $=0.395 \mathrm{~mm}$ ), which corresponded to the period of organogenesis, and subsequent cephalopodium development. The internal yolk sac then began to increase in size (Stage $26=0.5 \mathrm{~mm}$ width; Stage $28=0.6 \mathrm{~mm}$ width) as yolk was transferred from the outer yolk sac to the inner yolk sac. A maximum inner yolk sac width of $0.8 \mathrm{~mm}$ was achieved by Stage 29 .

Pulsations of the outer yolk sac began at late stage 18 , at a rate of one yolk pulse every $80 \mathrm{sec}$. Yolk pulses traveled over the external yolk sac from the dorsal (oral) side to the ventral (funnel) side. Yolk pulses increased to a rate of $6 / \mathrm{min}$ by Stage 20 ( $6 \mathrm{sec}$ peripheral pass and $4 \mathrm{sec}$ between the end of one yolk pulse and the beginning of the next yolk pulse). This rate was maintained through Stage 23. Rates dropped to 3-4 yolk pulses per minute during Stage 24, mainly due to an increase in time (from $4-7.5 \mathrm{sec}$ ) between the end of one yolk pulse and the beginning of the next. From Stage 25 until hatching, the rate of yolk pulses increased again (Stage $27=6$ yolk pulses $/ \mathrm{min}$; Stage $29=10$ yolk pulses/min) mainly due to a decrease in the amount of time needed for a yolk pulse to travel over the external yolk sac's periphery. This decrease in time was due to the reduction of the size of the external yolk sac as yolk was transferred to the internal yolk sac. Internal 
yolk pulses were seen from Stage 29 until hatching. Although no consistent pattern was ever observed, internal yolk pulses could be seen at least once per minute.

Based on seawater temperatures of $17.4^{\circ} \mathrm{C}$, irregular branchial heart beats (e.g., do not beat together and no consistent pulse) were observed first between late Stage 22 and early Stage 23 at a rate of $6 / \mathrm{min}$. Regular systemic heart beats first appeared mid-Stage 23 at a rate of $22 / \mathrm{min}$. Branchial heart beat rates quickly increased to $26 / \mathrm{min}$ by mid-Stage 23 . By late Stage 23 , consistent systemic heart beats were observed at a rate of $32 / \mathrm{min}$, while branchial heart beats continued irregularly at a rate of $28-30 / \mathrm{min}$. By Stage 24 , systemic heart beat rates increased further to $32-46 / \mathrm{min}$. Regular branchial heart beats (e.g., branchial hearts beating simultaneously and in alternation with the systemic heart) were observed by Stage 25 . Although variable, heart rates significantly increased with increasing development $\left(\mathrm{t}\right.$-test; $\mathrm{N}=17, \mathrm{r}^{2}=0.688, \mathrm{t}=4.38, \mathrm{p}<0.001$; Stage $27=46-60 / \mathrm{min}$; Stage $29=72-85 / \mathrm{min}$.; Stage $30=90-105 / \mathrm{min}$.). In the later stages of development, heart beat rates may be temperature dependent with rates increasing with increasing temperature. Embryos developing at $13.5-15.5^{\circ} \mathrm{C}$ had heart beat rates of $46 / \mathrm{min}$ at Stage 27 and $70 / \mathrm{min}$ at Stage 30. A decrease in temperature of approximately $3^{\circ} \mathrm{C}$ produced a $30 \%$ decrease in heart rate.

Arm primordia were seen first at Stage 19. Two uniserial sucker primordia appeared simultaneously at Stage 22. During Stage 23 sucker development continued from two suckers through the development of the fourth sucker primordium. By Stage 24 all four suckers and arms were well developed. From Stage 24-28 the arms underwent symmetrical growth, slightly increasing in length and width; all suckers slightly increased in size. Independent arm movement was first seen at Stage 26 , but frequent movement was not seen until late Stage 29 to early Stage 30. Asymmetric growth of the arm tips and nearly a doubling in size of the four suckers occurred from Stage 29-30.

Random mantle contractions were observed from Stage 25 until hatching. 
Although no regular pattern was ever detected, contractions could be seen at least once every $5 \mathrm{~min}$.

Pigmentation was first seen at Stage 19 as faint orange retinal pigment. Retinal pigmentation increased to brick-red by Stage 24 and black by Stage 28 . Ink first appeared in the ink sac during Stage 29. Body chromatophores were first seen at the end of Stage 24. The majority of body chromatophores developed during Stages 27-29 (Fig. 17; Table 5).

Time of development was $52 \pm 3 d(n=7), 70 \pm 3 d(n=3)$, and $91 \pm 6 d(n=11)$ at mean temperatures of $17.7^{\circ} \mathrm{C}, 16.3^{\circ} \mathrm{C}$, and $14.8^{\circ} \mathrm{C}$, respectively. A typical sequence of embryonic development at these three temperatures is presented in Figure 18. Although slight, development time significantly differed among breeding seasons with seawater temperatures of $13.5-15.5^{\circ} \mathrm{C}$ (ANOVA; $\mathrm{n}=11, \mathrm{~F}=5.114, \mathrm{p}=0.0371$ ). Development time was inversely correlated with temperature ( $t-t e s t ; N=21 ; r=-0.974, t=18.61, p<0.001$ ). Rates of embryonic development among temperatures were markedly different during the post-organogenetic phase.

Key to Stages of Embryonic Development of Octopus rubescens

A maximum of twenty steps are required for identifying the proper stage of development for any post-blastulated embryo of Octopus rubescens. To aid researchers in confirming chosen stages, further diagnostic characters are presented for each stage.

1. External yolk sac present.......... yes - go to 2

$$
\text { no - Stage } 30
$$

2. Ink visible in ink sac............... no - go to 3

yes - Stage 29 (arms approximately equal in length to external yolk sac) 
3. Arm chromatophores visible...... no - go to 4

yes - Stage

4. Arm base chromatophores visible on ventral arms (IV)...... no - go to 5

$$
\text { yes - Stage }
$$

5. Light orange chromatophores seen along ventral mantle edge... no - go to 6

yes - Stage

6. Olfactory tubercles apparent at head/mantle region posterior to ventral edge of retina............................ no - go to 7 yes - Stage

7. If embryo removed from chorion: four suckers present on all arms.......................... no - go to 8

If embryo not removed from yes - Stage 24 chorion: statocysts touching one another along midline no - go to 8 yes - Stage 24

8. If embryo removed from chorion: three sucker primordia present on all arms........................... no - go to 9

If embryo not removed from yes - Stage 23 chorion: statoliths visible in statocysts no - go to 9

yes - Stage
28 (funnel tip located closer to arm base chromatophores than to statoliths; primary lid covers eye)

27 (bases of arms I equidistant from each other as to bases of arms II)

(mouth opening not visible in lateral view of embryo; funnel tip located closer to statoliths than to arm bases; bases of arms I farther apart from each other than from bases of arms II) (mouth opening visible in lateral view of embryo; lateral portions of funnel completely covered by anteriorly extending ventral mantle; ventral mantle may or may not cover medial portion of funnel and anal opening)

(fourth sucker present on all arms; iris pigmentation (faint red) first seen; gills and lateral most edges of funnel covered by ventral mantle) 
9. If embryo removed from chorion: two sucker primordia present on ventral arms (IV)........................ no - go to 10

If embryo not removed from yes - Stage 22 chorion: funnel beginning to take form as the anterior end of funnel folds have fused along midline. no - go to 10 yes - Stage 22 (two sucker primordia present on at least the ventral arms (IV); statoliths not present; branchial hearts

10. Distal edge of anterior ends partially covered by ventral mantle)

of funnel folds raised and

bent toward midline (but

not yet fused)

no - go to 11

yes - Stage 21 (sucker primordia absent; branchial hearts completely exposed; mouth opening constricted and nearly closed; mouth less than $10 \%$ of eye diameter)

11. Eye vesicles closed with retinal pigmentation (orange) over entire surface, darkest at posterior edge................... no - go to 12
yes - Stage 20

yes - Stage 20 (mouth opening large (greater than $50 \%$ of eye diameter); salivary pit not visible within mouth)

12. Faint retinal pigmentation (lt. orange) around closing edges of eye vesicles. no - go to 13 yes - Stage 19 (salivary pit clearly evident in very large, crescent-shaped mouth; all eight arm primordia distinct)

13. Blastoderm covers vegetal pole... no - go to 14 yes - Stage 18

(retinal pigmentation absent; ring folds cover eye primordia; slight equatorial constriction; salivary pit absent; individual arm primordia not yet distinct)

14. Blastoderm covers greater than $90 \%$ of egg surface no - go to 15 yes - Stage 17

(depression of mouth distinct on dorsal surface; optic vesicle and statocyst primordia clearly visible)

15. Blastoderm covers approximately $60-70 \%$ of egg surface... no - go to 16 yes - Stage 16 
16. Blastoderm covers

approximately $50 \%$ of

egg surface...................... no - go to 17

17. Blastoderm covers

yes - Stage 15

approximately $30 \%$ of

egg surface....................... no - go to 18

18. Blastoderm extends slightly

yes - Stage 14

passed blastodisc.

no - go to 19

yes - Staga 13

19. Blastodisc elevated, cellular

throughout

no - go to 20

20. Peripheral edges of blastodisc

yes - Stage 12 (three germinal cell layers complete) invaginated into yolk (clearly

evident in lateral view).

yes - Stage 11 (gastrulation has begun)

no - Stage 10 (blastulation complete) or

Stages 1-9 (blastulation still occurring)

\section{DISCUSSION}

Many factors contribute to the variability of diagnostic characters used to describe embryonic development in octopuses. Some diagnostic characters are more subject to the investigator's interpretations than others. The presence or absence of a certain distinct morphology often is more easily discernable than its changing developmental state (e.g., position or size of a certain structure or, even worse, its relationship to other developing morphologies). Some diagnostic characters vary greatly between embryos laid at the same time by the same female. This high intraspecific variability may be seen even when objective characters have been chosen, because certain morphologies have inconsistent rates of development. Whether or not embryos are observed through their chorion may effect interpretations of embryonic development. Embryos are often compressed within their chorions and expand when removed (unpublished data). Also, this variability would only be amplified if proportions between the embryos and their chorions differed within a brood and/or between females of the same size and/or between 
females of different sizes.

The course of embryogenesis for Octopus rubescens was described in detail, based on a staging system comprising diagnostic characters having low intraspecific and interspecific variability. Stages developed for this species are very similar to stages developed for squids (Amold 1965) and cuttlefishes (Lemaire 1970), suggesting all coleoid cephalopods have similar embryonic development and that researchers are recognizing similar key "steps" of embryonic development (see also Fioroni 1990). The key to the embryonic development of $\underline{\underline{O}}$. rubescens should be sufficient to describe its embryonic development throughout its latitudinal (i.e., temperature) range, as no significant temporal variability, nor variability in the sequence of embryonic development with regards to temperature, was ever seen.

The key to the embryonic developmental stages of Octopus rubescens may also be sufficient to describe the embryonic developmental stages of other small-egg species of octopuses. The embryonic development of $\underline{\underline{O}}$ rubescens is quite similar to that presented for many other small-egg species including Octopus vulgaris (Naef 1928) and Octopus bimaculatus (Ambrose 1981). Minor shifts in timing account for observed differences, as the sequence of development of each major organ system is nearly identical.

The most recognized difference in embryogenesis among small-egg species of octopus involves the development and distribution of chromatophores. A few examples of chromatophore differences are discussed based on chromatophore development reported for Octopus bimaculatus (Ambrose 1981) and Octopus vulgaris (Fioroni 1965). Octopus $\underline{\text { rubescens }}$ and $\underline{\mathrm{O}}$. bimaculatus produce twice as many ventral mantle chromatophores (i.e., approximately 40 chromatophores) as $\underline{\mathrm{O}}$. vulgaris and in half the time. Also, the development of these 40 ventral mantle chromatophores is completed two stages earlier (i.e., Stage 28) in $\underline{\mathrm{O}}$. bimaculatus than in $\underline{\mathrm{O}}$. rubescens. At time of hatching $\underline{\mathrm{O}}$. rubescens and $\underline{\mathrm{O}}$. bimaculatus have more chromatophores (161 and 168, respectively) than $\underline{\mathrm{O}}$. 
vulgaris (40; Fioroni 1965) and 으. tetricus (48; Joll 1976), but fewer than 으. burryi (205; Forsythe and Hanlon 1985). Chromatophore patterns can be used exclusively to differentiate planktonic hatchlings of the most common California octopuses (Table 6).

Temperature plays an important role in the embryonic development of octopuses. Throughout all investigations of embryonic development in Octopus rubescens, temperature was not held constant and warming trends in water temperature were observed. Although the effects of this remain unclear, they do represent conditions the embryos normally would be exposed to in the natural environment.

Time of embryonic development in Octopus rubescens was correlated inversely with temperature. Similar results have been obtained for many other octopuses. Ambrose (1981) compiled development time verse temperature data for four species of octopuses and found these data best represented by the mathematical relationship $\operatorname{lnDT}=-0.07(\mathrm{~T})+5.21$; $(\mathrm{N}=65, \mathrm{r}=0.84, \mathrm{p}<0.01)$. Based on this formula, the difference of actual versus estimated development times for $\underline{\mathrm{O}}$. rubescens were $-40 \%,-21 \%$, and $+2 \%$ at $14.8{ }^{\circ} \mathrm{C}, 16.3^{\circ} \mathrm{C}$, and $17.7^{\circ} \mathrm{C}$, respectively. Ambrose's equation increasingly underestimated development time of $\underline{\underline{O}}$ rubescens as temperatures decreased.

For Octopus rubescens, rates of embryonic development between temperatures were markedly different during the post-organogenetic phase. Boletzky (1987) noted that with decreasing temperature, the length of the post-organogenetic phase relative to the preceding phases decreases. For $\underline{\mathrm{O}}$. rubescens, an absolute increase in the length of the post-organogenetic phase was observed with decreasing temperature, but relative to the preceding phases, the length of the post-organogenetic phase remained similar (e.g., at $17.7^{\circ} \mathrm{C}, 16.3^{\circ} \mathrm{C}$, and $14.8^{\circ} \mathrm{C}$, the post-organogenetic phase comprised $42 \%, 56 \%$, and $44 \%$ of the entire development time, respectively). Whether this contradiction is real and not a artifact of the small sample sizes remains to be determined. 


\section{MISCELLANEOUS NOTES ON OCTOPUS RUBESCENS}

\section{Post-Hatching Behavior}

Once embryos reached late-Stage 29 , slight changes in their environment would induce hatching. Paralarvae (i.e., planktonic hatchlings in the case of Octopus rubescens) were induced to hatch by physically manipulating the festoons or by placing the festoons in stagnant and/or slightly warmer seawater. Hatching usually commenced within 1-3 min depending on the developmental state of the paralarvae.

Immediately following hatching in the laboratory, the negatively buoyant paralarvae were observed to vigorously swim in $\mathbf{4 5}^{\circ}$ angle (posterior end up) toward the water surface. At this time, many paralarvae would fold themselves ventrally and insert the ventral (IV) arms into the ventral portion of the mantle cavity. The paralarvae moved these arms in a sweeping motion along the inside of the ventral mantle where the posterio-ventral edge of the funnel contacts the ventral mantle. The paralarvae may have been trying to disconnect any 'sticky' areas between the two structures. This process normally was preceded and followed by vigorous exhalations through the funnel.

Paralarvae of Octopus rubescens exhibited a positive phototaxis for the first 10-15 min following hatching. No significant geotaxic response, positive or negative, was observed during this time. The positive phototaxis was strongest immediately upon hatching and subsided to only a moderately photopositive response within $5 \mathrm{~min}$. Since gravid females of this species form or find small dens into which they deposit their eggs, the strong positive phototaxis displayed by paralarvae immediately upon hatching would allow the paralarvae to quickly and easily exit the den openings, thus entering the open ocean. Such reasoning also explains why paralarvae swim immediately to the surface following hatching in open ocean waters (Ambrose 1981). 


\section{Rearing of Paralarvae}

Attempts to rear paralarvae of Octopus rubescens under a variety of environmental conditions (e.g., aquaria sizes ranging from 10-4000 L, open and closed seawater systems, various seawater flow rates, a host of different irradiance levels, complex diets consisting of $24 \mathrm{hr}$ old Artemia nauplii, laboratory-maintained Tigriopus, and daily collected zooplankton tows) proved futile as all paralarvae died approximately $4-6 \mathrm{~d}$ post-hatching. This appeared to coincide with the depletion of the internal yolk reserves. A slight increase in arm length was the only post-hatching growth observed.

Only two studies have reported to successfully rear octopus paralarvae in the laboratory (Itami et al. 1963; Villanueva 1994). In both studies paralarvae of Octopus vulgaris were fed diets of newly-hatched decapod zoea with a total length equivalent to 50 $100 \%$ of the paralarvae's mantle length. Such diets may allow successful laboratory rearing of Octopus rubescens paralarvae as well.

\section{Ectoparasite}

Throughout the first two seasons of embryonic observations, an ectoparasite was observed on many of the developing embryos (Fig. 19). Infestations of up to $50 \%$ of each brood commonly occurred. During the third season of embryonic observations, laboratory water temperatures increased from approximately $14.5^{\circ} \mathrm{C}$ to approximately $16.5^{\circ} \mathrm{C}$.

During this season only two of these ectoparasites were observed. Since then they have never been observed. Histological sections revealed what appeared to be a cell wall, suggesting these organisms were a species of fungus and not a dinoflagellate, as originally thought. If this organism is a species of fungus, further identification requires observations of spore release in live organisms, as the structure of the spore's flagella is the key characteristic in identification. 


\section{LITERATURE CITED}

Ainley, D.G. and R.J. Boekelheide. 1990. Seabirds of the Farallon Islands. Stanford University Press, Palo Alto. 173 pp.

Amaratunga, T. 1987. Population Biology. In: Cephalopod Life Cycles, Volume II. Boyle, P.R. (ed.). Academic Press, London. pp. 239-252.

Ambrose, R.F. 1981. Observations on the embryonic development and early postembryonic behavior of Octopus bimaculatus. Veliger 24: 139-146.

Arnold, J.M. 1965. Normal embryonic stages of the squid Loligo pealii (Lesueur). Biol. Bull. 128: 24-32.

Ballering, R.G., M.A. Jalving, D.A. Ventresca, L.E. Hallacher, J.T. Tomlinson, and D.R. Wobber. 1972. Octopus evenomation through a plastic bag via a salivary proboscis. Toxicon 10: 245-248.

Beamish, R.J. and D.A. Fournier. 1981. A method for comparing the precision of a set of age determinations. Can. J. Fish. Aquatic Sci. 38(8): 982-983.

Berry, S.S. 1953. Preliminary diagnoses of six west American species of Qctopus. Leaflets in Malac. 1: 51-58.

Berry, S.S. and B.W. Halstead. 1954. Octopus bites - a second report. Leaflets in Malac. 1: 59-94.

Beverton, R.J.H. and S.J. Holt. 1957. On the dynamics of exploited fish populations. Fishery Invest. Lond. Ser. 2, 19: 1-533.

Boletzky, S.v. 1969. Zum Vergleich der Ontogenesen von Octopus vulgaris, ㅇ. joubini,

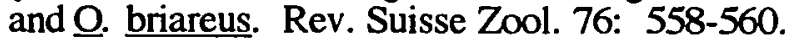

Boletzky, S.v. 1971. Zu den Lageveranderungen von Octopoden-Embryonen (Mollusca: Cephalopoda). Rev. suisse Zool. 76: 716-726.

Boletzky, S.v. 1974. The "larvae" of Cephalopoda: a review. Thalass. Jugo. 10(1/2): 45-76.

Boletzky, S.v. 1975. Le developpement d'Eledone moschata (Mollusca, Cephalopoda) elevee au laboratoire. Bull. Soc. Zool. Fr. 100: 361-367.

Boletzky, S.v. 1977. Post-hatching behaviour and mode of life in Cephalopods. Symp. zool. Soc., Lond. 38: 557-567.

Boletzky, S.v. 1984. The embryonic development of the octopus Scaeurgus unicirrhus (Mollusca: Cephalopoda). Vie et Milieu 34 (2/3): 87-93.

Boletzky, S.v. 1987. Embryonic Phase. In: Cephalopod Life Cycles, Volume II. Boyle, P.R. (ed.). Academic Press, London. pp. 5-31. 
Boletzky, S.v. 1989. Recent studies on spawning, embryonic development, and hatching in the Cephalopoda. In: Advances in Marine Biology. Baxter, J.H.S. and A.J. Southward (eds.). Academic Press, London. pp. 85-115.

Boletzky, S.v., and M.v. Boletzky. 1969. First results in rearing Octopus joubini Robson, 1929. Verh. naturf. Ges. Basei 80: 56-61.

Boyle, P.R., K. Mangold, and M. Ngoile. 1988. Biological variation in Eledone cirrhosa (Cephalopoda: Octopoda): Simultaneous comparisons on North Sea and Mediterranean populations. Malacologia 29: 77-87.

Bradbury, H.E. 1974. The gross morphology of some aspects of the development of the octopod Eledone cirrhosa. Mar. Sci. Res. Lab. Newfoundland, Tech. Rep. No. 13.

Brocco, S.L., R.M. O'Claire and R.A. Cloney. 1974. Cephalopod integument: the ultrastructure of Kolliker's organs and their relationship to setae. Cell Tissue Res. 151: 293-308.

Butler, J. 1992. ROV line transects and bottom trawls compared. Southwest Fisheries Science Center Monthly Report. Coastal Fisheries Resources Division. Jan.-Feb. pp. 4-5.

Caddy, J.F. (ed.). 1983. Advances in assessment of world cephalopod resources. FOA Fish. Tech. Paper 231: 1-452.

Chang, W.Y.B. 1982. A statistical method for evaluating the reproducibility of age determinations. Can. J. Fish. Aquatic Sci. 39: 1208-1210.

Dew, B. 1959. Some observations on the development of two Australian octopuses. Proc. Roy. Soc., N.S.W. 1957-1959: 44-52.

Dorsey, E.M. 1976. Natural history and social behavior of Octopus rubescens Berry. M.S. Thesis, University of Washington, Seattle. $44 \mathrm{pp}$.

Fioroni, P. 1965. Die embryonale Musterentwicklung bei einigen mediterranean Tintenfischarten. Vie et Milieu 16(2A): 655-756.

Fioroni, P. 1970. Die embryonale Genese der Chromatophoren bei Octopus vulgaris. Acta. anat. 75(2): 199-224.

Fioroni, P. 1978. Cephalopoda. In: Morphogenese der Tiere. Seidel, F. (ed.). Lieferung 2: G5-I, Gustav Fischer Verlag, Jena. 181 pp.

Fioroni, P. 1990. Our recent knowledge of the development of the cuttlefish (Sepia officinalis). Zoologischer Anzeiger 224(1/2): 1-25.

Fisher, W.K. 1923. Brooding habits of a cephalopod. Ann. Mag. Nat. Hist. 12: 147149.

Fisher, W.K. 1925. On the habits of an octopus. Ann. Mag. Nat. Hist. 15: 411-414. 
Forsythe, J.W. and R.T. Hanlon. 1985. Aspects of egg development, post-hatching behavior, growth and reproductive biology of Octopus burryi Voss, 1950 (Mollusca: Cephalopoda). Vie et Milieu 35 (3/4): 273-282.

Fuchs, E.v. 1973. Zur Embryonalentwicklung von Eledone cirrosa Lam. (Cephalopoda, Octopoda): Eine Beschreibung der Embryonalstadien an Hand der Aussenmorphologie. Zool. Jahrb. Abt. Anat. Ontog. Tiere 91: 19-30.

Gabe, S. 1975. Reproduction in the giant octopus of the North Pacific, Octopus dofleini martini. Veliger 18(2): 146-150.

Gravely, F.H. 1908. Notes on the spawning of Eledone and on the occurrence of Eledone with suckers in double rows. Mem. Manchester Lit. Phil. Soc. 53(4): 1-14.

Green, M. 1973. Taxonomy and distribution of planktonic octopods in the northeastern Pacific. M.S. Thesis, University of Washington, Seattle. $98 \mathrm{pp}$.

Halstead, B.W. 1949. Octopus bites in human beings. Leaflets in Malac. 1: 17-22.

Hanlon, R.T. 1983. Octopus joubini. In: Cephalopod Life Cycles, Volume I. Boyle, P.R. (ed.). Academic Press, London. pp. 293-310.

Hanlon, R.T. 1983. Octopus briareus. In: Cephalopod Life Cycles, Volume I. Boyle, P.R. (ed.). Academic Press, London. pp. 251-266.

Hochberg, F.G. 1980. Class Cephalopoda. In: Common Intertidal Invertebrates of the Gulf of California. Brusca, R.C. (ed.). University of Arizona Press, Tuscon. pp. 201-204.

Hochberg, F.G. 1987. Class Cephalopoda. In: Marine Invertebrates of the Pacific Northwest. Kozloff, E.N. (ed.). University of Washington Press, Seattle. pp. 291-295.

Hochberg, F.G. 1990. Diseases of Mollusca: Cephalopoda. 1.2. Diseases caused by protistans and metazoans. In: Diseases of Marine Animals, Vol. III. Kinne, O. (ed.). Biologische Anstalt Helgoland, Hamburg. pp. 47-202.

Hochberg, F.G. and W.G. Fields. 1980. Cephalopoda: the squids and octopuses. In: Intertidal Invertebrates of California. Morris, R.H., D.P. Abbott, and E.C. Haderlie (eds.). Stanford University Press, Stanford. pp. 429-444.

Hochberg, F.G., M. Nixon and R.B. Toll. 1992. Order Octopoda Leach, 1818. In: Larval and Juvenile Cephalopods: A Manual for their Identification. Sweeney, M., C.F.E. Roper, K.M. Mangold, M.R. Clarke and S.v. Boletzky (eds.). Smithsonian Institution Press, Washington, DC. pp. 213-279.

Hun Baeg, G., Y. Sakurai, and K. Shimazaki. 1992. Embryonic stages of Loligo bleekeri Keferstein (Mollusca: Cephalopoda). Veliger 35(3): 234-241. 
Itami, K., Y. Izawa, S. Maeda and K. Nakai. 1963. Notes on the laboratory culture of the octopus larvae. Bull. Jap. Soc. Scient. Fish. 29: 514-520.

Joll, L.M. 1976. Mating, egg-laying, and hatching of Octopus tetricus (Mollusca: Cephalopoda) in the laboratory. Mar. Biol. Berlin 36: 327-333.

Joll, L.M. 1978. Observations on the embryonic development of Octopus tetricus (Mollusca: Cephalopoda). Austral. J. Mar. Freshw. Res. 28: 45-56.

Joll, L.M. 1983. Octopus tetricus. In: Cephalopod Life Cycles, Volume I. Boyle, P.R. (ed.). Academic Press, London. pp. 325-334.

Kubodera, T. and T. Okutani. 1981. The systematics and identification of larval cephalopods from the northern North Pacific. Research Institute of the North Pacific Fisheries, Hokkaido University, special volume: 131-159.

Kuehl, M. 1988. A contribution to the reproductive biology and geographical distribution of Antarctic Octopodidae (Cephalopoda). Malacologia 29: 89-100.

Lemaire, J. 1970. Table de developpement embryonnaire de Sepia officinalis L. (Mollusque: Cephalopode). Bull. Soc. Zool. Fr. 95: 773-782.

Macalaster, E.G. 1976. The natural history and biology of the deep-water octopus, Bathypolypus arcticus (Prosch). M.Sc. Thesis. Dalhousie University, Halifax, Nova Scotia. 81 pp.

MacGinitie, G.E. and N. MacGinitie. 1968. Natural History of Marine Animals. McGraw-Hill, New York. 523 pp.

Mangold, K. 1983. Octopus vulgaris. In: Cephalopod Life Cycles, Volume I. Boyle, P.R. (ed.). Academic Press, London. pp. 335-364.

Mangold, K. 1987. Reproduction. In: Cephalopod Life Cycles, Volume II. Boyle, P.R. (ed.). Academic Press, London. pp. 157-200.

Mangold, K., S.v. Boletzky, and D. Frosch. 1971. Reproductive biology and embryonic development of Eledone cirrosa (Cephalopoda: Octopoda). Mar. Biol. 8: 109117.

Mather, J.A. and R.C. Anderson. 1993. "Personalities" of octopuses (Qctopus rubescens). J. Comp. Psych. 107: 336-340.

McConnaughey, B.H. 1941. Two new Mesozoa from California, Dicyemennea californica and Dicyemennea brevicephala (Dicyemidae). J. Parasit. 27: 63-69.

McConnaughey, B.H. 1949. Mesozoa of the family Dicyemidae from California. Univ. of Calif. Pubs. Zool. 55: 1-34.

McGowan, J.A. 1967. Distributional atlas of pelagic molluscs in the California Current region. Calif. Coop. Oceanic Fish. Invest. Atlas 6: 1-218. 
Mills, C. 1983. Distribution and biology of planktonic Octopus larvae from Friday Harbor, Washington and the Straits of Georgia, British Columbia. Ann. Meet., Western Society of Naturalists, 64: 27 (Abstract).

Naef, A. 1923. Die Cephalopoden. Fauna Flora Golf. Neapel, 35(I): 1-863.

Naef, A. 1928. Die Cephalopoden. Fauna Flora Golf. Neapel, 35(II): 1-357.

Oglesby, L.C. 1972. Octopus bites in California. Ann. Meet., Western Society of Naturalists, 53: 3 (Abstract).

Opresko, L. and R. Thomas. 1975. Observations of Octopus joubini: some aspects of reproductive biology and growth. Mar. Biol. 31: 51-61.

Oxman, D.S. 1995. Seasonal abundance, movements, and food habits of harbor seals (Phoca vitulina richardsi) in Elkhorn Slough, California. M.S. Thesis, CSU Stanislaus, Moss Landing Marine Laboratories, Moss Landing. 126 pp.

Packard, A. 1985. Size and distribution of chromatophores during post-embryonic development in cephalopods. Vie et Milieu 35(3/4): 285-298.

Packard, A. and F.G. Hochberg. 1977. Skin patterning in Octopus and other genera. Symp. Zool. Soc. Lond. 38: 191-231.

Perez, J.A. and M. Haimovici. 1991. Sexual maturation and reproductive cycle of Eledone massyae Voss 1964 (Cephalopoda: Octopodidae) in southern Brazil. Bull. Mar. Sci. 49 (1-2): 270-279.

Pickford, G.E. and B.H. McConnaughey. 1949. The Octopus bimaculatus problem: a study of sibling species. Bull. Bingham Oceanogr. Coll. 12: 1-66.

Rasmussen, A. and M. Kronman. 1990. Prospects for developing an Octopus fishery on California's south-central coast. Unpub. Report to California's Secretary of Environmental Affairs. 124 pp.

Rathjen, W.F. and G.L. Voss. 1987. The cephalopod fisheries: a review. In: Cephalopod Life Cycles, Volume II. Boyle, P.R. (ed.). Academic Press, London. pp. 253-275.

Richard, A. 1970. Differenciation sexualle des cephalopodes en culture in vitro. Annee Biol. 9: 409-415.

Ricker, W.E. 1958. Maximum sustained yields from fluctuating environments and mixed populations. Bull. Fish. Res. Board, Can. 191: 991-1006.

Segawa, S. 1987. Life history of the oval squid Sepioteuthis lessoniana in Kominato and adjacent waters, central Honshu, Japan. J. Tokyo Univ. Fish. 74: 67-105.

Strathman, M.F. 1987. Reproduction and Development of Marine Invertebrates of the Northern California Coast. University of Washington Press, Washington. $374 \mathrm{pp}$. 
Tait, R.W. 1980. Aspects of the ecology and life history of Octopus australis Hoyle, from northern Port Phillip Bay. B.S. Thesis, Monash University, Clayton, Victoria. 77 pp.

Van Heukelem, W.F. 1976. Growth, bioenergetics and life span of Octopus cyanea and Octopus maya. Ph.D. Dissertation. University of Hawaii, $224 \mathrm{pp}$.

Van Heukelem, W.F. 1983. Octopus cyanea. In: Cephalopod Life Cycles, Volume I. Boyle, P.R. (ed.). Academic Press, London. pp. 267-276.

Villanueva, R. 1994. Decapod crab zoeae as food for rearing cephalopod paralarvae. Aquaculture 128(1-2): 143-152.

Warren, L.R., M.F. Sheier and D.A. Riley. 1974. Color changes of Octopus rubescens during attacks on unconditioned and conditioned stimuli. Anim. Behav. 22: 211219.

Wells, M.J. and J. Wells. 1959. Hormonal control of sexual maturity in Octopus. J. Exp. Biol. 36: 1-33.

Yamamoto, M. 1982. Normal stages in the development of the cuttlefish, Sepiella japonica Sasaki. Zool. Mag. 91: 146-157.

Yamashita, Y. 1974. Spawning and hatching of Paroctopus dofleini dofleini (Wulker). Monthly Rep. Hokkaido Fish. Exp. Stat. 31(7): 10-22.

Young, R.E. 1972. The systematics and areal distribution of pelagic cephalopods from the seas off southern California. Smithsonian Contr. Zool. 97: 1-159.

Young, R.E., R.F. Harman, and F.G. Hochberg. 1989. Octopodid paralarvae from Hawaiian waters. Veliger 32(2): 152-165.

Zar, J.H. 1984. Biostatistical Analysis. Prentice-Hall, Inc., Englewood Cliffs, New Jersey. 718 pp. 
Table 1. Comparisons of accuracy and precision of egg counts between five readers. $\mathrm{n}=$ sample size (number of festoons). APE $=$ average percent error. $\mathrm{V}=$ coefficient of variation. $\mathrm{D}=$ index of precision. S.E. = one standard error. $\mathrm{APE}, \mathrm{V}$, and $\mathrm{D}$ values are presented in percent. Asterisks denote statistically significant differences.

\begin{tabular}{|c|c|c|c|c|c|c|}
\hline \multirow[b]{2}{*}{ Reader } & \multirow[b]{2}{*}{$\mathrm{n}$} & \multirow[b]{2}{*}{ t value } & \multirow[b]{2}{*}{$p$ value } & \multirow[b]{2}{*}{ Reader } & \multicolumn{2}{|c|}{$\overline{\mathrm{APE}}$} \\
\hline & & & & & Mean & S.E. \\
\hline \multirow[t]{2}{*}{1 vs. 2} & \multirow[t]{2}{*}{20} & \multirow[t]{2}{*}{1.89} & \multirow[t]{2}{*}{0.0670} & 1 & 1.3 & 0.16 \\
\hline & & & & 2 & 1.9 & 0.22 \\
\hline \multirow[t]{2}{*}{1 vs. 3} & \multirow[t]{2}{*}{19} & \multirow[t]{2}{*}{0.67} & \multirow[t]{2}{*}{0.5057} & 1 & 1.5 & 0.21 \\
\hline & & & & 3 & 1.7 & 0.14 \\
\hline \multirow[t]{2}{*}{1 vs. 4} & \multirow[t]{2}{*}{20} & \multirow[t]{2}{*}{2.76} & \multirow[t]{2}{*}{$0.0089^{*}$} & 1 & 0.7 & 0.10 \\
\hline & & & & 4 & 1.3 & 0.23 \\
\hline \multirow[t]{2}{*}{1 vs. 5} & \multirow[t]{2}{*}{20} & \multirow[t]{2}{*}{1.94} & \multirow[t]{2}{*}{0.0605} & 1 & 0.8 & $\overline{0.14}$ \\
\hline & & & & 5 & 1.3 & 0.25 \\
\hline
\end{tabular}

Overall: \begin{tabular}{|c|c|c|c|c|}
\hline Reader & $\mathrm{N}$ & $\mathrm{APE}$ & $\mathrm{V}$ & $\mathrm{D}$ \\
\hline 1 & 79 & 1.04 & 1.08 & 0.62 \\
\hline 2 & 20 & 1.88 & 1.63 & 0.94 \\
\hline 3 & 19 & 1.71 & 1.53 & 0.88 \\
\hline 4 & 20 & 1.25 & 1.11 & 0.64 \\
\hline 5 & 20 & 1.28 & 1.06 & 0.61 \\
\hline
\end{tabular}




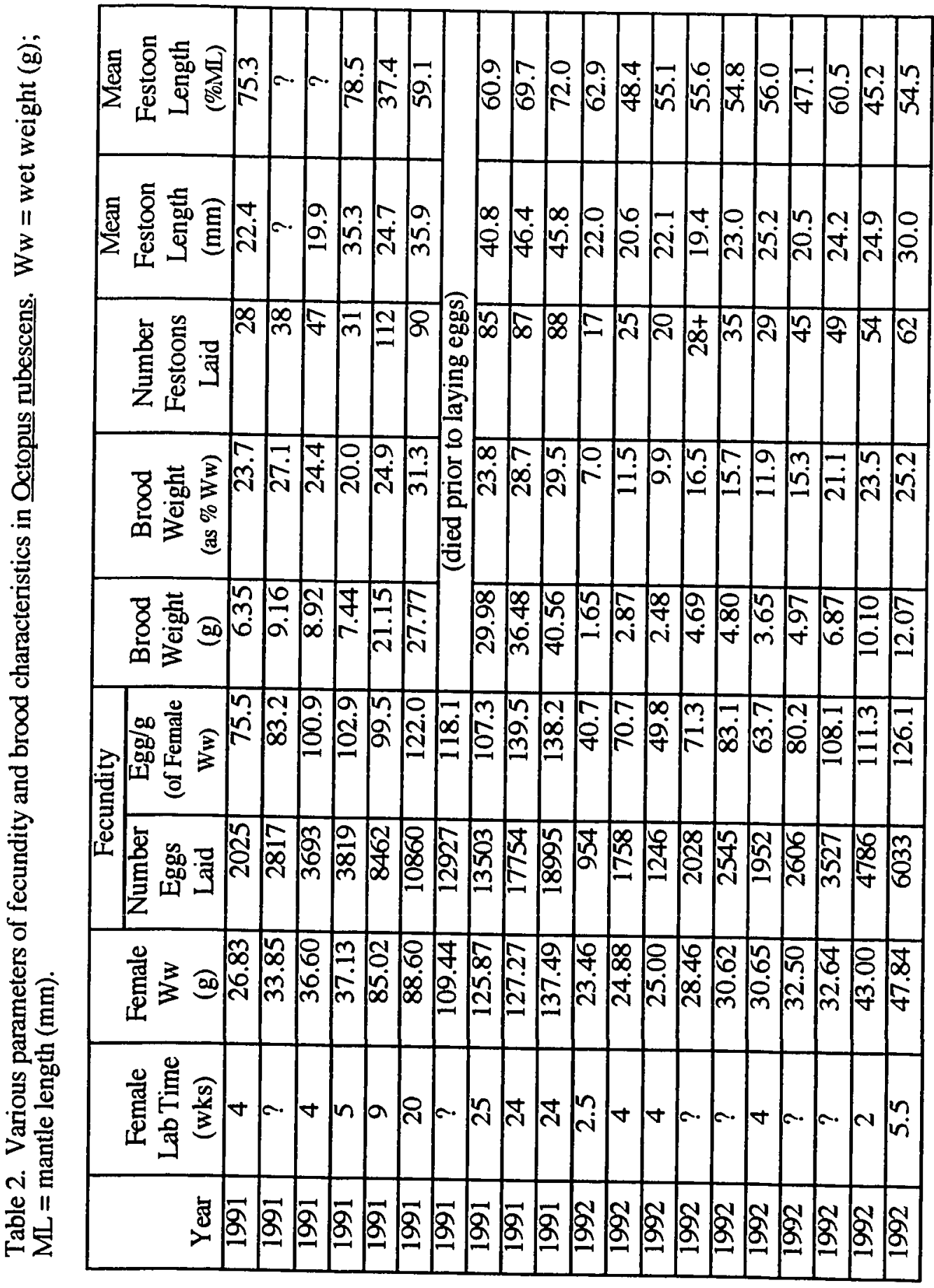


Table 3. Statistical comparisons of the relationship between mean egg density per size class of festoon length and festoon length within each brood.

\begin{tabular}{llrrr}
\hline & & $\begin{array}{c}\text { Regression } \\
\text { Coefficient } \\
\text { (r-squared) }\end{array}$ & $\begin{array}{c}\text { Test } \\
\text { Statistic }\end{array}$ & $\begin{array}{c}\text { p } \\
\text { Value }\end{array}$ \\
\hline EGG DENSITY & & & & \\
Related to Festoon Length Size Classes for. & & & & \\
Brood 1 & 3 & 0.209 & $\mathrm{t}=-0.51$ & $\mathrm{p}>.50$ \\
Brood 2 & 3 & 0.799 & $\mathrm{t}=2.00$ & $.20<\mathrm{p}<.50$ \\
Brood 3 & 4 & 0.692 & $\mathrm{t}=2.12$ & $.10<\mathrm{p}<.20$ \\
Brood 4 & 5 & 0.347 & $\mathrm{t}=-1.26$ & $.20<\mathrm{p}<.50$ \\
Brood 5 & 6 & 0.018 & $\mathrm{t}=0.34$ & $\mathrm{p}>.50$ \\
Brood 6 & 7 & 0.003 & $\mathrm{t}=0.13$ & $\mathrm{p}>.50$ \\
Brood 7 & 9 & 0.200 & $\mathrm{t}=1.32$ & $.20<\mathrm{p}<.50$ \\
Brood 8 & 4 & 0.767 & $\mathrm{t}=2.57$ & $.10<\mathrm{p}<.20$ \\
Brood 9 & 4 & 0.598 & $\mathrm{t}=1.72$ & $.20<\mathrm{p}<.50$ \\
Brood 10 & 5 & 0.165 & $\mathrm{t}=-0.77$ & $\mathrm{p}>.50$ \\
Brood 11 & 3 & 0.925 & $\mathrm{t}=3.54$ & $.10<\mathrm{p}<.20$ \\
Brood 12 & 4 & 0.007 & $\mathrm{t}=0.04$ & $\mathrm{p}>.50$ \\
Brood 13 & 4 & 0.259 & $\mathrm{t}=0.84$ & $.20<\mathrm{p}<.50$ \\
Brood 14 & 4 & 0.005 & $\mathrm{t}=0.03$ & $\mathrm{p}>.50$ \\
Brood 15 & 3 & 0.308 & $\mathrm{t}=-0.67$ & $\mathrm{p}>.50$ \\
\hline
\end{tabular}




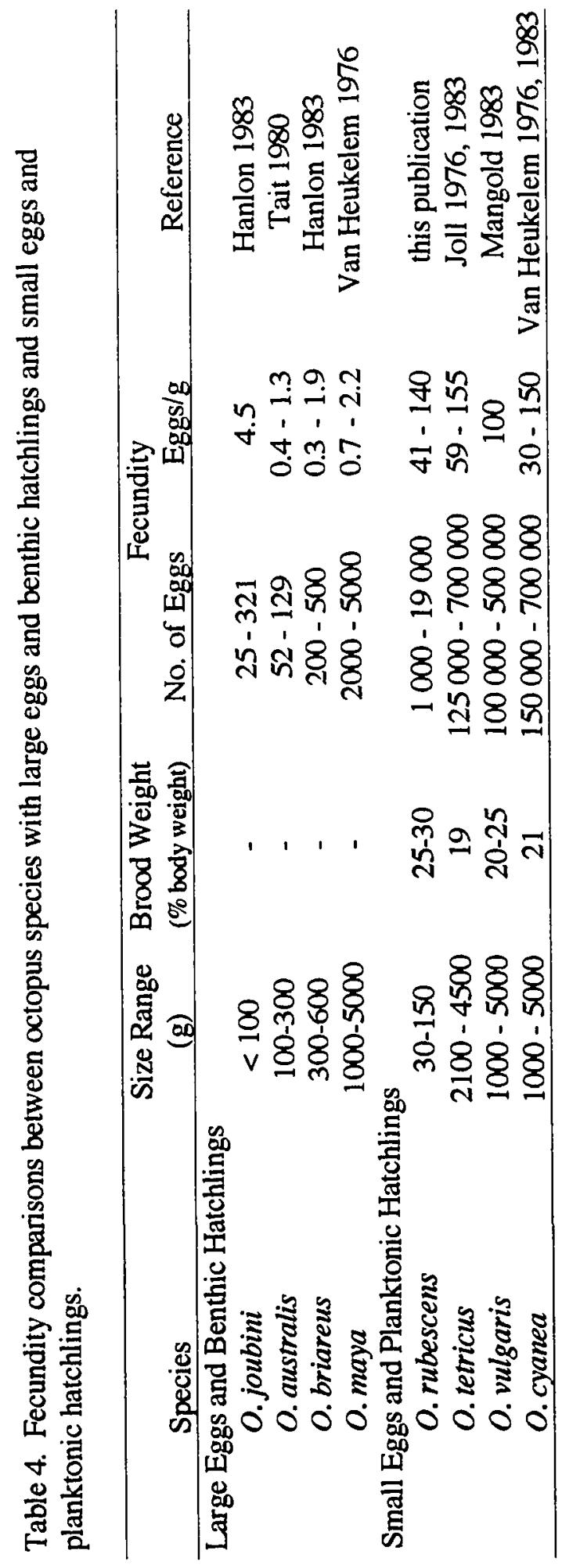




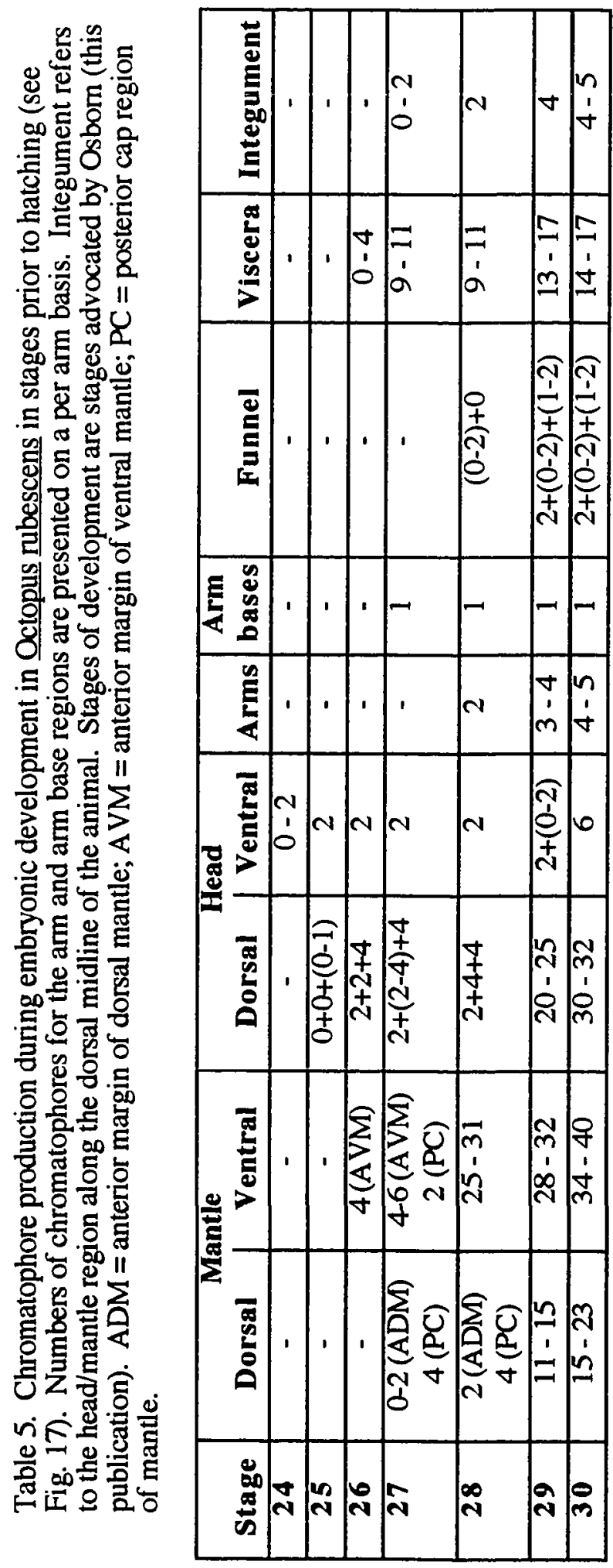




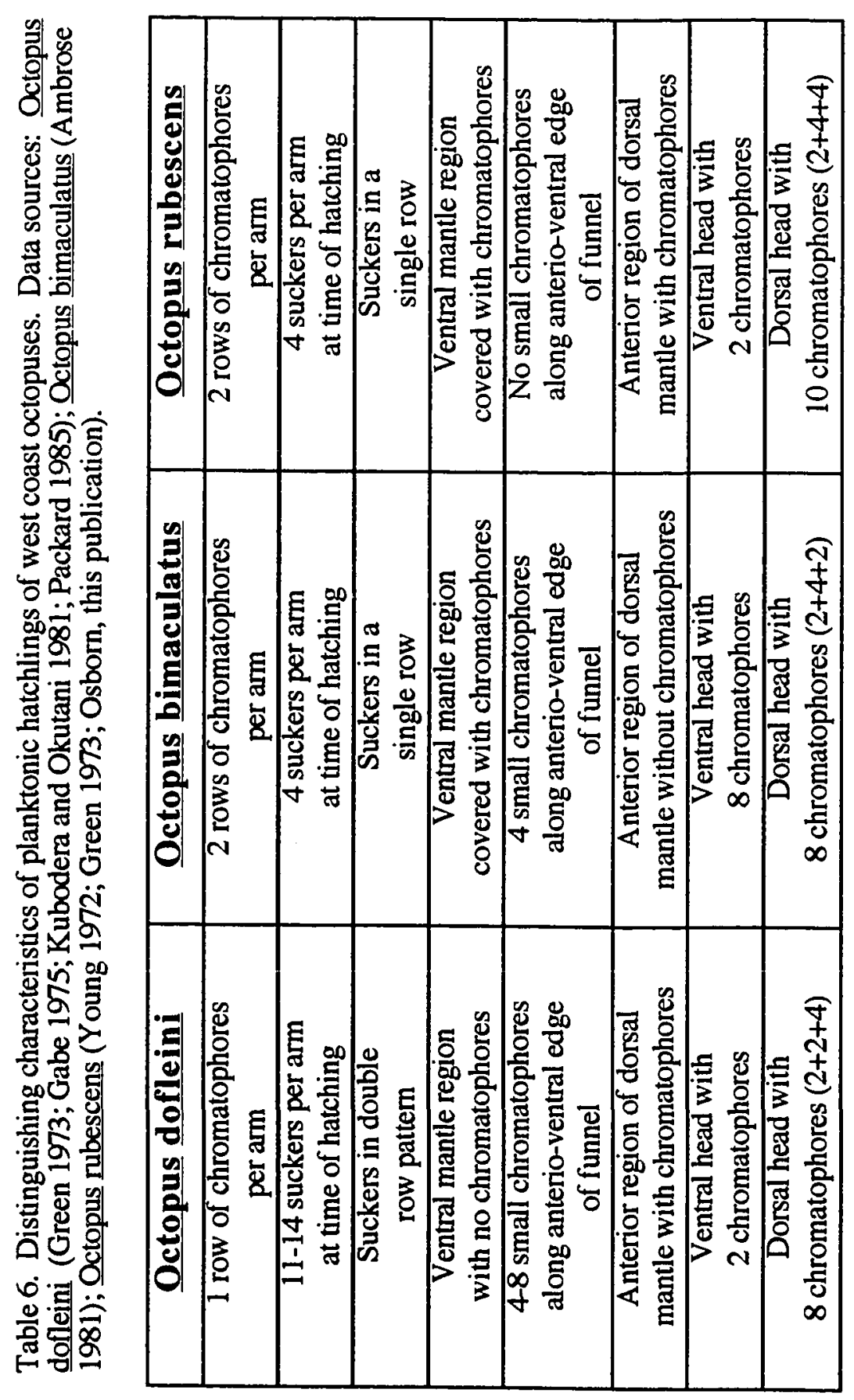




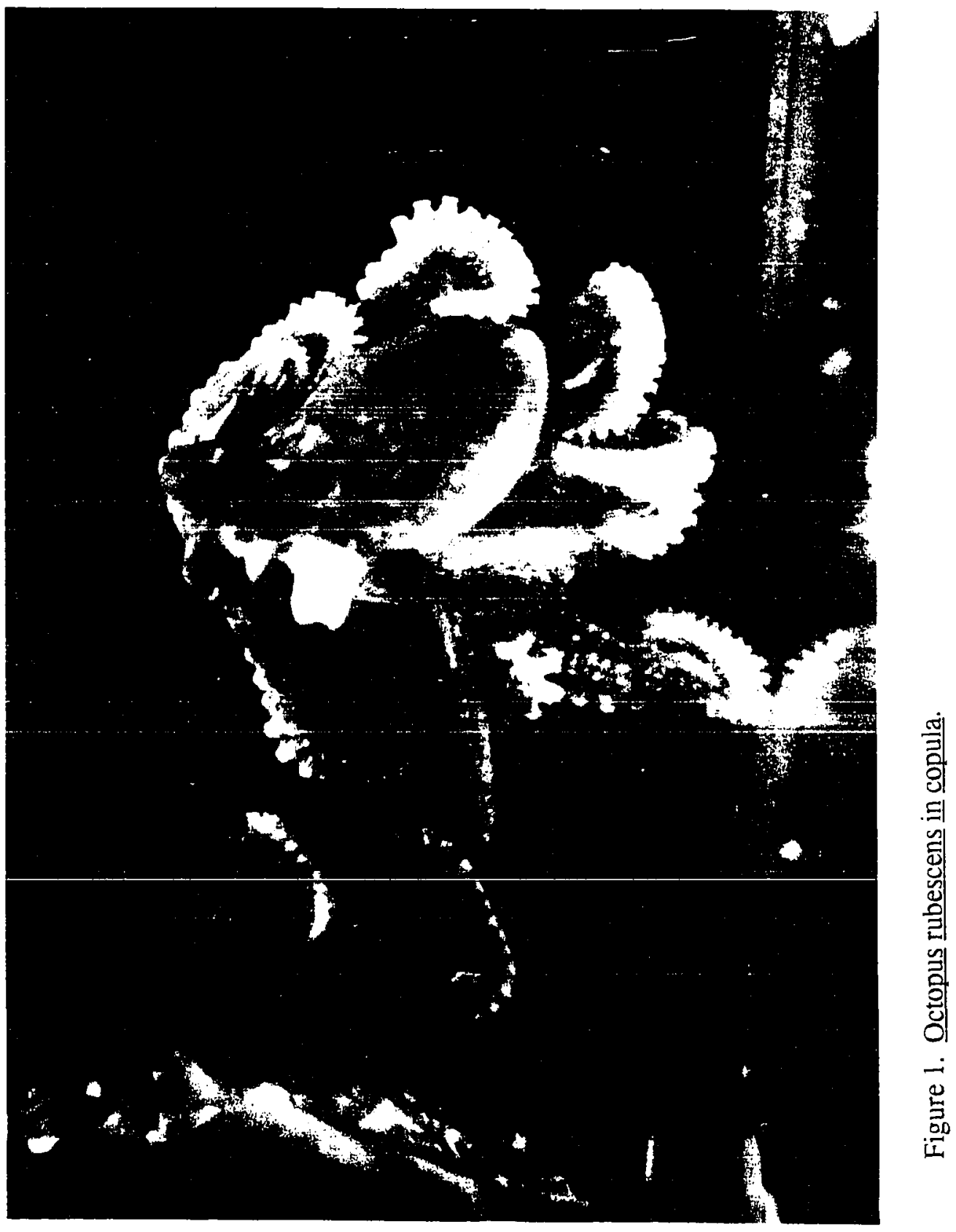



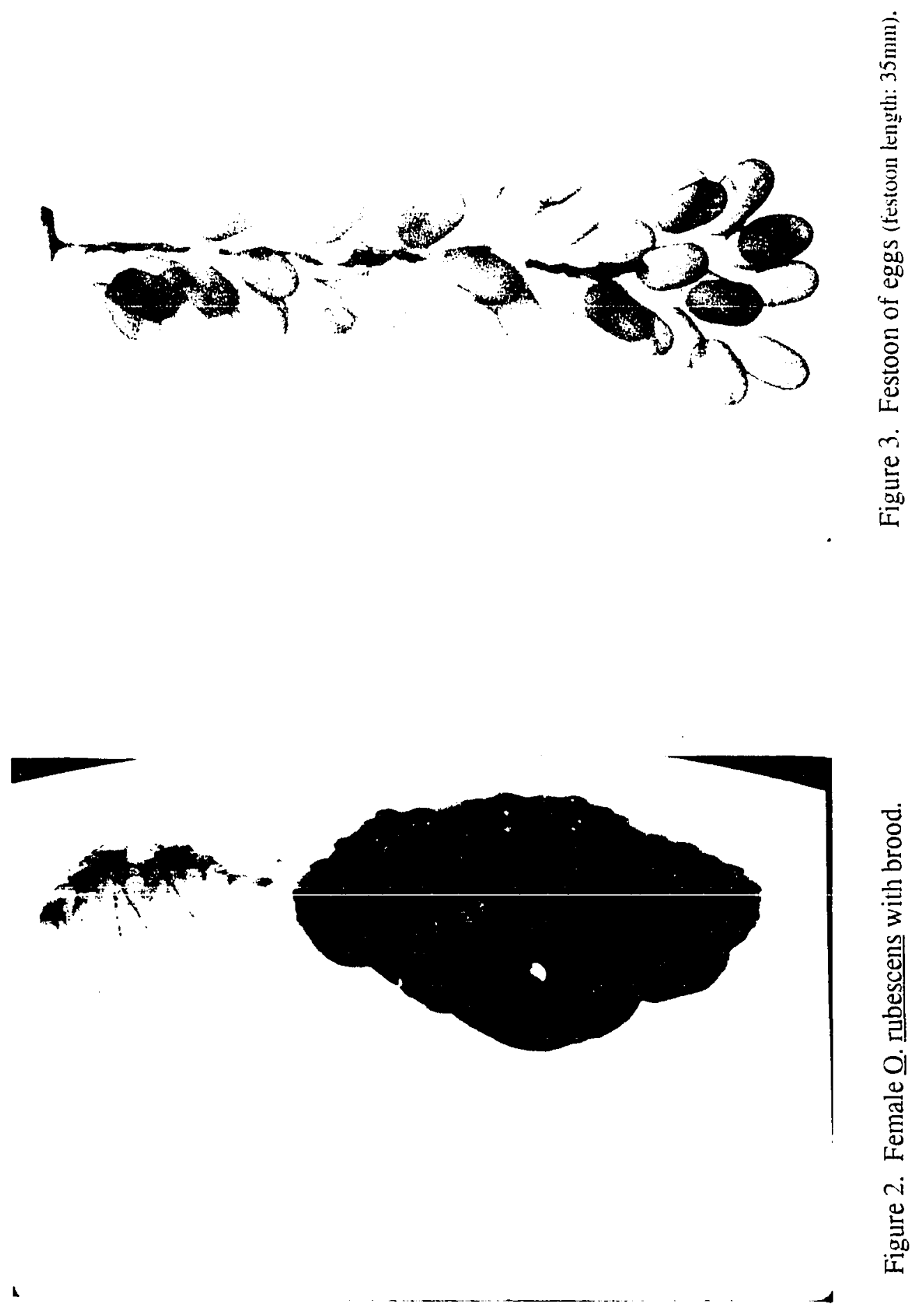


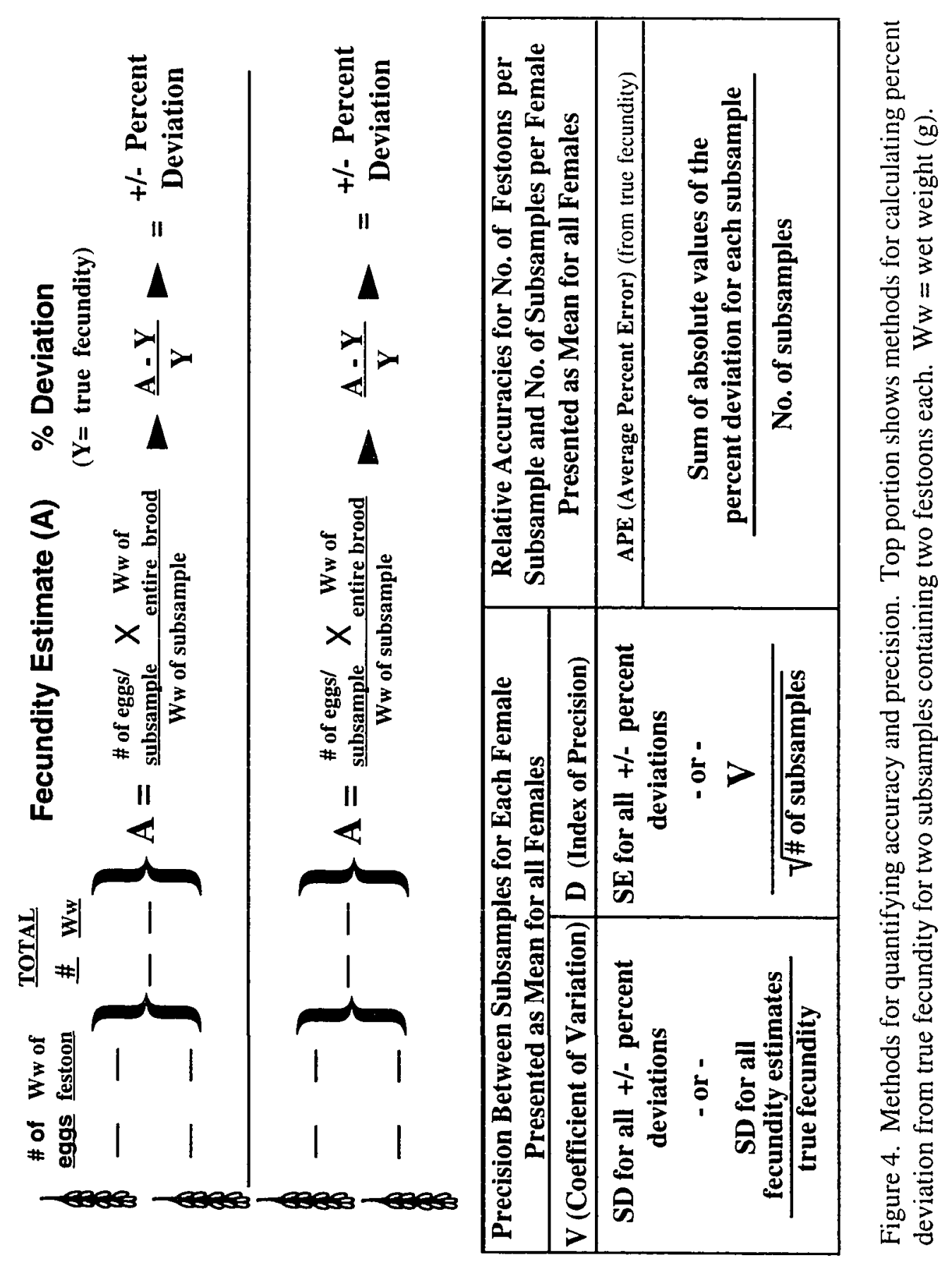




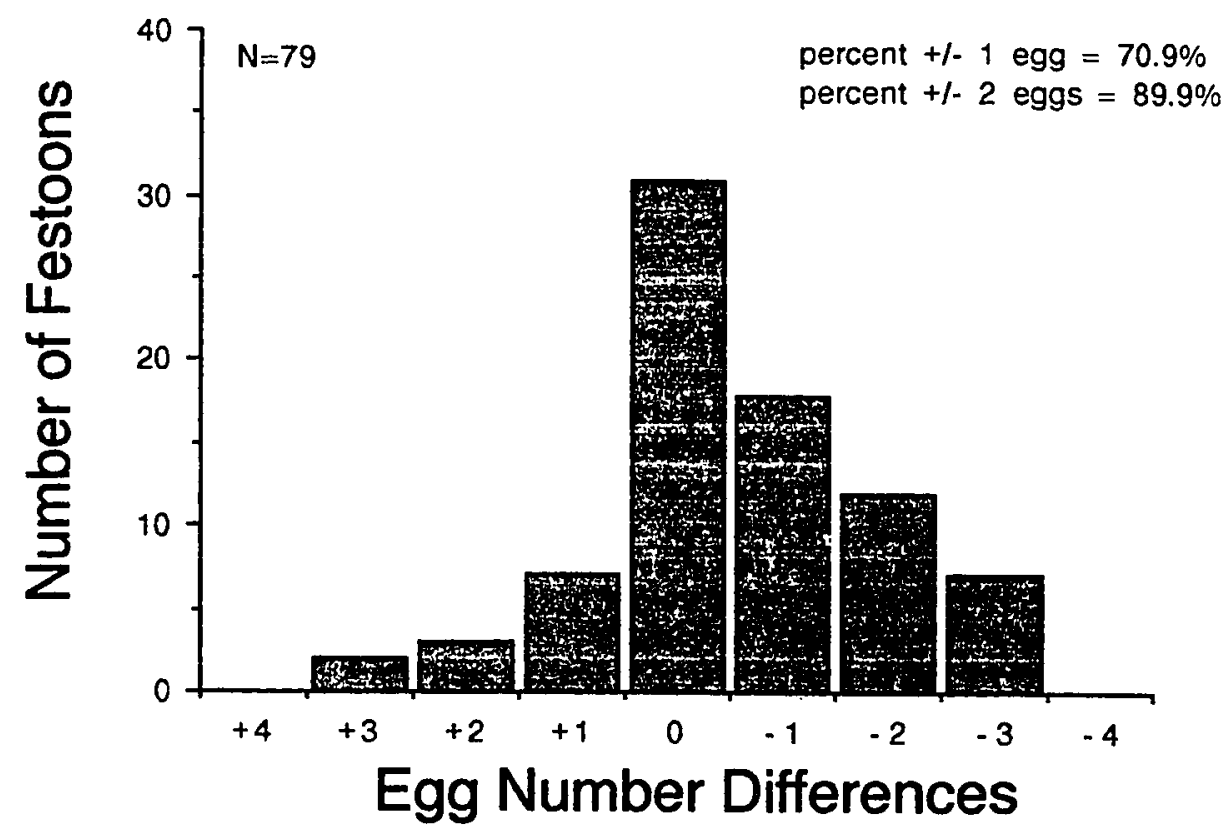

Figure 5. Frequency of differences in egg numbers between readers. Number of eggs per festoon ranged from $29-144$. 

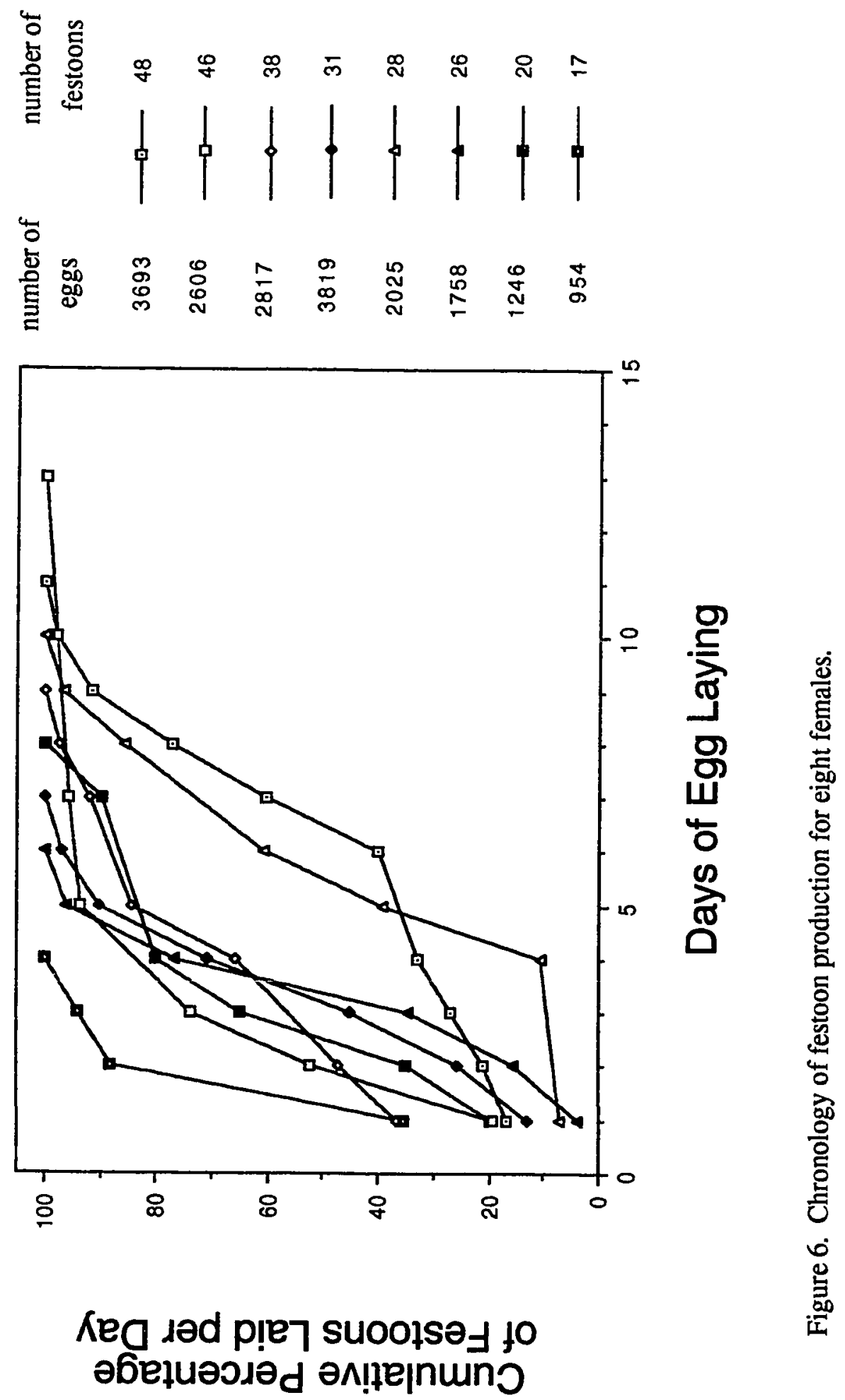


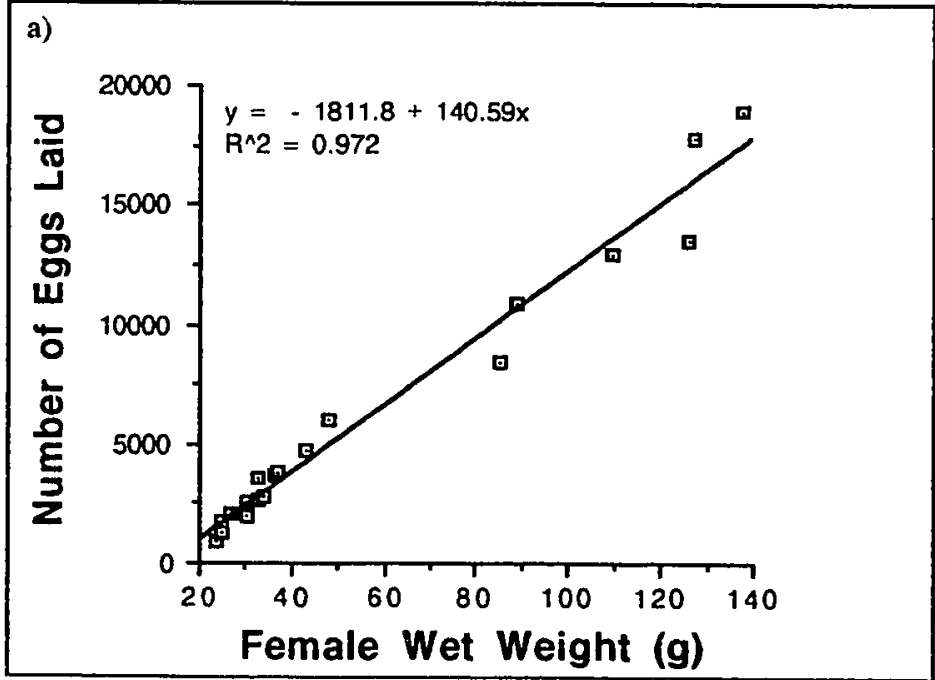

b)

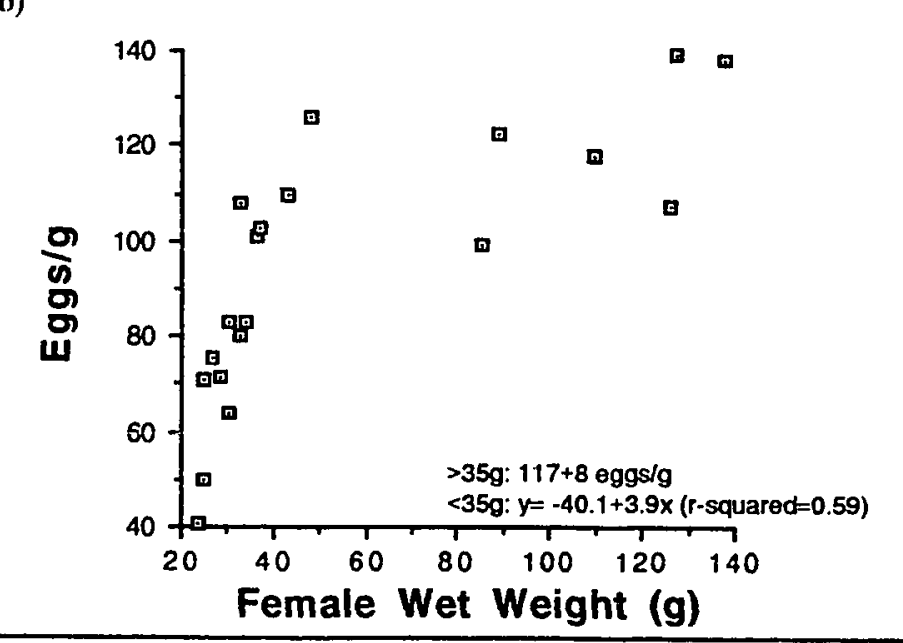

Figure 7. Relationship of female wet weight to fecundity presented as: a) total number of eggs laid per female; and b) eggs per gram of female wet weight. 


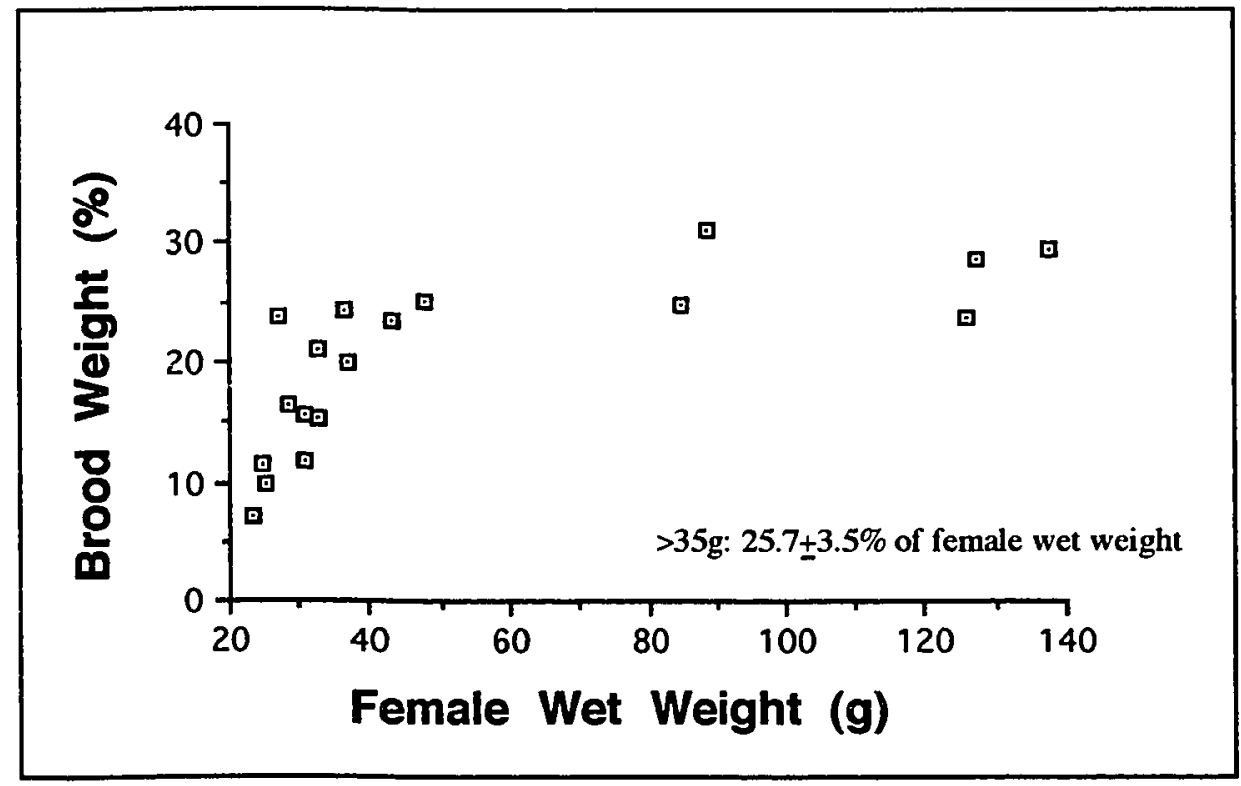

Figure 8. Relationship of female wet weight to brood weight. Brood weights are presented as percent female wet weight. 

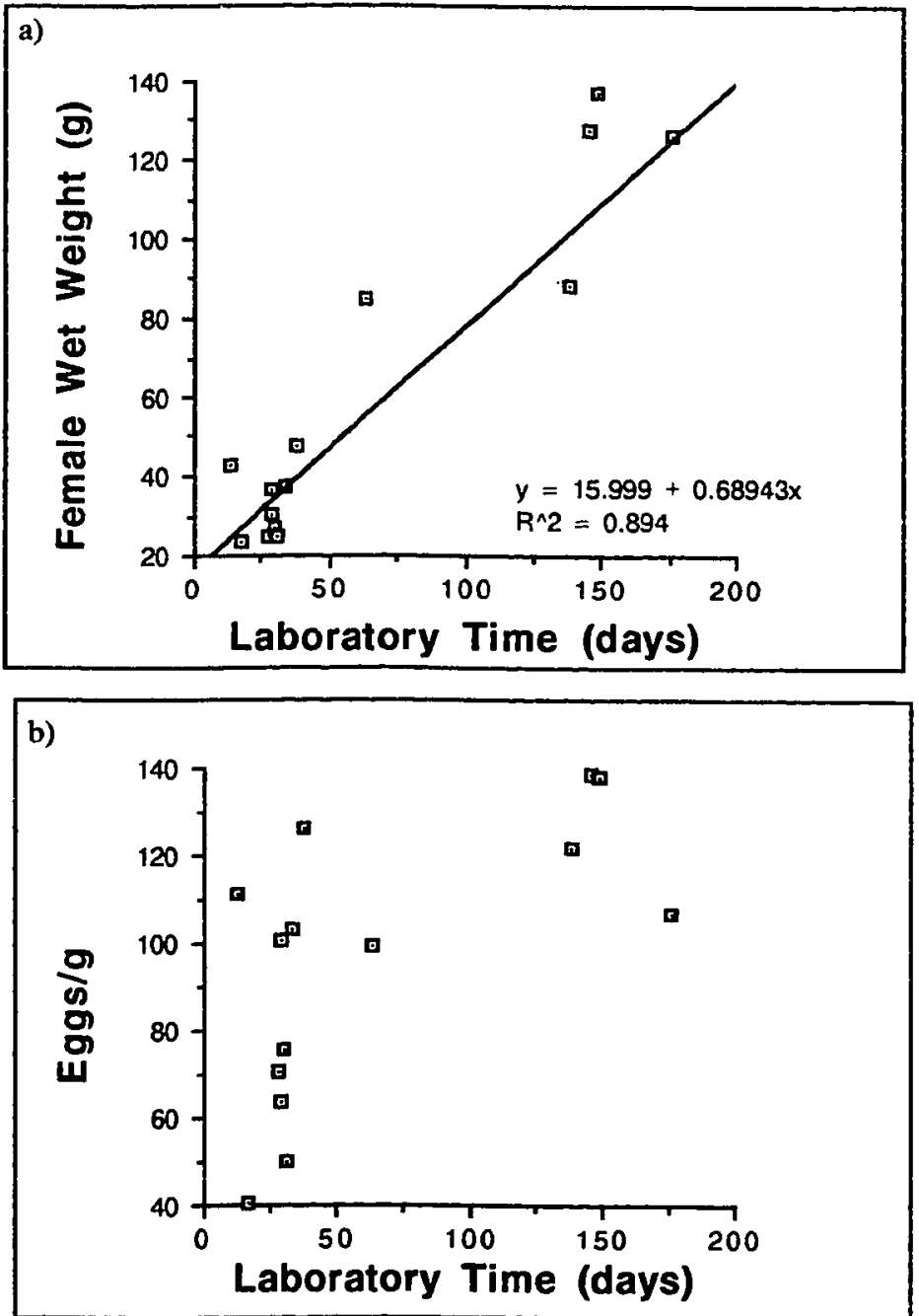

Figure 9. Effects of laboratory time on: a) female wet weight; and b) fecundity. Laboratory time is the number of days in the laboratory prior to egg-laying. Egg/g = eggs per gram of female wet weight. 

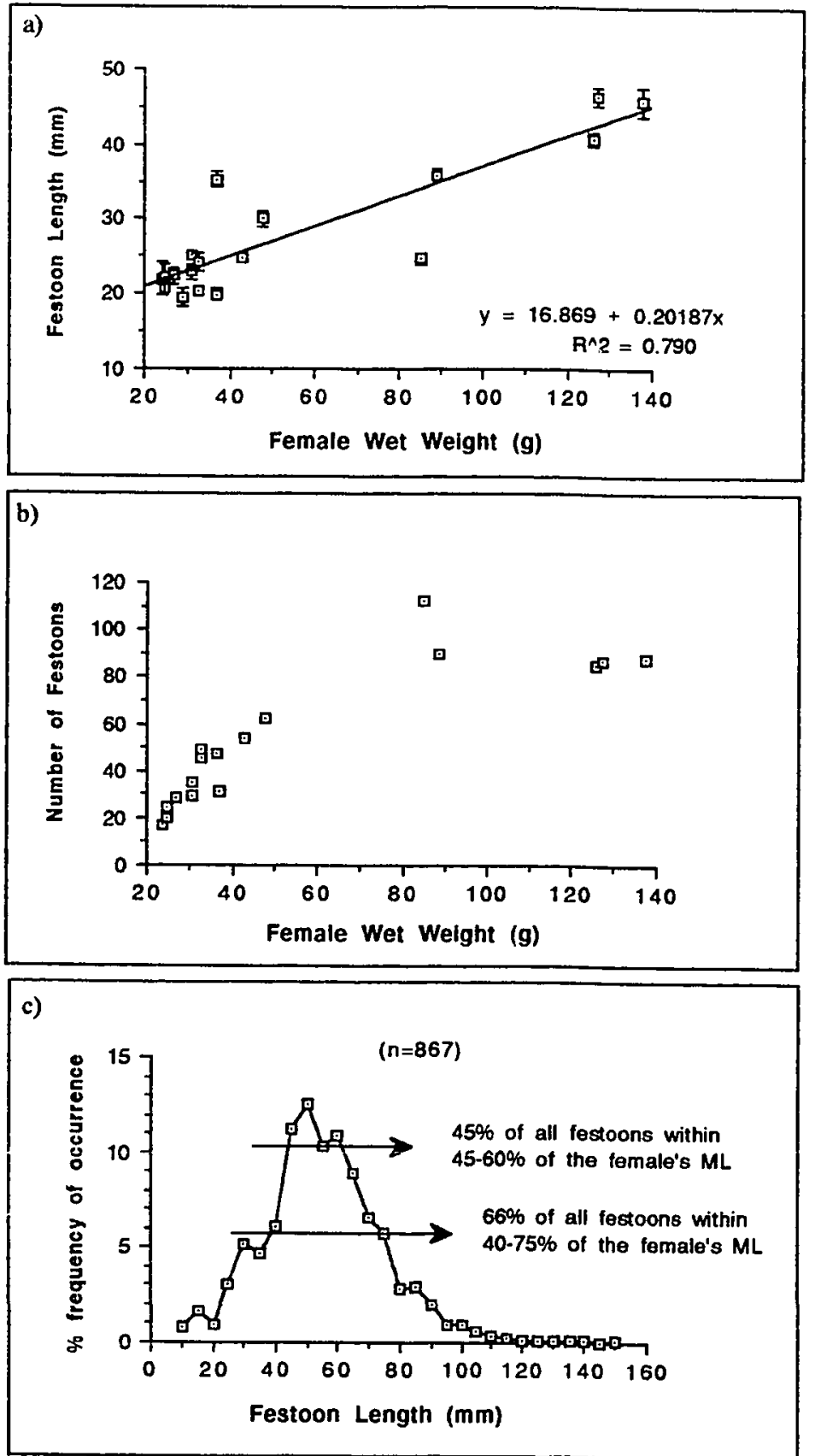

Figure 10. Relationship of female size to: a) mean festoon length per female; b) number of festoons laid per female; and c) festoon length presented as percent female mantle length. Error bars are \pm one standard error. $\mathbf{M L}=$ mantle length. 


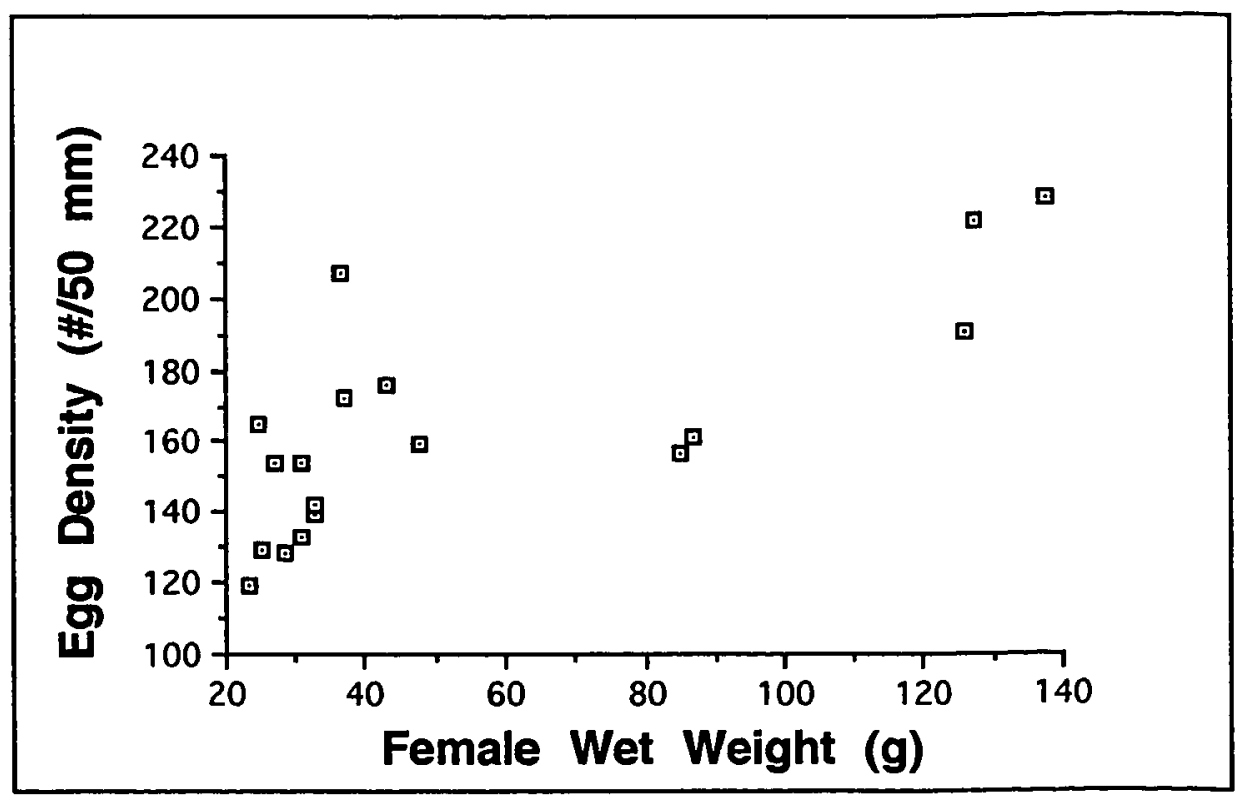

Figure 11. Relationship of female wet weight to egg density. Egg densities are presented as the number of eggs per standardized $50 \mathrm{~mm}$ length festoon. 


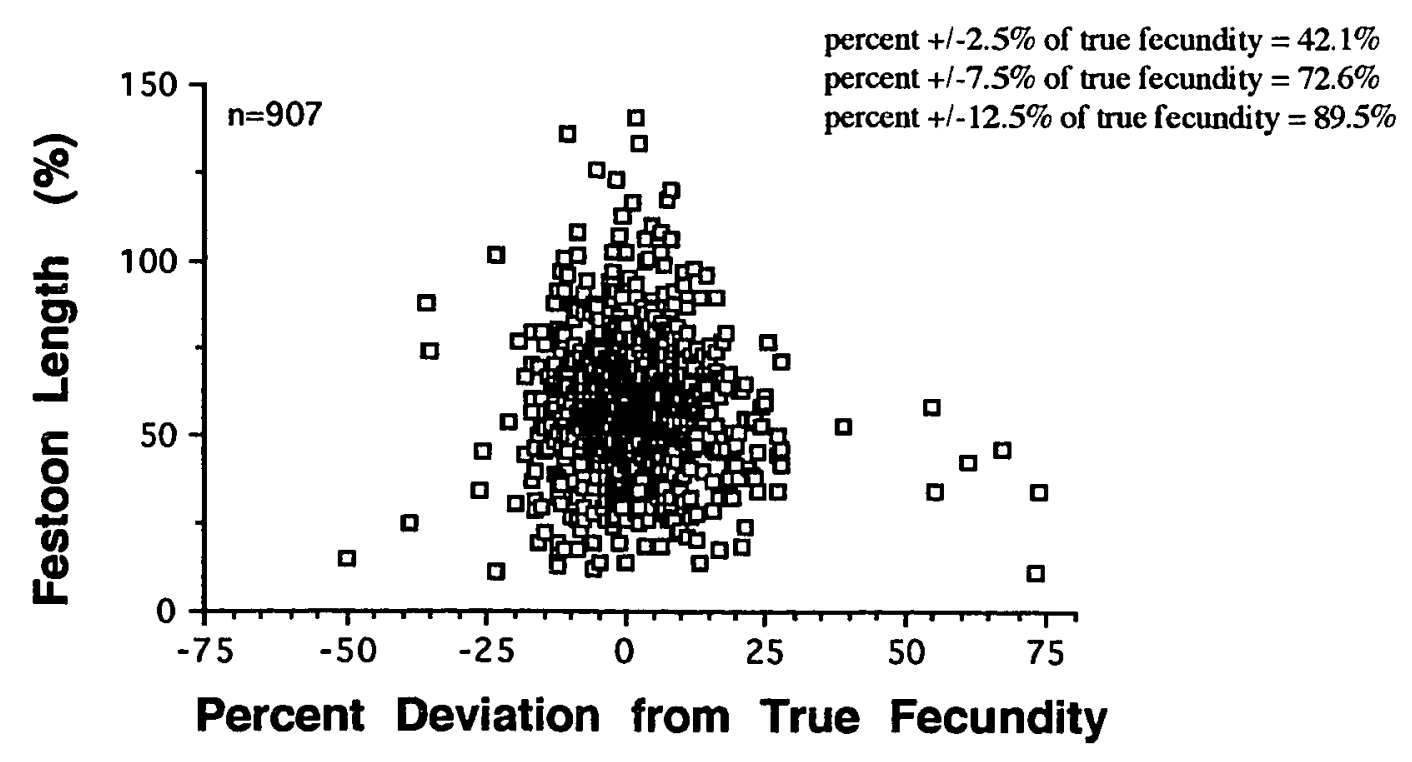

Figure 12. Percent deviation from true fecundity (the actual number of eggs per brood) using each individual festoon to estimate fecundity. Festoon length is presented as percent female mantle length. 

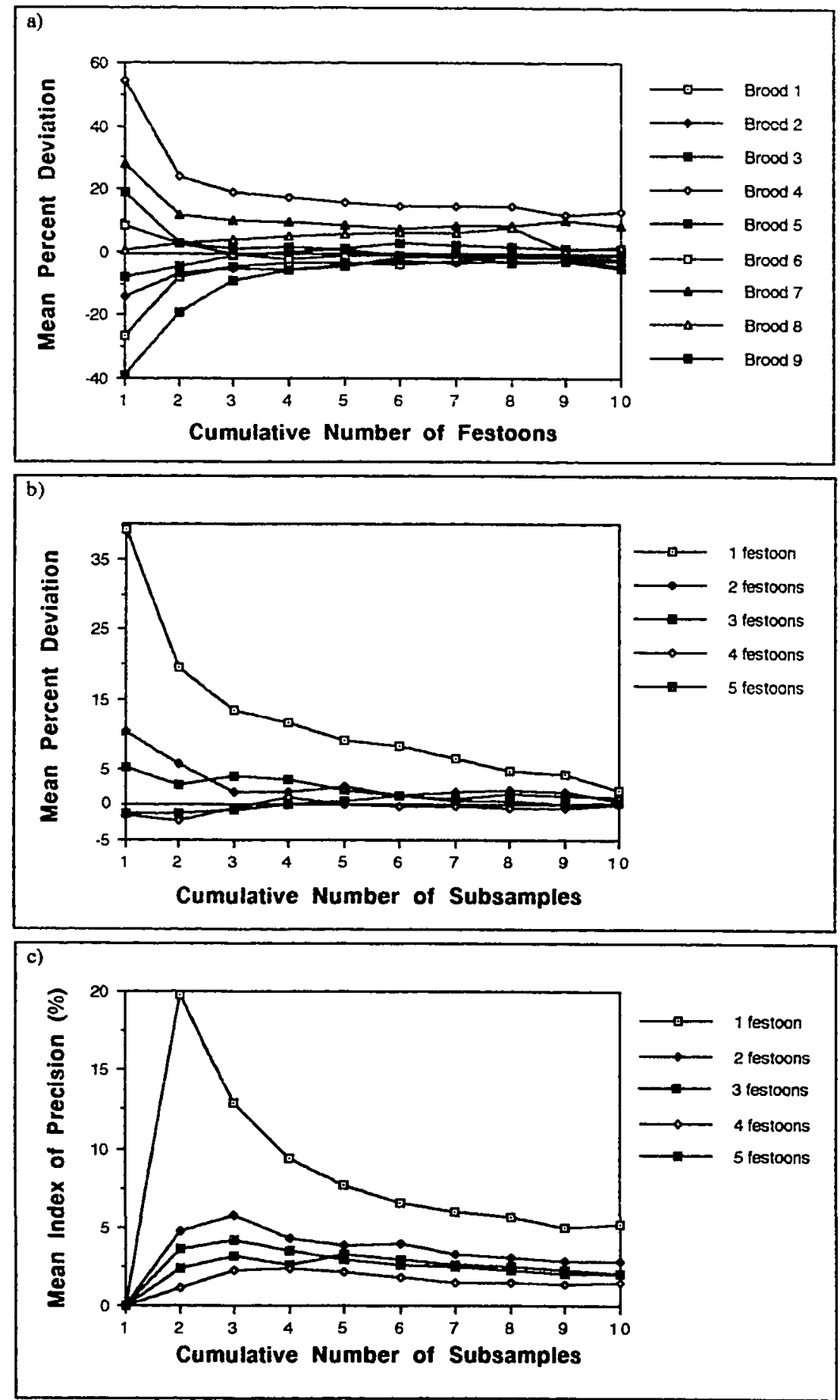

Figure 13. Effects of numbers of festoons per subsample $(a, b, c)$ and numbers of subsamples $(b, c)$ on the accuracy $(a, b)$ and precision $(c)$ of fecundity estimates. Mean percent deviation is the \pm percent deviation from the true fecundity (e.g., actual number of eggs in the brood). In legends of (a) and (b), numbers of festoons denote numbers of festoons per subsample. Barring data for one festoon in (a), all data points represent the mean of three replicates. 

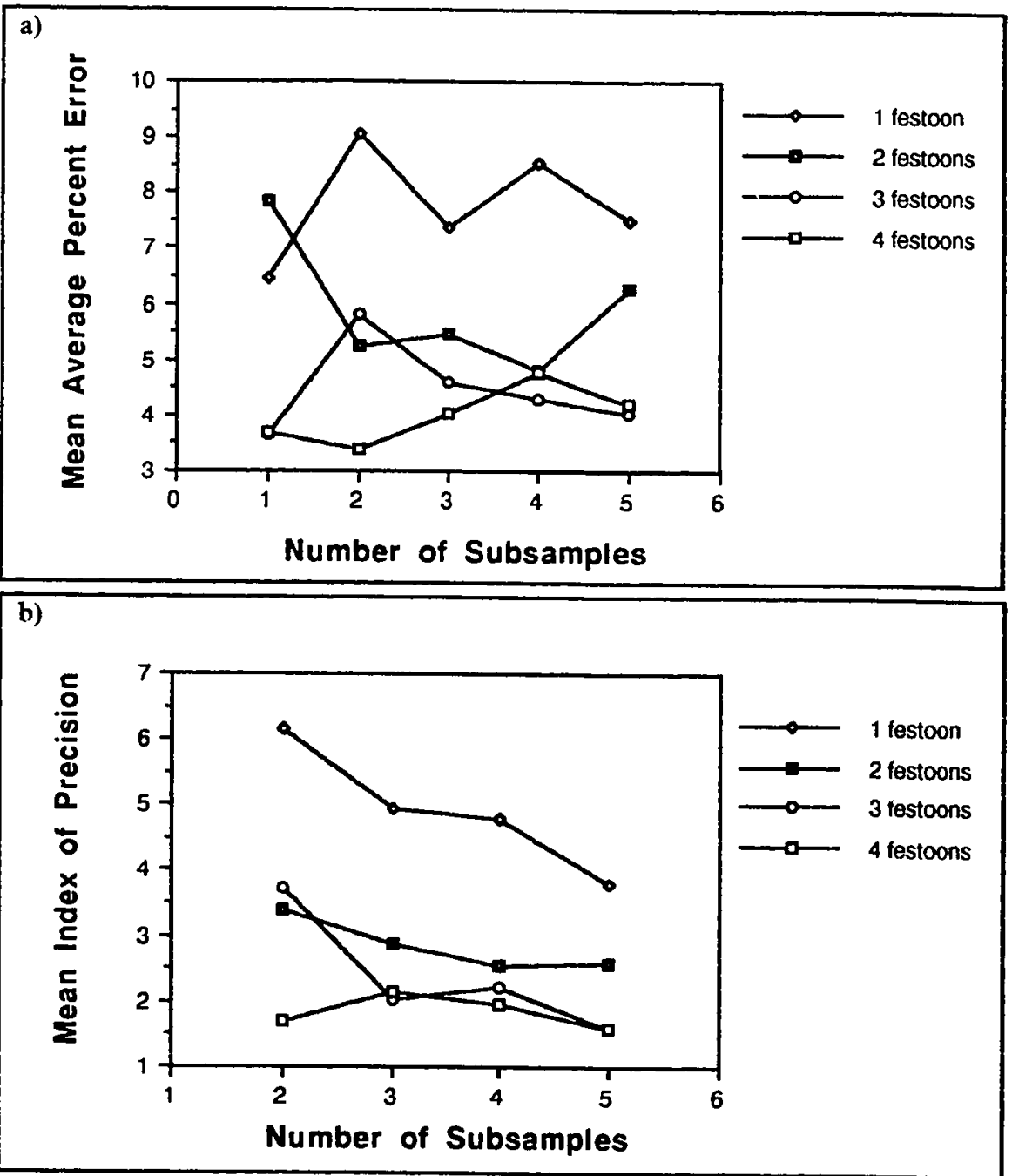

Figure 14. Effects of numbers of subsamples and numbers of festoons per subsample on: a) accuracy; and b) precision of fecundity estimates for eighteen females. Each data point represents the mean of 18 replicates (e.g., 18 females). Average percent error and index of precision are presented as percent from the true fecundity (e.g., actual number of eggs in a brood). In legends, numbers of festoons denote numbers of festoons per subsample. Errors for all data points are presented in Appendix 2. 

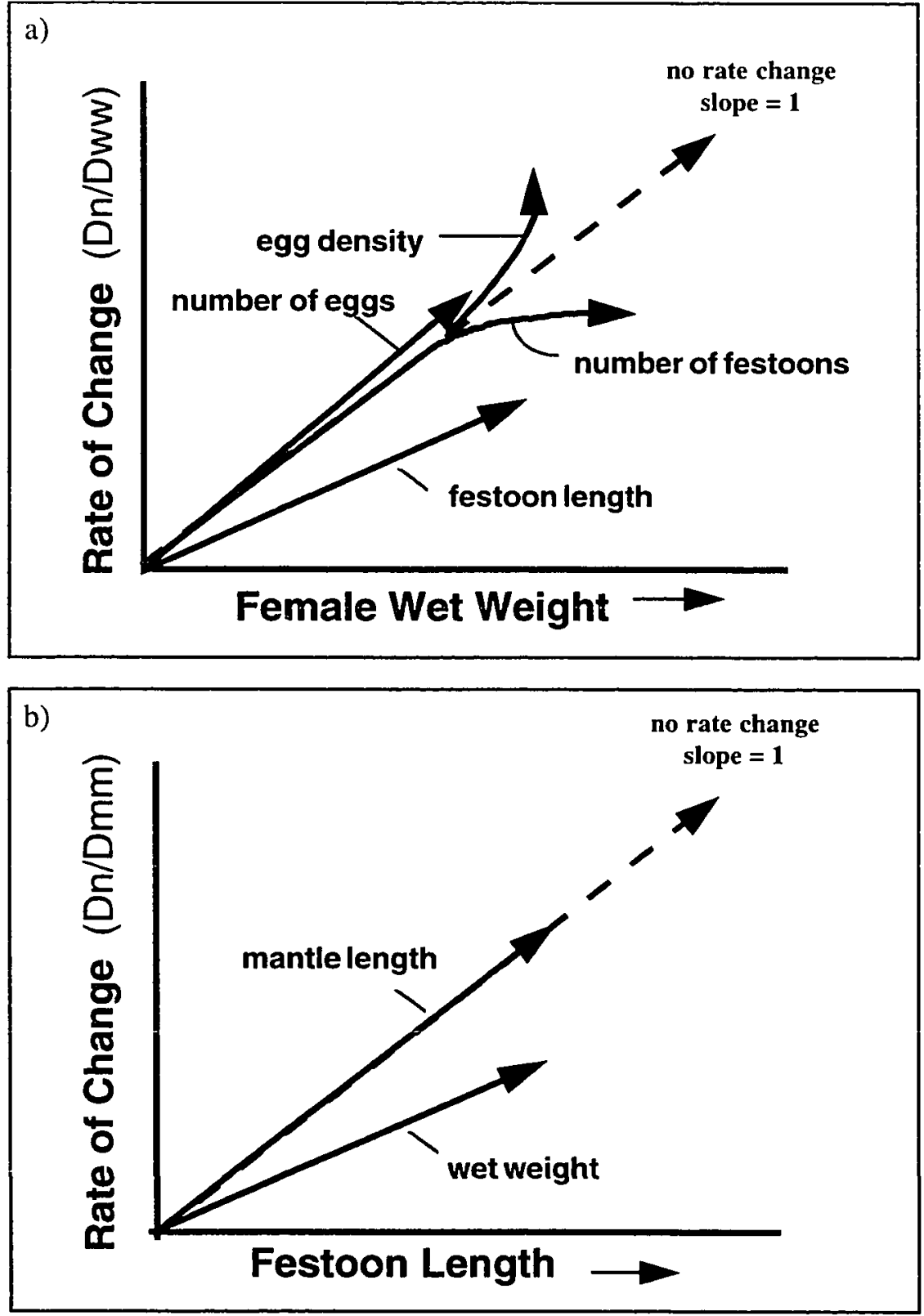

Figure 15. Synthesis of brood charcteristics and their theoretical relationship to: a) increasing female size; and b) increasing festoon length. Based on data from 20 females. All parameters presented as rates of change. 


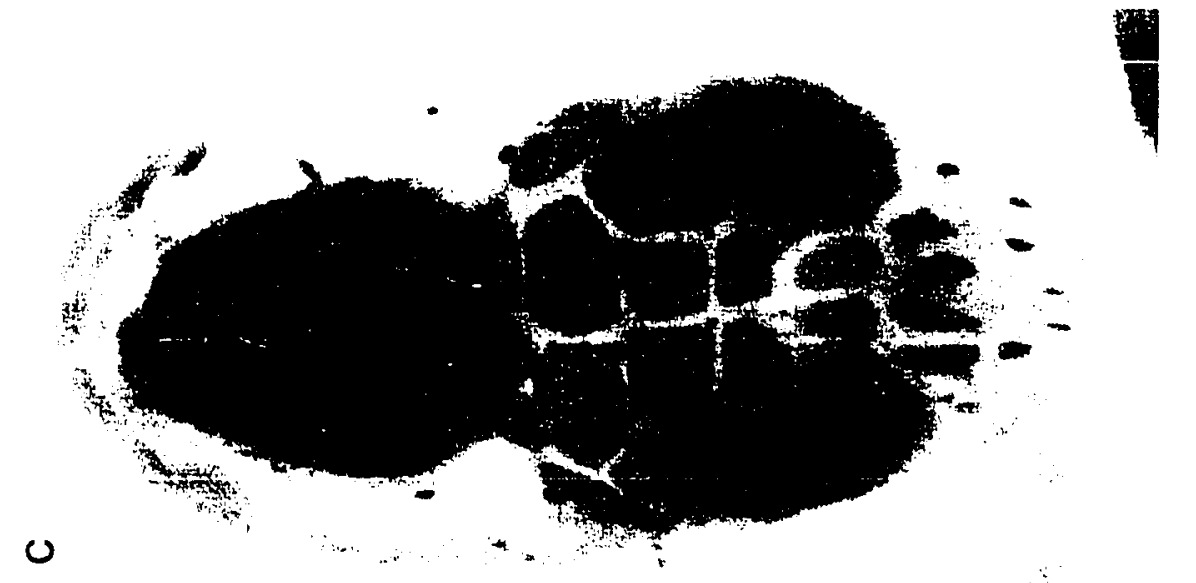

$\boldsymbol{\infty}$
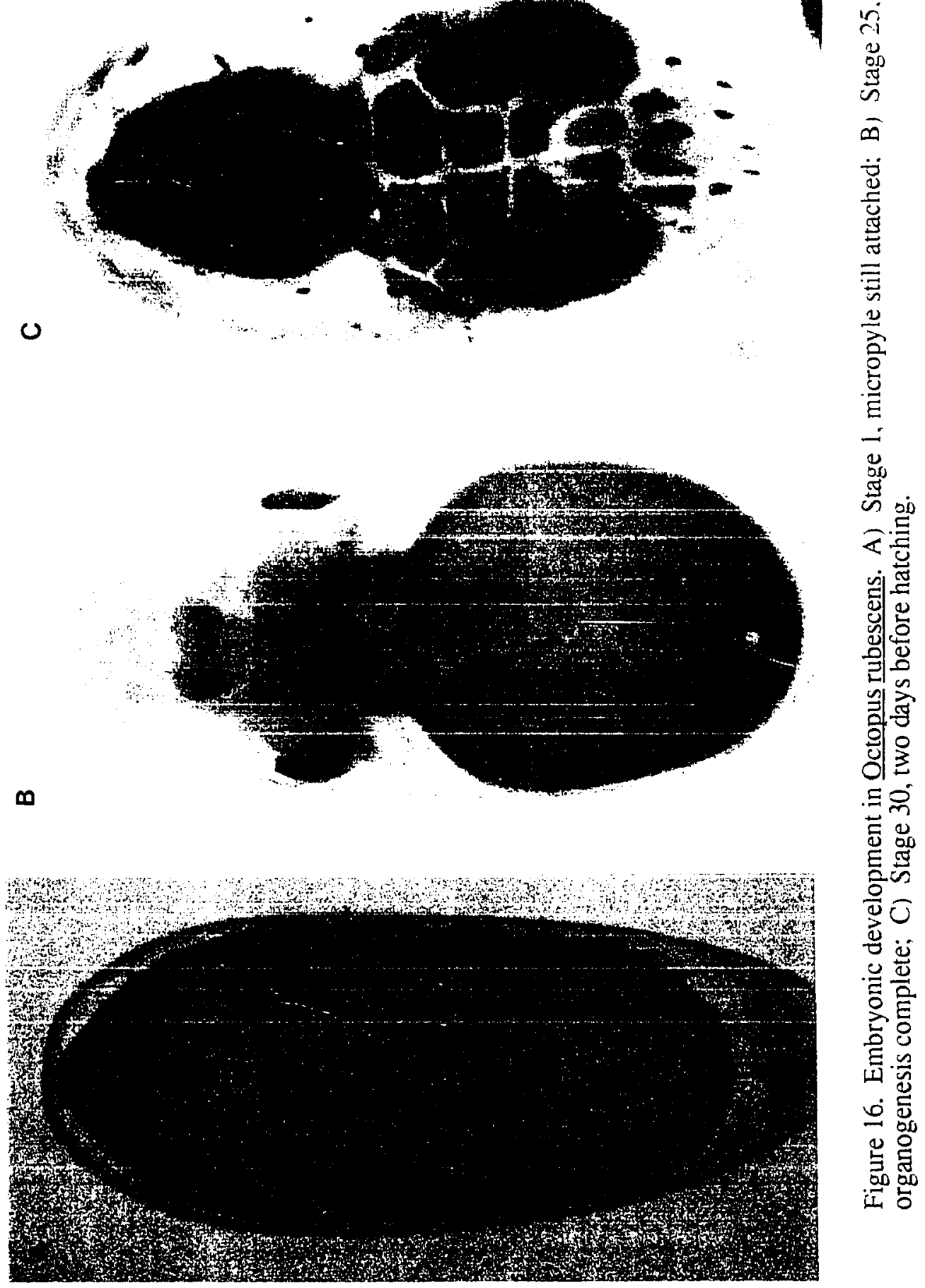


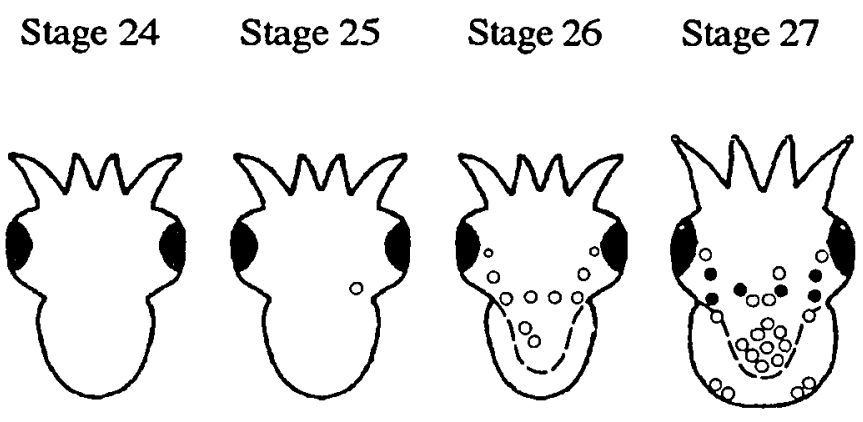

Stage 28 Stage 29
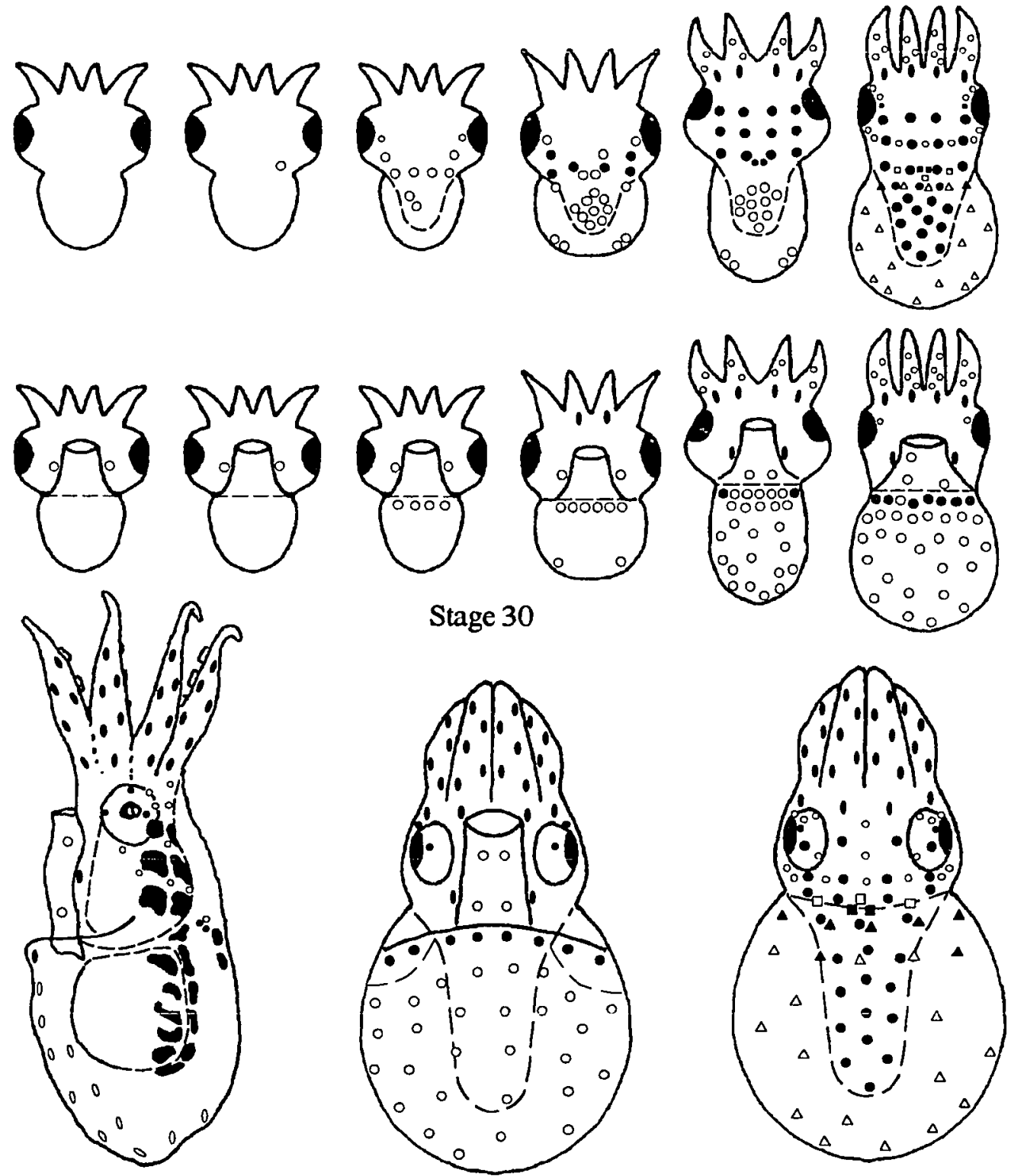

Stage 30
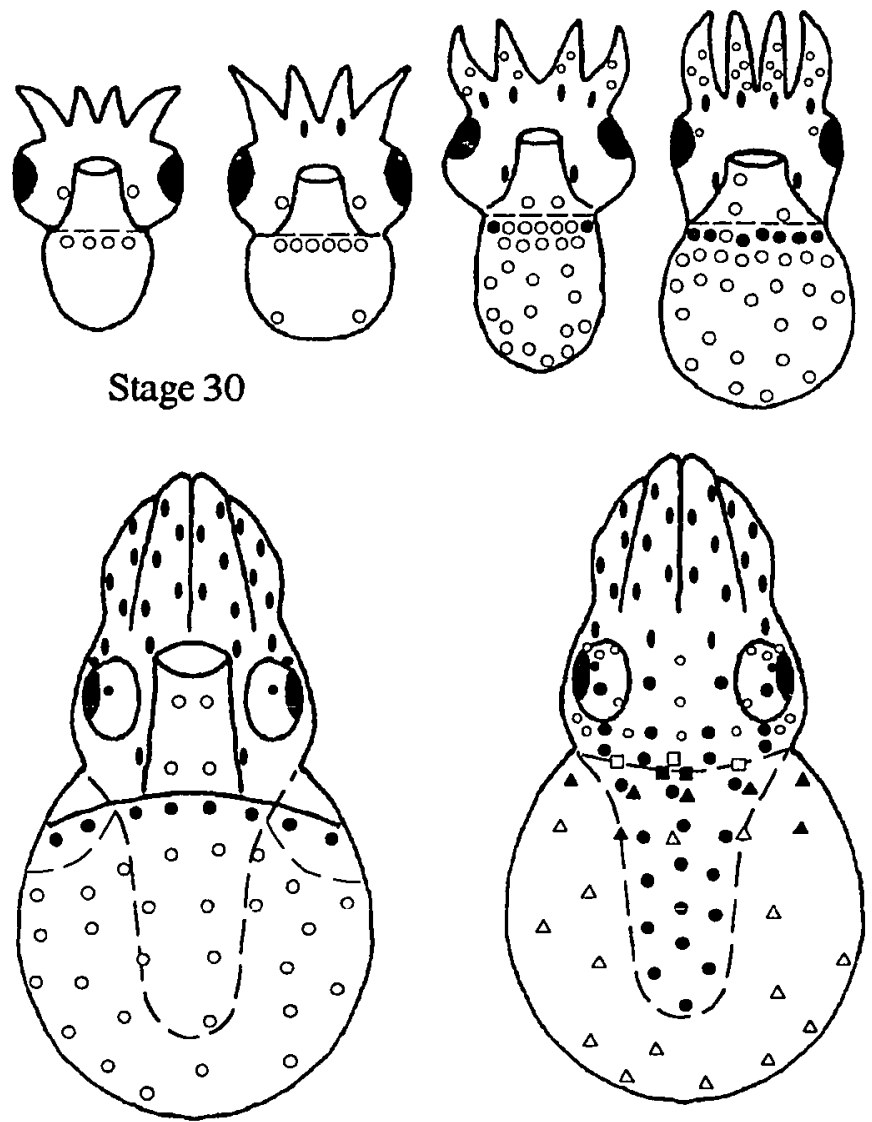

\section{Stages 24-30}

- - brown chromatophores $\circ 0$
$\square \Delta$ - orange chromatophores
Stage 29-30 (dorsal view)

$: 0$ - arm, head, and viscera chromatophores

- $\mathrm{-} \mathrm{integumental}$ chromatophores

$\Delta \Delta$ - dorsal mantle chromatophores

Figure 17. Chromatophore production in Octopus rubescens. Stage 24-29: embryos in dorsal view (upper row) and in ventral view (lower row). Stage 30: embryos in dorsal view (right), ventral view (middle) and lateral view (left). Stages as advocated by Osborn (this publication). Drawings modified from Forsythe \& Hanlon (1985) and Young et al. (1989). 


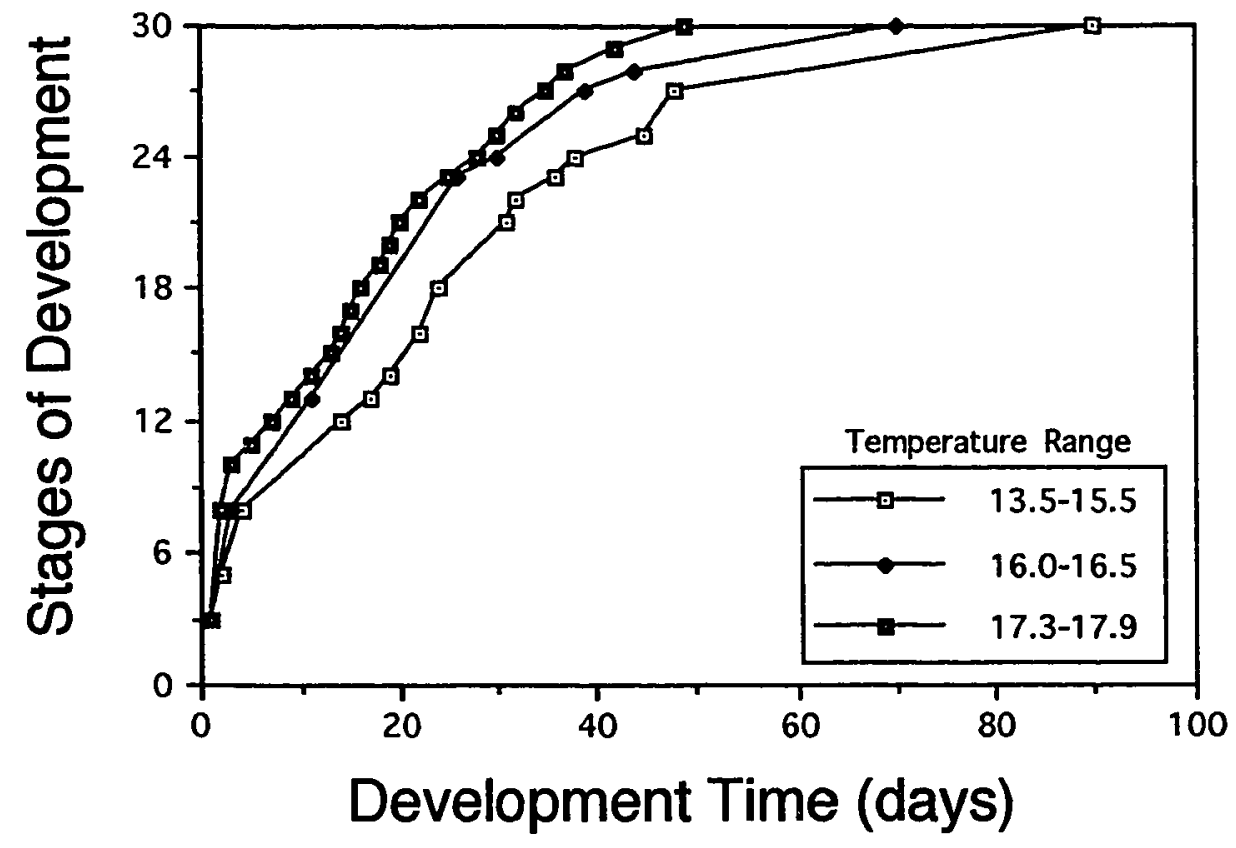

Figure 18. Typical sequence of embryonic development in Octopus nubescens recorded at three temperature ranges. Stages of development are stages advocated by Osborn (this publication). Temperatures are in degrees Celsius. 


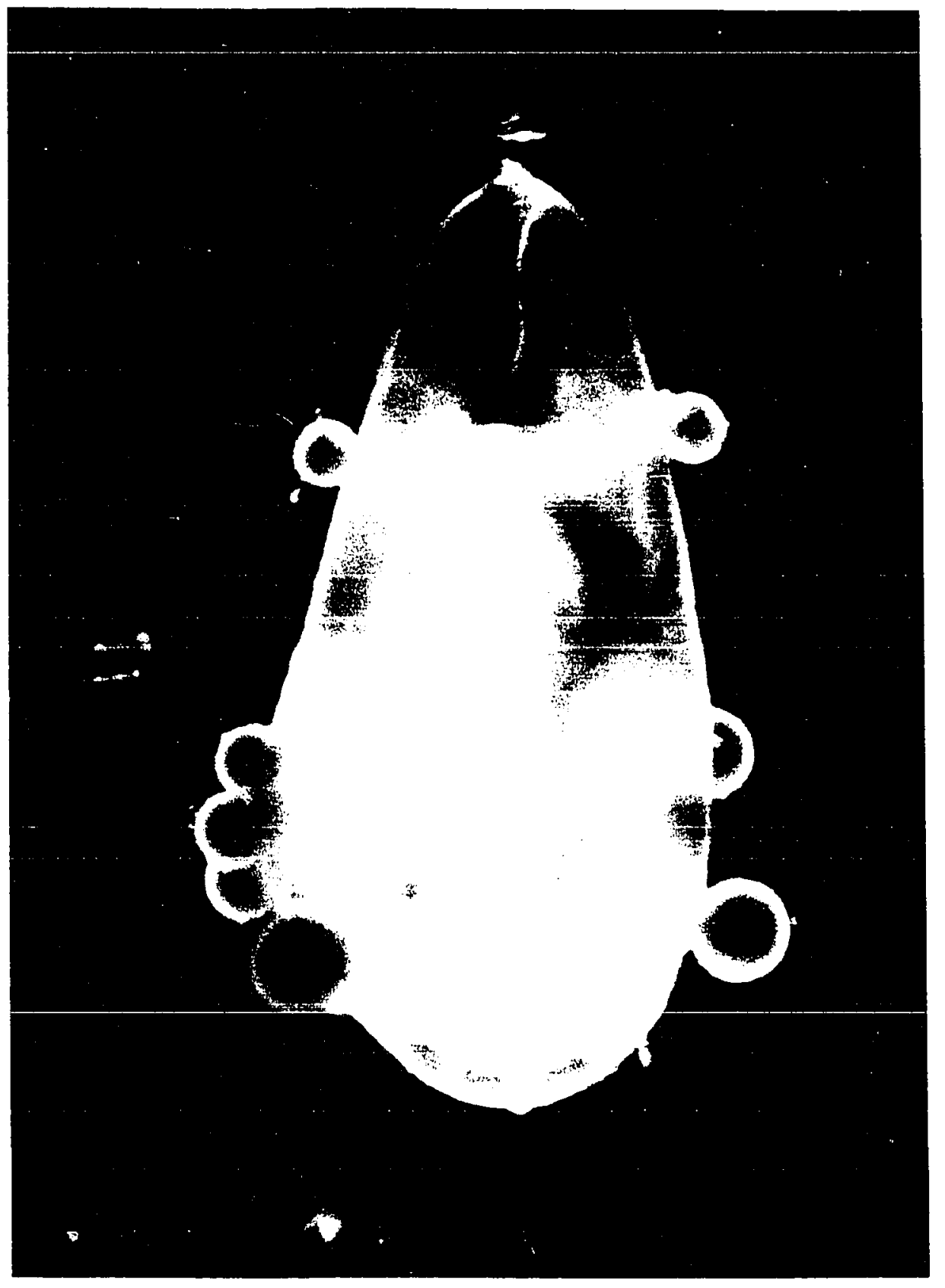

Figure 19. Ectoparasites on an egg of Octopus rubescens. Egg length: $3.1 \mathrm{~mm}$. 
Appendix 1. Festoon data used for fecundity analyses.

\begin{tabular}{|c|c|c|c|c|c|c|}
\hline Year & Female & $\begin{array}{l}\text { Festoon } \\
\text { Number }\end{array}$ & $\begin{array}{c}\text { Number of } \\
\text { Eggs/Festoon }\end{array}$ & $\begin{array}{l}\text { Festoon Wet } \\
\text { Weight (g) }\end{array}$ & $\begin{array}{l}\text { Festoon Wet } \\
\text { Volume (ml) }\end{array}$ & $\begin{array}{c}\text { Festoon } \\
\text { Length }(\mathrm{mm})\end{array}$ \\
\hline 1991 & 3 & 1 & 99 & 0.22 & 0.16 & 18.80 \\
\hline 1991 & 3 & 2 & 61 & 0.14 & 0.13 & 14.00 \\
\hline 1991 & 3 & 3 & 108 & 0.27 & 0.20 & 22.00 \\
\hline 1991 & 3 & 4 & 74 & 0.17 & 0.19 & 18.00 \\
\hline 1991 & 3 & 5 & 130 & 0.33 & 0.29 & 28.40 \\
\hline 1991 & 3 & $\frac{5}{6}$ & 84 & 0.18 & 0.20 & 19.50 \\
\hline 1991 & 3 & 7 & 81 & 0.20 & 0.20 & 20.20 \\
\hline 1991 & 3 & 8 & 99 & 0.23 & 0.21 & 22.20 \\
\hline 1991 & 3 & 9 & 106 & 0.26 & 0.20 & 23.00 \\
\hline 1991 & 3 & 10 & 87 & 0.21 & 0.19 & 20.00 \\
\hline 1991 & 3 & 11 & 120 & 0.28 & 0.28 & 24.30 \\
\hline 1991 & 3 & 12 & 100 & 0.26 & 0.23 & 23.90 \\
\hline 1991 & 3 & 13 & 86 & 0.20 & 0.15 & 18.80 \\
\hline 1991 & 3 & 14 & 85 & 0.21 & 0.18 & 21.90 \\
\hline 1991 & 3 & 15 & 96 & 0.27 & 0.26 & 26.90 \\
\hline 1991 & 3 & 16 & 91 & 0.24 & 0.25 & 21.90 \\
\hline 1991 & 3 & 17 & 93 & 0.25 & 0.19 & 23.10 \\
\hline 1991 & 3 & 18 & 75 & 0.18 & 0.17 & 18.70 \\
\hline 1991 & 3 & 19 & 102 & 0.26 & 0.27 & 22.80 \\
\hline 1991 & 3 & 20 & 94 & 0.21 & 0.19 & 20.00 \\
\hline 1991 & 3 & 21 & 71 & 0.16 & 0.14 & 16.90 \\
\hline 1991 & 3 & 22 & 71 & 0.19 & 0.17 & 20.20 \\
\hline 1991 & 3 & 23 & 88 & 0.22 & 0.20 & 25.80 \\
\hline 1991 & 3 & 24 & 137 & 0.34 & 0.30 & 29.90 \\
\hline 1991 & 3 & 25 & 89 & 0.21 & 0.20 & 21.80 \\
\hline 1991 & 3 & 26 & 84 & 0.22 & 0.20 & 21.50 \\
\hline 1991 & 3 & 27 & 98 & 0.24 & 0.22 & 22.80 \\
\hline 1991 & 3 & 28 & 71 & 0.18 & 0.15 & 18.00 \\
\hline 1991 & 3 & 29 & 76 & 0.18 & 0.15 & 16.90 \\
\hline 1991 & 3 & 30 & 54 & 0.11 & 0.09 & 12.80 \\
\hline 1991 & 3 & 31 & 41 & 0.11 & 0.10 & 13.00 \\
\hline 1991 & 3 & 32 & 62 & 0.14 & 0.13 & 14.70 \\
\hline 1991 & 3 & 33 & 58 & 0.13 & 0.15 & 14.80 \\
\hline 1991 & 3 & 34 & 44 & 0.10 & 0.09 & 12.70 \\
\hline 1991 & 3 & 35 & 48 & 0.10 & 0.12 & 14.50 \\
\hline 1991 & 3 & 36 & 42 & 0.10 & 0.10 & 11.60 \\
\hline 1991 & 3 & 37 & 39 & 0.09 & 0.08 & 10.60 \\
\hline 1991 & 3 & 38 & 79 & 0.20 & 0.18 & 21.00 \\
\hline 1991 & 3 & 39 & 135 & 0.34 & 0.32 & 29.40 \\
\hline 1991 & 8 & 1 & 56 & 0.13 & 0.10 & 19.80 \\
\hline 1991 & 8 & 2 & 57 & 0.14 & 0.15 & 24.70 \\
\hline 1991 & 8 & 3 & 196 & 0.43 & 0.40 & 46.80 \\
\hline 1991 & 8 & 4 & 201 & 0.47 & 0.43 & 50.50 \\
\hline
\end{tabular}


Appendix 1. Continued.

\begin{tabular}{|c|c|c|c|c|c|c|}
\hline 1991 & 8 & 5 & 172 & 0.40 & 0.35 & 49.50 \\
\hline 1991 & 8 & 6 & 188 & 0.43 & 0.40 & 60.40 \\
\hline 1991 & 8 & 7 & 206 & 0.48 & 0.46 & 53.60 \\
\hline 1991 & 8 & 8 & 225 & 0.50 & 0.45 & 50.00 \\
\hline 1991 & 8 & 9 & 229 & 0.51 & 0.48 & 50.40 \\
\hline 1991 & 8 & 10 & 170 & 0.40 & 0.31 & 51.60 \\
\hline 1991 & 8 & 11 & 203 & 0.44 & 0.41 & 50.00 \\
\hline 1991 & 8 & 12 & 118 & 0.26 & 0.21 & 30.60 \\
\hline 1991 & 8 & 13 & 193 & 0.43 & 0.41 & 43.50 \\
\hline 1991 & 8 & 14 & 161 & 0.35 & 0.35 & 40.00 \\
\hline 1991 & 8 & 15 & 153 & 0.38 & 0.36 & 44.60 \\
\hline 1991 & 8 & 16 & 151 & 0.37 & 0.37 & 41.40 \\
\hline 1991 & 8 & 17 & 192 & 0.47 & 0.42 & 47.50 \\
\hline 1991 & 8 & 18 & 176 & 0.41 & 0.40 & 45.50 \\
\hline 1991 & 8 & 19 & 138 & 0.28 & 0.28 & 39.00 \\
\hline 1991 & 8 & 20 & 149 & 0.36 & 0.33 & 44.20 \\
\hline 1991 & 8 & 21 & 160 & 0.39 & 0.38 & 37.10 \\
\hline 1991 & 8 & 22 & 216 & 0.48 & 0.38 & 49.10 \\
\hline 1991 & 8 & 23 & 114 & 0.27 & 0.24 & 34.70 \\
\hline 1991 & 8 & 24 & 149 & 0.38 & 0.36 & 43.20 \\
\hline 1991 & 8 & 25 & 144 & 0.37 & 0.31 & 43.00 \\
\hline 1991 & 8 & 26 & 186 & 0.43 & 0.40 & 46.30 \\
\hline 1991 & 8 & 27 & 143 & 0.36 & 0.34 & 42.80 \\
\hline 1991 & 8 & 28 & 195 & 0.42 & 0.40 & 48.10 \\
\hline 1991 & 8 & 29 & 94 & 0.23 & 0.15 & 32.60 \\
\hline 1991 & 8 & 30 & 211 & 0.51 & 0.48 & 48.60 \\
\hline 1991 & 8 & 31 & 174 & 0.42 & 0.38 & 43.90 \\
\hline 1991 & 8 & 32 & 201 & 0.45 & 0.41 & 46.30 \\
\hline 1991 & 8 & 33 & 142 & 0.30 & 0.24 & 46.40 \\
\hline 1991 & 8 & 34 & 218 & 0.49 & 0.47 & 42.30 \\
\hline 1991 & 8 & 35 & 111 & 0.23 & 0.20 & 23.50 \\
\hline 1991 & 8 & 36 & 156 & 0.37 & 0.31 & 48.10 \\
\hline 1991 & 8 & 37 & 141 & 0.30 & 0.29 & 32.10 \\
\hline 1991 & 8 & 38 & 76 & 0.16 & 0.19 & 21.50 \\
\hline 1991 & 8 & 39 & 179 & 0.41 & 0.40 & 47.40 \\
\hline 1991 & 8 & 40 & 169 & 0.41 & 0.31 & 43.10 \\
\hline 1991 & 8 & 41 & 140 & 0.33 & 0.30 & 34.10 \\
\hline 1991 & 8 & 42 & 107 & 0.20 & 0.20 & 27.20 \\
\hline 1991 & 8 & 43 & 130 & 0.26 & 0.20 & 35.00 \\
\hline 1991 & 8 & 44 & 181 & 0.41 & 0.41 & 38.90 \\
\hline 1991 & 8 & 45 & 177 & 0.41 & 0.40 & 35.30 \\
\hline 1991 & 8 & 46 & 162 & 0.39 & 0.32 & 45.80 \\
\hline 1991 & 8 & 47 & 177 & 0.39 & 0.38 & 38.00 \\
\hline 1991 & 8 & 48 & 146 & 0.34 & 0.29 & 44.60 \\
\hline 1991 & 8 & 49 & 168 & 0.42 & 0.32 & 34.40 \\
\hline 1991 & 8 & 50 & 142 & 0.35 & 0.30 & 39.80 \\
\hline
\end{tabular}


Appendix 1. Continued.

\begin{tabular}{|c|c|c|c|c|c|c|}
\hline 1991 & 8 & 51 & 161 & 0.41 & 0.36 & 41.60 \\
\hline 1991 & 8 & 52 & 130 & 0.30 & 0.24 & 37.40 \\
\hline 1991 & 8 & 53 & 76 & 0.14 & 0.15 & 25.70 \\
\hline 1991 & 8 & 54 & 183 & 0.41 & 0.34 & 43.40 \\
\hline 1991 & 8 & 55 & 157 & 0.32 & 0.28 & 42.20 \\
\hline 1991 & 8 & 56 & 155 & 0.31 & 0.28 & 41.20 \\
\hline 1991 & 8 & 57 & 148 & 0.31 & 0.25 & 37.30 \\
\hline 1991 & 8 & 58 & 178 & 0.38 & 0.38 & 44.10 \\
\hline 1991 & 8 & 59 & 111 & 0.23 & 0.20 & 37.70 \\
\hline 1991 & 8 & 60 & 149 & 0.35 & 0.30 & 40.50 \\
\hline 1991 & 8 & 61 & 158 & 0.37 & 0.33 & 42.90 \\
\hline 1991 & 8 & 62 & 96 & 0.18 & 0.17 & 22.10 \\
\hline 1991 & 8 & 63 & 186 & 0.42 & 0.38 & 42.70 \\
\hline 1991 & 8 & 64 & 179 & 0.43 & 0.37 & 46.70 \\
\hline 1991 & 8 & 65 & 150 & 0.31 & 0.26 & 33.90 \\
\hline 1991 & 8 & 66 & 202 & 0.47 & 0.43 & 47.60 \\
\hline 1991 & 8 & 67 & 193 & 0.42 & 0.34 & 44.20 \\
\hline 1991 & 8 & 68 & 64 & 0.15 & 0.15 & 27.90 \\
\hline 1991 & 8 & 69 & 131 & 0.33 & 0.26 & 35.70 \\
\hline 1991 & 8 & 70 & 187 & 0.43 & 0.36 & 43.40 \\
\hline 1991 & 8 & 71 & 206 & 0.46 & 0.39 & 52.10 \\
\hline 1991 & 8 & 72 & 178 & 0.38 & 0.34 & 43.10 \\
\hline 1991 & 8 & 73 & 189 & 0.45 & 0.36 & 45.50 \\
\hline 1991 & 8 & 74 & 133 & 0.33 & 0.31 & 43.50 \\
\hline 1991 & 8 & 75 & 151 & 0.31 & 0.28 & 40.00 \\
\hline 1991 & 8 & 76 & 148 & 0.29 & 0.27 & 40.50 \\
\hline 1991 & 8 & 77 & 207 & 0.49 & 0.41 & 45.70 \\
\hline 1991 & 8 & 78 & 106 & 0.19 & 0.18 & 30.40 \\
\hline 1991 & 8 & 79 & 169 & 0.37 & 0.31 & 44.00 \\
\hline 1991 & 8 & 80 & 90 & 0.20 & 0.19 & 31.50 \\
\hline 1991 & 8 & 81 & 145 & 0.29 & 0.28 & 36.70 \\
\hline 1991 & 8 & 82 & 192 & 0.43 & 0.33 & 44.70 \\
\hline 1991 & 8 & 83 & 137 & 0.29 & 0.29 & 40.80 \\
\hline 1991 & 8 & 84 & 149 & 0.36 & 0.30 & 42.30 \\
\hline 1991 & 8 & 85 & 64 & 0.16 & 0.13 & 33.50 \\
\hline 1991 & 10 & 1 & 315 & 0.65 & 0.60 & 54.00 \\
\hline 1991 & 10 & 2 & 290 & 0.58 & 0.50 & 48.30 \\
\hline 1991 & 10 & 3 & 210 & 0.46 & 0.40 & 36.20 \\
\hline 1991 & 10 & 4 & 410 & 0.88 & 0.80 & 72.50 \\
\hline 1991 & 10 & 5 & 240 & 0.52 & 0.58 & 43.90 \\
\hline 1991 & 10 & 6 & 374 & 0.75 & 0.68 & 65.60 \\
\hline 1991 & 10 & 7 & 252 & 0.55 & 0.51 & 52.20 \\
\hline 1991 & 10 & 8 & 133 & 0.31 & 0.23 & 35.00 \\
\hline 1991 & 10 & 9 & 158 & 0.37 & 0.37 & 35.10 \\
\hline 1991 & 10 & 10 & 179 & 0.40 & 0.36 & 39.40 \\
\hline 1991 & 10 & 11 & 246 & 0.49 & 0.42 & 42.20 \\
\hline
\end{tabular}


Appendix 1. Continued.

\begin{tabular}{|c|c|c|c|c|c|c|}
\hline 1991 & 10 & 12 & 344 & 0.71 & 0.66 & 64.10 \\
\hline 1991 & 10 & 13 & 319 & 0.64 & 0.60 & 69.10 \\
\hline 1991 & 10 & 14 & 281 & 0.62 & 0.54 & 60.60 \\
\hline 1991 & 10 & 15 & 376 & 0.77 & 0.72 & 70.50 \\
\hline 1991 & 10 & 16 & 329 & 0.69 & 0.61 & 60.00 \\
\hline 1991 & 10 & 17 & 295 & 0.61 & 0.55 & 54.10 \\
\hline 1991 & 10 & 18 & 309 & 0.61 & 0.61 & 51.20 \\
\hline 1991 & 10 & 19 & 190 & 0.45 & 0.41 & 46.20 \\
\hline 1991 & 10 & 20 & 301 & 0.64 & 0.58 & 61.20 \\
\hline 1991 & 10 & 21 & 220 & 0.48 & 0.46 & 42.90 \\
\hline 1991 & 10 & 22 & 289 & 0.60 & 0.55 & 45.60 \\
\hline 1991 & 10 & 23 & 128 & 0.26 & 0.25 & 37.60 \\
\hline 1991 & 10 & 24 & 116 & 0.28 & 0.25 & 35.10 \\
\hline 1991 & 10 & 25 & 256 & 0.58 & 0.55 & 49.80 \\
\hline 1991 & 10 & 26 & 120 & 0.31 & 0.29 & 36.40 \\
\hline 1991 & 10 & 27 & 111 & 0.29 & 0.28 & 28.50 \\
\hline 1991 & 10 & 28 & 161 & 0.40 & 0.34 & 42.60 \\
\hline 1991 & 10 & 29 & 477 & 1.00 & 0.94 & 89.80 \\
\hline 1991 & 10 & 30 & 139 & 0.33 & 0.36 & 38.50 \\
\hline 1991 & 10 & 31 & 166 & 0.40 & 0.36 & 43.00 \\
\hline 1991 & 10 & 32 & 177 & 0.40 & 0.39 & 41.00 \\
\hline 1991 & 10 & 33 & 210 & 0.47 & 0.40 & 42.60 \\
\hline 1991 & 10 & 34 & 464 & 0.97 & 0.89 & 85.10 \\
\hline 1991 & 10 & 35 & 328 & 0.77 & 0.67 & 65.50 \\
\hline 1991 & 10 & 36 & 136 & 0.28 & 0.25 & 38.20 \\
\hline 1991 & 10 & 37 & 160 & 0.36 & 0.30 & 37.50 \\
\hline 1991 & 10 & 38 & 172 & 0.39 & 0.39 & 41.10 \\
\hline 1991 & 10 & 39 & 102 & 0.26 & 0.22 & 25.50 \\
\hline 1991 & 10 & 40 & 150 & 0.30 & 0.28 & 35.00 \\
\hline 1991 & 10 & 41 & 170 & 0.43 & 0.40 & 50.70 \\
\hline 1991 & 10 & 42 & 181 & 0.42 & 0.39 & 39.00 \\
\hline 1991 & 10 & 43 & 461 & 1.04 & 0.91 & 80.60 \\
\hline 1991 & 10 & 44 & 392 & 0.78 & 0.75 & 75.10 \\
\hline 1991 & 10 & 45 & 208 & 0.50 & 0.44 & 51.10 \\
\hline 1991 & 10 & 46 & 143 & 0.35 & 0.31 & 39.00 \\
\hline 1991 & 10 & 47 & 126 & 0.28 & 0.25 & 30.60 \\
\hline 1991 & 10 & 48 & 142 & 0.36 & 0.32 & 31.90 \\
\hline 1991 & 10 & 49 & 224 & 0.54 & 0.51 & 49.10 \\
\hline 1991 & 10 & 50 & 213 & 0.55 & 0.49 & 50.70 \\
\hline 1991 & 10 & 51 & 225 & 0.55 & 0.52 & 58.40 \\
\hline 1991 & 10 & 52 & 423 & 0.92 & 0.80 & 79.00 \\
\hline 1991 & 10 & 53 & 517 & 1.10 & 1.01 & 98.70 \\
\hline 1991 & 10 & 54 & 331 & 0.70 & 0.67 & 74.60 \\
\hline 1991 & 10 & 55 & 186 & 0.43 & 0.38 & 41.00 \\
\hline 1991 & 10 & 56 & 169 & 0.39 & 0.34 & 42.90 \\
\hline 1991 & 10 & 57 & 134 & 0.32 & 0.28 & 29.00 \\
\hline
\end{tabular}


Appendix 1. Continued.

\begin{tabular}{|c|c|c|c|c|c|c|}
\hline 1991 & 10 & 58 & 89 & 0.23 & 0.20 & 23.40 \\
\hline 1991 & 10 & 59 & 164 & 0.34 & 0.31 & 36.70 \\
\hline 1991 & 10 & 60 & 135 & 0.30 & 0.30 & 31.20 \\
\hline 1991 & 10 & 61 & 82 & 0.20 & 0.19 & 12.60 \\
\hline 1991 & 10 & 62 & 113 & 0.25 & 0.24 & 31.10 \\
\hline 1991 & 10 & 63 & 188 & 0.36 & 0.44 & 41.20 \\
\hline 1991 & 10 & 64 & 108 & 0.24 & 0.22 & 32.50 \\
\hline 1991 & 10 & 65 & 128 & 0.31 & 0.28 & 30.30 \\
\hline 1991 & 10 & 66 & 142 & 0.31 & 0.29 & 36.90 \\
\hline 1991 & 10 & 67 & 94 & 0.24 & 0.20 & 29.80 \\
\hline 1991 & 10 & 68 & 96 & 0.21 & 0.20 & 26.80 \\
\hline 1991 & 10 & 69 & 113 & 0.24 & 0.28 & 28.90 \\
\hline 1991 & 10 & 70 & 261 & 0.57 & 0.50 & 51.50 \\
\hline 1991 & 10 & 71 & 137 & 0.33 & 0.33 & 37.60 \\
\hline 1991 & 10 & 72 & 131 & 0.32 & 0.29 & 32.30 \\
\hline 1991 & 10 & 73 & 151 & 0.39 & 0.38 & 38.80 \\
\hline 1991 & 10 & 74 & 232 & 0.57 & 0.50 & 56.30 \\
\hline 1991 & 10 & 75 & 180 & 0.42 & 0.42 & 33.10 \\
\hline 1991 & 10 & 76 & 283 & 0.79 & 0.62 & 65.50 \\
\hline 1991 & 10 & 77 & 132 & 0.34 & 0.30 & 44.80 \\
\hline 1991 & 10 & 78 & 179 & 0.40 & 0.39 & 36.00 \\
\hline 1991 & 10 & 79 & 168 & 0.38 & 0.31 & 34.60 \\
\hline 1991 & 10 & 80 & 105 & 0.23 & 0.22 & 16.90 \\
\hline 1991 & 10 & 81 & 154 & 0.38 & 0.37 & 37.00 \\
\hline 1991 & 10 & 82 & 260 & 0.58 & 0.51 & 44.60 \\
\hline 1991 & 10 & 83 & 361 & 0.86 & 0.76 & 87.10 \\
\hline 1991 & 10 & 84 & 52 & 0.10 & 0.12 & 13.80 \\
\hline 1991 & 10 & 85 & 90 & 0.22 & 0.21 & 24.50 \\
\hline 1991 & 10 & 86 & 344 & 0.83 & 0.79 & 64.60 \\
\hline 1991 & 10 & 87 & 127 & 0.30 & 0.29 & 33.10 \\
\hline 1991 & 10 & 88 & 144 & 0.39 & 0.31 & 34.50 \\
\hline 1991 & 9 & 1 & 262 & 0.51 & 0.48 & 49.70 \\
\hline 1991 & 9 & 2 & 250 & 0.48 & 0.47 & 45.00 \\
\hline 1991 & 9 & 3 & 315 & 0.61 & 0.59 & 54.50 \\
\hline 1991 & 9 & 4 & 220 & 0.43 & 0.38 & 40.50 \\
\hline 1991 & 9 & 5 & 230 & 0.48 & 0.41 & 46.00 \\
\hline 1991 & 9 & 6 & 51 & 0.12 & 0.11 & 12.20 \\
\hline 1991 & 9 & 7 & 205 & 0.41 & 0.31 & 44.00 \\
\hline 1991 & 9 & 8 & 159 & 0.31 & 0.29 & 30.00 \\
\hline 1991 & 9 & 9 & 360 & 0.71 & 0.63 & 66.50 \\
\hline 1991 & 9 & 10 & 200 & 0.49 & 0.44 & 46.00 \\
\hline 1991 & 9 & 11 & 225 & 0.49 & 0.42 & 49.60 \\
\hline 1991 & 9 & 12 & 230 & 0.53 & 0.48 & 63.50 \\
\hline 1991 & 9 & 13 & 260 & 0.55 & 0.51 & 56.90 \\
\hline 1991 & 9 & 14 & 173 & 0.40 & 0.34 & 41.90 \\
\hline 1991 & 9 & 15 & 171 & 0.40 & 0.33 & 41.40 \\
\hline
\end{tabular}


Appendix 1. Continued.

\begin{tabular}{|c|c|c|c|c|c|c|}
\hline 1991 & 9 & 16 & 223 & 0.46 & 0.41 & 54.00 \\
\hline 1991 & 9 & 17 & 200 & 0.38 & 0.38 & 45.00 \\
\hline 1991 & 9 & 18 & 242 & 0.51 & 0.41 & 62.40 \\
\hline 1991 & 9 & 19 & 205 & 0.41 & 0.39 & 47.00 \\
\hline 1991 & 9 & 20 & 212 & 0.40 & 0.30 & 51.30 \\
\hline 1991 & 9 & 21 & 228 & 0.58 & 0.50 & 50.40 \\
\hline 1991 & 9 & 22 & 203 & 0.38 & 0.33 & 51.40 \\
\hline 1991 & 9 & 23 & 202 & 0.44 & 0.40 & 43.50 \\
\hline 1991 & 9 & 24 & 205 & 0.44 & 0.39 & 40.70 \\
\hline 1991 & 9 & 25 & 211 & 0.53 & 0.41 & 44.30 \\
\hline 1991 & 9 & 26 & 198 & 0.45 & 0.39 & 50.00 \\
\hline 1991 & 9 & 27 & 224 & 0.42 & 0.40 & 49.20 \\
\hline 1991 & 9 & 28 & 167 & 0.27 & 0.23 & 33.10 \\
\hline 1991 & 9 & 29 & 178 & 0.32 & 0.29 & 37.50 \\
\hline 1991 & 9 & 30 & 247 & 0.51 & 0.50 & 54.40 \\
\hline 1991 & 9 & 31 & 220 & 0.48 & 0.46 & 48.80 \\
\hline 1991 & 9 & 32 & 240 & 0.56 & 0.48 & 64.00 \\
\hline 1991 & 9 & 33 & 266 & 0.56 & 0.50 & 58.40 \\
\hline 1991 & 9 & 34 & 238 & 0.53 & 0.50 & 56.30 \\
\hline 1991 & 9 & 35 & 240 & 0.50 & 0.42 & 50.30 \\
\hline 1991 & 9 & 36 & 219 & 0.45 & 0.46 & 46.80 \\
\hline 1991 & 9 & 37 & 239 & 0.48 & 0.41 & 49.90 \\
\hline 1991 & 9 & 38 & 193 & 0.38 & 0.40 & 38.80 \\
\hline 1991 & 9 & 39 & 288 & 0.59 & 0.50 & 62.00 \\
\hline 1991 & 9 & 40 & 229 & 0.39 & 0.38 & 43.00 \\
\hline 1991 & 9 & 41 & 261 & 0.54 & 0.44 & 60.20 \\
\hline 1991 & 9 & 42 & 218 & 0.39 & 0.38 & 46.10 \\
\hline 1991 & 9 & 43 & 198 & 0.43 & 0.40 & 37.90 \\
\hline 1991 & 9 & 44 & 198 & 0.39 & 0.35 & 39.90 \\
\hline 1991 & 9 & 45 & 191 & 0.42 & 0.39 & 40.80 \\
\hline 1991 & 9 & 46 & 186 & 0.36 & 0.31 & 47.80 \\
\hline 1991 & 9 & 47 & 166 & 0.53 & 0.45 & 58.20 \\
\hline 1991 & 9 & 48 & 168 & 0.28 & 0.38 & 35.80 \\
\hline 1991 & 9 & 49 & 207 & 0.37 & 0.31 & 46.90 \\
\hline 1991 & 9 & 50 & 201 & 0.37 & 0.35 & 48.50 \\
\hline 1991 & 9 & 51 & 230 & 0.50 & 0.44 & 56.00 \\
\hline 1991 & 9 & 52 & 200 & 0.47 & 0.42 & 52.90 \\
\hline 1991 & 9 & 53 & 229 & 0.50 & 0.47 & 58.10 \\
\hline 1991 & 9 & 54 & 207 & 0.47 & 0.37 & 57.50 \\
\hline 1991 & 9 & 55 & 225 & 0.49 & 0.48 & 55.60 \\
\hline 1991 & 9 & 56 & 220 & 0.53 & 0.48 & 50.30 \\
\hline 1991 & 9 & 57 & 252 & 0.52 & 0.49 & 67.80 \\
\hline 1991 & 9 & 58 & 185 & 0.31 & 0.23 & 35.30 \\
\hline 1991 & 9 & 59 & 223 & 0.46 & 0.43 & 54.00 \\
\hline 1991 & 9 & 60 & 244 & 0.55 & 0.47 & 57.00 \\
\hline 1991 & 9 & 61 & 276 & 0.55 & 0.50 & 70.10 \\
\hline
\end{tabular}


Appendix 1. Continued.

\begin{tabular}{|c|c|c|c|c|c|c|}
\hline 1991 & 9 & $62 \mid$ & 246 & 0.51 & 0.49 & 59.80 \\
\hline 1991 & 9 & 63 & 178 & 0.33 & 0.30 & 39.70 \\
\hline 1991 & 9 & 64 & 212 & 0.49 & 0.40 & 51.70 \\
\hline 1991 & 9 & 65 & 162 & 0.26 & 0.28 & 30.70 \\
\hline 1991 & 9 & 66 & 151 & 0.26 & 0.21 & 33.40 \\
\hline 1991 & 9 & 67 & 231 & 0.43 & 0.40 & 47.00 \\
\hline 1991 & 9 & 68 & 134 & 0.23 & 0.21 & 32.10 \\
\hline 1991 & 9 & 69 & 151 & 0.29 & 0.22 & 36.70 \\
\hline 1991 & 9 & 70 & 208 & 0.44 & 0.37 & 51.10 \\
\hline 1991 & 9 & 71 & 101 & 0.19 & 0.16 & 28.00 \\
\hline 1991 & 9 & 72 & 194 & 0.39 & 0.39 & 52.50 \\
\hline 1991 & 9 & 73 & 159 & 0.29 & 0.28 & 33.20 \\
\hline 1991 & 9 & 74 & 231 & 0.48 & 0.42 & 55.50 \\
\hline 1991 & 9 & 75 & 158 & 0.30 & 0.28 & 39.90 \\
\hline 1991 & 9 & 76 & 222 & 0.47 & 0.40 & 54.30 \\
\hline 1991 & 9 & 77 & 146 & 0.29 & 0.24 & 39.50 \\
\hline 1991 & 9 & 78 & 189 & 0.34 & 0.31 & 41.70 \\
\hline 1991 & 9 & 79 & 206 & 0.39 & 0.38 & 49.10 \\
\hline 1991 & 9 & 80 & 183 & 0.27 & 0.22 & 34.80 \\
\hline 1991 & 9 & 81 & 187 & 0.23 & 0.23 & 30.40 \\
\hline 1991 & 9 & 82 & 53 & 0.11 & 0.10 & 19.30 \\
\hline 1991 & 9 & 83 & 149 & 0.24 & 0.20 & 29.10 \\
\hline 1991 & 9 & 84 & 48 & 0.10 & 0.09 & 13.10 \\
\hline 1991 & 9 & 85 & 222 & 0.43 & 0.46 & 48.30 \\
\hline 1991 & 9 & 86 & 216 & 0.43 & 0.40 & 53.30 \\
\hline 1991 & 9 & 87 & 109 & 0.23 & 0.22 & 31.40 \\
\hline 1991 & 6 & 1 & 108 & 0.27 & 0.27 & 35.80 \\
\hline 1991 & 6 & 2 & 64 & 0.20 & 0.20 & 20.20 \\
\hline 1991 & 6 & 3 & 123 & 0.30 & 0.30 & 32.10 \\
\hline 1991 & 6 & 4 & 121 & 0.31 & 0.25 & 30.95 \\
\hline 1991 & 6 & 5 & 96 & 0.24 & 0.20 & 30.00 \\
\hline 1991 & 6 & 6 & 141 & 0.34 & 0.35 & 37.80 \\
\hline 1991 & 6 & 7 & i21 & 0.31 & 0.29 & 32.20 \\
\hline 1991 & 6 & 8 & 60 & 0.14 & 0.13 & 21.70 \\
\hline 1991 & 6 & 9 & 131 & 0.32 & 0.29 & 35.50 \\
\hline 1991 & 6 & 10 & 61 & 0.17 & 0.11 & 18.00 \\
\hline 1991 & 6 & 11 & 142 & 0.35 & 0.31 & 38.40 \\
\hline 1991 & 6 & 12 & 91 & 0.23 & 0.21 & 26.10 \\
\hline 1991 & 6 & 13 & 90 & 0.21 & 0.20 & 24.00 \\
\hline 1991 & 6 & 14 & 76 & 0.17 & 0.17 & 26.90 \\
\hline 1991 & 6 & 15 & 50 & 0.13 & 0.11 & 17.00 \\
\hline 1991 & 6 & 16 & 125 & 0.27 & 0.22 & 30.60 \\
\hline 1991 & 6 & 17 & 119 & 0.29 & 0.28 & 35.10 \\
\hline 1991 & 6 & 18 & 123 & 0.28 & 0.24 & 32.30 \\
\hline 1991 & 6 & 19 & 87 & 0.22 & 0.20 & 27.20 \\
\hline 1991 & 6 & 20 & 96 & 0.24 & 0.26 & 29.00 \\
\hline
\end{tabular}




\begin{tabular}{|c|c|c|c|c|c|c|}
\hline 1991 & 6 & 21 & 43 & 0.10 & 005 & 1700 \\
\hline 1991 & 6 & 22 & 109 & 0.26 & 0.27 & 31.00 \\
\hline 1991 & 6 & 23 & 121 & 0.30 & 0.29 & 32.00 \\
\hline 1991 & 6 & 24 & 132 & 0.34 & 0.41 & 34.60 \\
\hline 1991 & 6 & 25 & 122 & 0.31 & 0.29 & 34.00 \\
\hline 1991 & 6 & 26 & 72 & 0.18 & 0.11 & 21.90 \\
\hline 1991 & 6 & 27 & 75 & 0.20 & 0.20 & 23.20 \\
\hline 1991 & 6 & 28 & 112 & 0.26 & 0.29 & 27.00 \\
\hline 1991 & 6 & 29 & 113 & 0.26 & 0.21 & 30.80 \\
\hline 1991 & 6 & 30 & 90 & 0.22 & 0.20 & 24.40 \\
\hline 1991 & 6 & 31 & 103 & 0.24 & 0.20 & 28.70 \\
\hline 1991 & 6 & 32 & 99 & 0.24 & 0.29 & 27.20 \\
\hline 1991 & 6 & 33 & 128 & 0.32 & 0.29 & 34.10 \\
\hline 1991 & 6 & 34 & 59 & 0.14 & 0.12 & 21.90 \\
\hline 1991 & 6 & 35 & 106 & 0.28 & 0.24 & 31.40 \\
\hline 1991 & 6 & 36 & 63 & 0.16 & 0.16 & 20.30 \\
\hline 1991 & 6 & 37 & 61 & 0.15 & 0.11 & 21.30 \\
\hline 1991 & 6 & 38 & 82 & 0.21 & 0.19 & 24.00 \\
\hline 1991 & 6 & 39 & 130 & 0.32 & 0.30 & 34.90 \\
\hline 1991 & 6 & 40 & 120 & 0.28 & 0.24 & 34.90 \\
\hline 1991 & 6 & 41 & 136 & 0.35 & 0.34 & 37.00 \\
\hline 1991 & 6 & 42 & 96 & 0.22 & 0.22 & 33.00 \\
\hline 1991 & 6 & 43 & 72 & 0.17 & 0.17 & 25.10 \\
\hline 1991 & 6 & 44 & 119 & 0.28 & 0.23 & 33.80 \\
\hline 1991 & 6 & 45 & 112 & 0.27 & 0.28 & 34.80 \\
\hline 1991 & 6 & 46 & 60 & 0.15 & 0.12 & 22.00 \\
\hline 1991 & 6 & 47 & 107 & 0.27 & 0.24 & 30.80 \\
\hline 1991 & 6 & 48 & 75 & 0.17 & 0.16 & 25.50 \\
\hline 1991 & 6 & 49 & 86 & 0.20 & 0.20 & 27.10 \\
\hline 1991 & 6 & 50 & 85 & 0.23 & 0.18 & 25.10 \\
\hline 1991 & 6 & 51 & 99 & 0.24 & 0.29 & 30.60 \\
\hline 1991 & 6 & 52 & 146 & 0.33 & 0.34 & 37.90 \\
\hline 1991 & 6 & 53 & 120 & 0.28 & 0.29 & 34.10 \\
\hline 1991 & 6 & 54 & 88 & 0.22 & 0.14 & 32.10 \\
\hline 1991 & 6 & 55 & 91 & 0.21 & 0.22 & 21.70 \\
\hline 1991 & 6 & 56 & 75 & 0.17 & 0.15 & 20.80 \\
\hline 1991 & 6 & 57 & 57 & 0.13 & 0.11 & 21.90 \\
\hline 1991 & 6 & 58 & 86 & 0.22 & 0.22 & 27.20 \\
\hline 1991 & 6 & 59 & 85 & 0.21 & 0.20 & 23.10 \\
\hline 1991 & 6 & 60 & 71 & 0.18 & 0.17 & 21.30 \\
\hline 1991 & 6 & 61 & 49 & 0.11 & 0.11 & 17.80 \\
\hline 1991 & 6 & 62 & 87 & 0.20 & 0.19 & 30.40 \\
\hline 1991 & 6 & 63 & 109 & 0.27 & 0.21 & 31.90 \\
\hline 1991 & 6 & 64 & 143 & 0.33 & 0.32 & 39.00 \\
\hline 1991 & 6 & 65 & 121 & 0.28 & 0.28 & 33.20 \\
\hline 1991 & 6 & 66 & 77 & 0.19 & 0.18 & 24.60 \\
\hline
\end{tabular}


Appendix 1. Continued.

\begin{tabular}{|c|c|c|c|c|c|c|}
\hline 1991 & 6 & 67 & 43 & 0.11 & 0.14 & 20.60 \\
\hline 1991 & 6 & 68 & 65 & 0.16 & 0.08 & 24.00 \\
\hline 1991 & 6 & 69 & 47 & 0.11 & 0.07 & 19.00 \\
\hline 1991 & 6 & 70 & 54 & 0.12 & 0.14 & 18.70 \\
\hline 1991 & 6 & 71 & 69 & 0.16 & 0.15 & 19.90 \\
\hline 1991 & 6 & 72 & 99 & 0.23 & 0.26 & 30.00 \\
\hline 1991 & 6 & 73 & 52. & 0.12 & 0.10 & 17.90 \\
\hline 1991 & 6 & 74 & 58 & 0.15 & 0.10 & 20.80 \\
\hline 1991 & 6 & 75 & 53 & 0.13 & 0.11 & 21.40 \\
\hline 1991 & 6 & 76 & 21 & 0.06 & 0.08 & 8.90 \\
\hline 1991 & 6 & 77 & 51 & 0.13 & 0.07 & 19.30 \\
\hline 1991 & 6 & 78 & 40 & 0.12 & 0.13 & 19.10 \\
\hline 1991 & 6 & 79 & 48 & 0.12 & 0.10 & 17.40 \\
\hline 1991 & 6 & 80 & 27 & 0.08 & 0.02 & 13.20 \\
\hline 1991 & 6 & 81 & 32 & 0.08 & 0.09 & 9.30 \\
\hline 1991 & 6 & 82 & 40 & 0.11 & 0.10 & 11.40 \\
\hline 1991 & 6 & 83 & 41 & 0.11 & 0.10 & 12.90 \\
\hline 1991 & 6 & 84 & 34 & 0.07 & 0.10 & 16.20 \\
\hline 1991 & 6 & 85 & 17 & 0.04 & 0.02 & 12.50 \\
\hline 1991 & 6 & 86 & 30 & 0.08 & 0.09 & 13.00 \\
\hline 1991 & 6 & 87 & 36 & 0.08 & 0.12 & 13.50 \\
\hline 1991 & 6 & 88 & 39 & 0.10 & 0.07 & 16.00 \\
\hline 1991 & 6 & 89 & 29 & 0.07 & 0.10 & 12.30 \\
\hline 1991 & 6 & 90 & 40 & 0.11 & 0.10 & 17.10 \\
\hline 1991 & 6 & 91 & 55 & 0.14 & 0.10 & 18.10 \\
\hline 1991 & 6 & 92 & 29 & 0.06 & 0.05 & 12.00 \\
\hline 1991 & 6 & 93 & 44 & 0.12 & 0.14 & 15.00 \\
\hline 1991 & 6 & 94 & 32 & 0.09 & 0.04 & 11.90 \\
\hline 1991 & 6 & 95 & 21 & 0.06 & 0.02 & 11.80 \\
\hline 1991 & 6 & 96 & 45 & 0.10 & 0.04 & 18.50 \\
\hline 1991 & 4 & 1 & 116 & 0.35 & 0.29 & 33.40 \\
\hline 1991 & 4 & 2 & 157 & 0.33 & 0.35 & 42.50 \\
\hline 1991 & 4 & 3 & 147 & 0.28 & 0.24 & 35.00 \\
\hline 1991 & 4 & 4 & 145 & 0.26 & 0.26 & 41.40 \\
\hline 1991 & 4 & 5 & 148 & 0.26 & 0.24 & 39.20 \\
\hline 1991 & 4 & 6 & 130 & 0.25 & 0.21 & 35.20 \\
\hline 1991 & 4 & 7 & 159 & 0.29 & 0.30 & 44.50 \\
\hline 1991 & 4 & 8 & 132 & 0.24 & 0.20 & 31.20 \\
\hline 1991 & 4 & 9 & 106 & 0.19 & 0.20 & 34.20 \\
\hline 1991 & 4 & 10 & 148 & 0.28 & 0.20 & 39.10 \\
\hline 1991 & 4 & 11 & 115 & 0.21 & 0.35 & 36.10 \\
\hline 1991 & 4 & 12 & 103 & 0.18 & 0.24 & 30.40 \\
\hline 1991 & 4 & 13 & 52 & 0.10 & 0.10 & 21.30 \\
\hline 1991 & 4 & 14 & 114 & 0.21 & 0.20 & 32.00 \\
\hline 1991 & 4 & 15 & 98 & 0.18 & 0.16 & 33.60 \\
\hline 1991 & 4 & 16 & 129 & 0.22 & 0.20 & 43.30 \\
\hline
\end{tabular}




\begin{tabular}{|c|c|c|c|c|c|c|}
\hline 1991 & 4 & & & & & \\
\hline 1991 & 4 & & 102 & 0.19 & 0.15 & 29.00 \\
\hline$i 991$ & 4 & $\frac{18}{19}$ & 98 & 0.19 & 0.20 & 34.90 \\
\hline 1991 & 4 & 20 & $\frac{139}{119}$ & 0.26 & 0.20 & 33.50 \\
\hline 1991 & 4 & 21 & $\frac{119}{84}$ & 0.22 & 0.20 & 37.90 \\
\hline 1991 & 4 & 22 & $\begin{array}{r}84 \\
87\end{array}$ & 0.15 & 0.13 & 28.00 \\
\hline 1991 & 4 & & 87 & 0.16 & 0.15 & 29.30 \\
\hline 1991 & 4 & 24 & 153 & 0.27 & 0.20 & 42.00 \\
\hline 1991 & 4 & & 134 & 0.25 & 0.25 & 40.20 \\
\hline 1991 & 4 & $\frac{25}{26}$ & 157 & 0.27 & 0.25 & 40.60 \\
\hline 1991 & 4 & $\frac{26}{27}$ & 88 & 0.15 & 0.20 & 28.90 \\
\hline 1991 & 4 & $\frac{27}{28}$ & 165 & 0.30 & 0.25 & 41.00 \\
\hline 1991 & 4 & $\frac{20}{29}$ & 164 & 0.29 & 0.30 & 43.70 \\
\hline 1991 & 4 & $\frac{29}{30}$ & 146 & 0.25 & 0.20 & 32.90 \\
\hline 1991 & 4 & 31 & 70 & 0.13 & 0.10 & 28.50 \\
\hline 1991 & 7 & & 98 & 0.18 & 0.20 & 33.00 \\
\hline 1991 & 7 & & 162 & 0.46 & 0.40 & 44.20 \\
\hline 1991 & 7 & & 166 & 0.41 & 0.40 & 42.50 \\
\hline 1991 & 7 & & 103 & 0.23 & 0.15 & 35.00 \\
\hline 1991 & 7 & 5 & 116 & 0.26 & 0.28 & 35.70 \\
\hline 1991 & 7 & $\frac{3}{6}$ & 149 & 0.34 & 0.32 & 42.00 \\
\hline 1991 & 7 & 7 & 128 & 0.34 & 0.34 & 41.00 \\
\hline 1991 & 7 & 8 & 129 & 0.34 & 0.34 & 38.00 \\
\hline 1991 & 7 & 9 & 138 & 0.33 & 0.33 & 39.60 \\
\hline 1991 & 7 & 10 & 129 & 0.33 & 0.33 & 35.40 \\
\hline 1991 & 7 & 11 & $\frac{105}{144}$ & 0.24 & 0.24 & 36.40 \\
\hline 1991 & 7 & 12 & $\begin{array}{r}144 \\
78\end{array}$ & 0.33 & 0.33 & 39.10 \\
\hline 1991 & 7 & 13 & $\begin{array}{l}78 \\
70\end{array}$ & 0.18 & 0.18 & 32.50 \\
\hline 1991 & 7 & 14 & $\begin{array}{r}70 \\
145\end{array}$ & 0.18 & 0.18 & 21.20 \\
\hline 1991 & 7 & 15 & $\begin{array}{l}145 \\
116\end{array}$ & 0.37 & 0.37 & 41.00 \\
\hline 1991 & 7 & & 116 & 0.27 & 0.25 & 37.00 \\
\hline 1991 & 7 & 16 & 114 & 0.26 & 0.25 & 32.80 \\
\hline 1991 & 7 & 17 & 159 & 0.41 & 0.40 & 42.00 \\
\hline 1991 & 7 & 18 & 131 & 0.31 & 0.28 & 36.80 \\
\hline 1991 & 7 & $\frac{19}{20}$ & 65 & 0.14 & 0.12 & 22.90 \\
\hline 1991 & 7 & 20 & 125 & 0.28 & 0.30 & 33.20 \\
\hline 1991 & 7 & $\frac{21}{27}$ & 132 & 0.33 & 0.30 & 34.10 \\
\hline 1991 & 7 & $\frac{22}{23}$ & 120 & 0.26 & 0.18 & 38.90 \\
\hline 1991 & 7 & 23 & 120 & 0.24 & 0.22 & 43.00 \\
\hline 1991 & 7 & 24 & 150 & 0.41 & 0.45 & 41.00 \\
\hline & & 25 & 166 & 0.45 & 0.38 & 44.40 \\
\hline 1991 & 7 & 26 & 102 & 0.27 & 0.30 & 29.50 \\
\hline 1991 & 7 & 27 & 119 & 0.28 & 0.20 & 35.90 \\
\hline 1991 & 7 & 28 & 114 & 0.25 & 0.22 & 37.00 \\
\hline 1991 & 7 & 29 & 98 & 0.22 & 0.20 & 36.00 \\
\hline 1991 & 7 & 30 & 180 & 0.44 & 0.41 & 46.00 \\
\hline 1991 & 7 & 31 & 136 & 0.33 & 0.25 & 41.00 \\
\hline
\end{tabular}


Appendix 1. Continued.

\begin{tabular}{|c|c|c|c|c|c|c|}
\hline 1991 & 7 & 32 & 155 & 0.39 & 0.38 & 37.00 \\
\hline 1991 & 7 & 33 & 120 & 0.28 & 0.22 & 31.50 \\
\hline 1991 & 7 & 34 & 149 & 0.36 & 0.35 & 39.00 \\
\hline 1991 & 7 & 35 & 113 & 0.26 & 0.23 & 31.00 \\
\hline 1991 & 7 & 36 & 123 & 0.27 & 0.22 & 41.60 \\
\hline 1991 & 7 & 37 & 93 & 0.19 & 0.20 & 37.00 \\
\hline 1991 & 7 & 38 & 141 & 0.34 & 0.30 & 37.00 \\
\hline 1991 & 7 & 39 & 91 & 0.22 & 0.20 & 26.00 \\
\hline 1991 & 7 & 40 & 114 & 0.24 & 0.23 & 39.00 \\
\hline 1991 & 7 & 41 & 120 & 0.29 & 0.27 & 38.00 \\
\hline 1991 & 7 & 42 & 131 & 0.33 & 0.28 & 36.00 \\
\hline 1991 & 7 & 43 & 133 & 0.35 & 0.27 & 36.00 \\
\hline 1991 & 7 & 44 & 110 & 0.29 & 0.25 & 31.70 \\
\hline 1991 & 7 & 45 & 118 & 0.25 & 0.16 & 38.00 \\
\hline 1991 & 7 & 46 & 112 & 0.28 & 0.17 & 36.40 \\
\hline 1991 & 7 & 47 & 98 & 0.20 & 0.20 & 36.00 \\
\hline 1991 & 7 & 48 & 114 & 0.24 & 0.29 & 33.10 \\
\hline 1991 & 7 & 49 & 43 & 0.10 & 0.09 & 14.20 \\
\hline 1991 & 7 & 50 & 138 & 0.33 & 0.23 & 44.00 \\
\hline 1991 & 7 & 51 & 101 & 0.26 & 0.28 & 26.90 \\
\hline 1991 & 7 & 52 & 174 & 0.45 & 0.41 & 47.20 \\
\hline 1991 & 7 & 53 & 147 & 0.33 & 0.30 & 39.80 \\
\hline 1991 & 7 & 54 & 168 & 0.39 & 0.40 & 46.00 \\
\hline 1991 & 7 & 55 & 133 & 0.34 & 0.28 & 37.00 \\
\hline 1991 & 7 & 56 & 165 & 0.43 & 0.42 & 42.90 \\
\hline 1991 & 7 & 57 & 153 & 0.33 & 0.30 & 41.00 \\
\hline 1991 & 7 & 58 & 131 & 0.33 & 0.39 & 42.00 \\
\hline 1991 & 7 & 59 & 117 & 0.24 & 0.20 & 35.00 \\
\hline 1991 & 7 & 60 & 118 & 0.28 & 0.21 & 38.90 \\
\hline 1991 & 7 & 61 & 134 & 0.34 & 0.45 & 44.50 \\
\hline 1991 & 7 & 62 & 111 & 0.29 & 0.37 & 46.70 \\
\hline 1991 & 7 & 63. & 120 & 0.27 & 0.13 & 41.00 \\
\hline 1991 & 7 & 64 & 101 & 0.24 & 0.07 & 37.00 \\
\hline 1991 & 7 & 65 & 110 & 0.24 & 0.28 & 39.80 \\
\hline 1991 & 7 & 66 & 108 & 0.30 & 0.20 & 41.20 \\
\hline 1991 & 7 & 67 & 74 & 0.16 & 0.18 & 28.10 \\
\hline 1991 & 7 & 68 & 100 & 0.22 & 0.16 & 31.90 \\
\hline 1991 & 7 & 69 & 109 & 0.26 & 0.28 & 33.80 \\
\hline 1991 & 7 & 70 & 44 & 0.11 & 0.10 & 20.50 \\
\hline 1991 & 7 & 71 & 60 & 0.15 & 0.14 & 18.30 \\
\hline 1991 & 7 & 72 & 85 & 0.22 & 0.25 & 31.30 \\
\hline 1991 & 7 & 73 & 59 & 0.16 & 0.11 & 16.60 \\
\hline 1991 & 7 & 74 & 111 & 0.25 & 0.25 & 38.10 \\
\hline 1991 & 7 & 75 & 79 & 0.18 & 0.34 & 28.00 \\
\hline 1991 & 7 & 76 & 112 & 0.29 & 0.26 & 41.40 \\
\hline 1991 & 7 & 77 & 134 & 0.31 & 0.25 & 41.00 \\
\hline
\end{tabular}


Appendix 1. Continued.

\begin{tabular}{|c|c|c|c|c|c|c|}
\hline 1991 & 7 & 78 & 107 & 0.26 & 0.28 & 45.20 \\
\hline 1991 & 7 & 79 & 80 & 0.17 & 0.22 & 31.00 \\
\hline 1991 & 7 & 80 & 123 & 0.32 & 0.20 & 45.50 \\
\hline 1991 & 7 & 81 & 77 & 0.18 & 0.10 & 30.00 \\
\hline 1991 & 7 & 82 & 27 & 0.09 & 0.19 & 6.80 \\
\hline 1991 & 7 & 83 & 96 & 0.21 & 0.24 & 40.30 \\
\hline 1991 & 7 & 84 & 52 & 0.13 & 0.23 & 27.30 \\
\hline 1991 & 1 & 1 & 67 & 0.20 & 0.27 & 21.20 \\
\hline 1991 & 1 & 2 & 67 & 0.20 & 0.18 & 20.00 \\
\hline 1991 & 1 & 3 & 59 & 0.17 & 0.20 & 19.80 \\
\hline 1991 & 1 & 4 & 72 & 0.21 & 0.19 & 24.00 \\
\hline 1991 & 1 & 5 & 68 & 0.17 & 0.20 & 23.00 \\
\hline 1991 & 1 & 6 & 73 & 0.22 & 0.20 & 24.00 \\
\hline 1991 & 1 & 7 & 86 & 0.25 & 0.28 & 31.90 \\
\hline 1991 & 1 & 8 & 73 & 0.21 & 0.21 & 24.50 \\
\hline 1991 & 1 & 9 & 53 & 0.15 & 0.11 & 17.80 \\
\hline 1991 & 1 & 10 & 57 & 0.17 & 0.10 & 22.00 \\
\hline 1991 & 1 & 11 & 83 & 0.24 & 0.20 & 26.40 \\
\hline 1991 & 1 & 12 & 73 & 0.22 & 0.20 & 23.10 \\
\hline 1991 & 1 & 13 & 78 & 0.22 & 0.20 & 24.00 \\
\hline 1991 & 1 & 14 & 74 & 0.20 & 0.20 & 22.10 \\
\hline 1991 & 1 & 15 & 72 & 0.20 & 0.20 & 22.60 \\
\hline 1991 & 1 & 16 & 66 & 0.18 & 0.18 & 22.70 \\
\hline 1991 & 1 & 17 & 50 & 0.13 & 0.12 & 19.00 \\
\hline 1991 & 1 & 18 & 77 & 0.22 & 0.20 & 22.90 \\
\hline 1991 & 1 & 19 & 79 & 0.21 & 0.20 & 23.90 \\
\hline 1991 & 1 & 20 & 63 & 0.17 & 0.17 & 26.90 \\
\hline 1991 & 1 & 21 & 64 & 0.18 & 0.14 & 18.30 \\
\hline 1991 & 1 & 22 & 71 & 0.19 & 0.20 & 23.10 \\
\hline 1991 & 1 & 23 & 77 & 0.23 & 0.20 & 24.00 \\
\hline 1991 & 1 & 24 & 75 & 0.21 & 0.19 & 29.50 \\
\hline 1991 & 1 & 25 & 74 & 0.15 & 0.11 & 17.40 \\
\hline 1991 & 1 & 26 & 110 & 0.32 & 0.31 & 36.00 \\
\hline 1991 & 1 & 27 & 19 & 0.06 & 0.06 & 10.00 \\
\hline 1991 & 1 & 28 & 39 & 0.12 & 0.11 & 12.10 \\
\hline 1991 & 1 & 29 & 72 & 0.21 & 0.21 & 17.90 \\
\hline 1992 & 11 & 1 & 79 & 0.14 & 0.15 & 27.00 \\
\hline 1332 & 11 & 2 & 70 & 0.13 & 0.14 & 25.00 \\
\hline 1992 & 11 & 3 & 58 & 0.09 & 0.08 & 20.00 \\
\hline 1992 & 11 & 4 & 95 & 0.18 & 0.21 & 38.00 \\
\hline 1992 & 11 & 5 & 91 & 0.16 & 0.12 & 32.00 \\
\hline 1992 & 11 & 6 & 82 & 0.16 & 0.12 & 32.00 \\
\hline 1992 & 11 & 7 & 97 & 0.17 & 0.20 & 37.50 \\
\hline 1992 & 11 & 8 & 54 & 0.11 & 0.10 & 21.00 \\
\hline 1992 & 11 & 9 & 73 & 0.13 & 0.15 & 30.00 \\
\hline 1992 & 11 & 10 & 48 & 0.08 & 0.05 & 19.00 \\
\hline
\end{tabular}


Appendix 1. Continued.

\begin{tabular}{|c|c|c|c|c|c|c|}
\hline 1992 & 11 & 11 & 27 & 0.03 & 0.07 & 12.00 \\
\hline 1992 & 11 & 12 & 47 & 0.08 & 0.05 & 18.00 \\
\hline 1992 & 11 & 13 & 28 & 0.03 & 0.08 & 15.00 \\
\hline 1992 & 11 & 14 & 53 & 0.09 & 0.08 & 20.00 \\
\hline 1992 & 11 & 15 & 17 & 0.04 & 0.05 & 12.00 \\
\hline 1992 & 11 & 16 & 17 & 0.03 & 0.00 & 12.00 \\
\hline 1992 & 11 & 17 & 7 & 0.01 & 0.01 & 4.00 \\
\hline 1992 & 12 & 1 & 52 & 0.09 & 0.10 & 16.00 \\
\hline 1992 & 12 & 2 & 53 & 0.09 & 0.09 & 16.00 \\
\hline 1992 & 12 & 3 & 70 & 0.11 & 0.09 & 18.50 \\
\hline 1992 & 12 & 4 & 68 & 0.11 & 0.13 & 22.00 \\
\hline 1992 & 12 & 5 & 74 & 0.12 & 0.06 & 20.00 \\
\hline 1992 & 12 & 6 & 65 & 0.11 & 0.14 & 23.00 \\
\hline 1992 & 12 & 7 & 58 & 0.10 & 0.06 & 23.50 \\
\hline 1992 & 12 & 8 & 41 & 0.07 & 0.05 & 19.50 \\
\hline 1992 & 12 & 9 & 67 & 0.11 & 0.10 & 23.50 \\
\hline 1992 & 12 & 10 & 75 & 0.13 & 0.10 & 22.00 \\
\hline 1992 & 12 & 11 & 58 & 0.10 & 0.13 & 20.00 \\
\hline 1992 & 12 & 12 & 70 & 0.11 & 0.08 & 20.00 \\
\hline 1992 & 12 & 13 & 71 & 0.11 & 0.07 & 21.00 \\
\hline 1992 & 12 & 14 & 73 & 0.11 & 0.10 & 24.50 \\
\hline 1992 & 12 & 15 & 89 & 0.14 & 0.17 & 20.00 \\
\hline 1992 & 12 & 16 & 42 & 0.07 & 0.11 & 16.00 \\
\hline 1992 & 12 & 17 & 75 & 0.12 & 0.10 & 22.00 \\
\hline 1992 & 12 & 18 & 64 & 0.10 & 0.10 & 18.00 \\
\hline 1992 & 12 & 19 & 69 & 0.10 & 0.09 & 24.00 \\
\hline 1992 & 12 & 20 & 79 & 0.13 & 0.16 & 19.00 \\
\hline 1992 & 12 & 21 & 73 & 0.10 & 0.08 & 18.00 \\
\hline 1992 & 12 & 22 & 67 & 0.10 & 0.08 & 21.00 \\
\hline 1992 & 12 & 23 & 85 & 0.13 & 0.12 & 24.00 \\
\hline 1992 & 12 & 24 & 65 & 0.10 & 0.10 & 19.00 \\
\hline 1992 & 12 & 25 & 85 & 0.14 & 0.14 & 24.00 \\
\hline 1992 & 13 & 1 & 61 & 0.13 & 0.12 & 22.50 \\
\hline 1992 & 13 & 2 & 72 & 0.14 & 0.11 & 24.00 \\
\hline 1992 & 13 & 3 & 62 & 0.12 & 0.14 & 21.00 \\
\hline 1992 & 13 & 4 & 95 & 0.19 & 0.13 & 28.00 \\
\hline 1992 & 13 & 5 & 95 & 0.20 & 0.20 & 35.00 \\
\hline 1992 & 13 & 6 & 103 & 0.21 & 0.20 & 39.00 \\
\hline 1992 & 13 & 7 & 61 & 0.12 & 0.10 & 23.00 \\
\hline 1992 & 13 & 8 & 46 & 0.09 & 0.10 & 20.00 \\
\hline 1992 & 13 & 9 & 95 & 0.19 & 0.15 & 36.00 \\
\hline 1992 & 13 & 10 & 35 & 0.08 & 0.08 & 15.50 \\
\hline 1992 & 13 & 11 & 32 & 0.07 & 0.05 & 13.00 \\
\hline 1992 & 13 & 12 & 32 & 0.06 & 0.09 & 16.00 \\
\hline 1992 & 13 & 13 & 16 & 0.03 & 0.03 & 11.00 \\
\hline 1992 & 13 & 14 & 36 & 0.07 & 0.05 & 12.00 \\
\hline
\end{tabular}


Appendix 1. Continued.

\begin{tabular}{|c|c|c|c|c|c|c|}
\hline 1992 & 13 & 15 & 22 & 0.04 & 0.05 & 9.00 \\
\hline 1992 & 13 & 16 & 98 & 0.19 & 0.15 & 31.00 \\
\hline 1992 & 13 & 17 & 42 & 0.08 & 0.08 & 17.00 \\
\hline 1992 & 13 & 18 & 65 & 0.12 & 0.11 & 29.00 \\
\hline 1992 & 13 & 19 & 66 & 0.13 & 0.13 & 21.00 \\
\hline 1992 & 13 & 20 & 37 & 0.07 & 0.08 & 18.00 \\
\hline 1992 & 14 & 1 & 61 & 0.15 & 0.11 & 20.00 \\
\hline 1992 & 14 & 2 & 51 & 0.11 & 0.11 & 18.00 \\
\hline 1992 & 14 & 3 & 66 & 0.16 & 0.15 & 18.00 \\
\hline 1992 & 14 & 4 & 25 & 0.05 & 0.05 & 13.00 \\
\hline 1992 & 14 & 5 & 74 & 0.17 & 0.18 & 22.00 \\
\hline 1992 & 14 & 6 & 32 & 0.07 & 0.02 & 13.00 \\
\hline 1992 & 14 & 7 & 58 & 0.13 & 0.16 & 20.00 \\
\hline 1992 & 14 & 8 & 118 & 0.28 & 0.24 & 36.00 \\
\hline 1992 & 14 & 9 & 72 & 0.16 & 0.17 & 27.00 \\
\hline 1992 & 14 & 10 & 63 & 0.14 & 0.13 & 28.50 \\
\hline 1992 & 14 & 11 & 72 & 0.17 & 0.17 & 25.00 \\
\hline 1992 & 14 & 12 & 62 & 0.15 & 0.13 & 21.00 \\
\hline 1992 & 14 & 13 & 69 & 0.15 & 0.15 & 23.00 \\
\hline 1992 & 14 & 14 & 56 & 0.13 & 0.11 & 24.00 \\
\hline 1992 & 14 & 15 & 72 & 0.16 & 0.16 & 20.00 \\
\hline 1992 & 14 & 16 & 41 & 0.10 & 0.10 & 19.00 \\
\hline 1992 & 14 & 17 & 48 & 0.12 & 0.10 & 20.00 \\
\hline 1992 & 14 & 18 & 48 & 0.13 & 0.10 & 18.00 \\
\hline 1992 & 14 & 19 & 80 & 0.19 & 0.18 & 31.00 \\
\hline 1992 & 14 & 20 & 40 & 0.10 & 0.09 & 17.00 \\
\hline 1992 & 14 & 21 & 47 & 0.11 & 0.10 & 24.00 \\
\hline 1992 & 14 & 22 & 41 & 0.09 & 0.11 & 16.00 \\
\hline 1992 & 14 & 23 & 41 & 0.09 & 0.09 & 13.00 \\
\hline 1992 & 14 & 24 & 23 & 0.05 & 0.03 & 13.00 \\
\hline 1992 & 14 & 25 & 15 & 0.02 & 0.03 & 12.00 \\
\hline 1992 & 14 & 26 & 20 & 0.04 & 0.07 & 10.00 \\
\hline 1992 & 14 & 27 & 26 & 0.06 & 0.03 & 12.00 \\
\hline 1992 & 14 & 28 & 18 & 0.05 & 0.06 & 11.00 \\
\hline 1992 & 15 & 1 & 56 & 0.11 & 0.09 & 28.00 \\
\hline 1992 & 15 & 2 & 63 & 0.14 & 0.13 & 22.00 \\
\hline 1992 & 15 & 3 & 70 & 0.12 & 0.12 & 28.00 \\
\hline 1992 & 15 & 4 & 91 & 0.18 & 0.18 & 30.00 \\
\hline 1992 & 15 & 5 & 72 & 0.11 & 0.10 & 16.00 \\
\hline 1992 & 15 & 6 & 64 & 0.12 & 0.11 & 21.00 \\
\hline 1992 & 15 & 7 & 84 & 0.18 & 0.20 & 33.00 \\
\hline 1992 & 15 & 8 & 93 & 0.16 & 0.20 & 29.00 \\
\hline 1992 & 15 & 9 & 84 & 0.18 & 0.19 & 27.00 \\
\hline 1992 & 15 & 10 & 85 & 0.14 & 0.13 & 24.00 \\
\hline 1992 & 15 & 11 & 55 & 0.09 & 0.09 & 21.00 \\
\hline
\end{tabular}


Appendix 1. Continued.

\begin{tabular}{|c|c|c|c|c|c|c|}
\hline 1992 & 15 & 12 & 69 & 0.13 & 0.13 & 23.00 \\
\hline 1992 & 15 & 13 & 75 & 0.14 & 0.11 & 20.00 \\
\hline 1992 & 15 & 14 & 84 & 0.18 & 0.19 & 28.00 \\
\hline 1992 & 15 & 15 & 87 & 0.17 & 0.14 & 26.00 \\
\hline 1992 & 15 & 16 & 71 & 0.14 & 0.10 & 25.50 \\
\hline 1992 & 15 & 17 & 74 & 0.15 & 0.13 & 21.50 \\
\hline 1992 & 15 & 18 & 69 & 0.12 & 0.15 & 26.00 \\
\hline 1992 & 15 & 19 & 105 & 0.20 & 0.16 & 26.00 \\
\hline 1992 & 15 & 20 & 72 & 0.13 & 0.09 & 28.00 \\
\hline 1992 & 15 & 21 & 82 & 0.15 & 0.18 & 25.00 \\
\hline 1992 & 15 & 22 & 92 & 0.18 & 0.13 & 27.00 \\
\hline 1992 & 15 & 23 & 72 & 0.13 & 0.20 & 21.00 \\
\hline 1992 & 15 & 24 & 97 & 0.20 & 0.10 & 27.00 \\
\hline 1992 & 15 & 25 & 62 & 0.12 & 0.13 & 18.00 \\
\hline 1992 & 15 & 26 & 72 & 0.14 & 0.14 & 21.00 \\
\hline 1992 & 15 & 27 & 73 & 0.15 & 0.13 & 24.00 \\
\hline 1992 & 15 & 28 & 68 & 0.12 & 0.11 & 22.00 \\
\hline 1992 & 15 & 29 & 65 & 0.10 & 0.09 & 23.00 \\
\hline 1992 & 15 & 30 & 53 & 0.09 & 0.08 & 23.00 \\
\hline 1992 & 15 & 31 & 86 & 0.17 & 0.19 & 28.00 \\
\hline 1992 & 15 & 32 & 33 & 0.06 & 0.03 & 11.00 \\
\hline 1992 & 15 & 33 & 66 & 0.12 & 0.09 & 21.00 \\
\hline 1992 & 15 & 34 & 12 & 0.02 & 0.02 & 6.00 \\
\hline 1992 & 15 & 35 & 15 & 0.03 & 0.02 & 5.00 \\
\hline 1992 & 16 & 1 & 64 & 0.11 & 0.11 & 30.50 \\
\hline 1992 & 16 & 2 & 58 & 0.11 & 0.09 & 29.00 \\
\hline 1992 & 16 & 3 & 65 & 0.12 & 0.16 & 29.00 \\
\hline 1992 & 16 & 4 & 74 & 0.14 & 0.10 & 28.00 \\
\hline 1992 & 16 & 5 & 65 & 0.12 & 0.14 & 25.00 \\
\hline 1992 & 16 & 6 & 77 & 0.14 & 0.12 & 27.00 \\
\hline 1992 & 16 & 7 & 78 & 0.15 & 0.15 & 28.00 \\
\hline 1992 & 16 & 8 & 70 & 0.13 & 0.10 & 26.00 \\
\hline 1992 & 16 & 9 & 64 & 0.11 & 0.08 & 24.00 \\
\hline 1992 & 16 & 10 & 78 & 0.15 & 0.14 & 28.00 \\
\hline 1992 & 16 & 11 & 74 & 0.15 & 0.13 & 28.00 \\
\hline 1992 & 16 & 12 & 64 & 0.13 & 0.08 & 25.00 \\
\hline 1992 & 16 & 13 & 49 & 0.10 & 0.12 & 28.00 \\
\hline 1992 & 16 & 14 & 70 & 0.14 & 0.11 & 26.00 \\
\hline 1992 & 16 & 15 & 64 & 0.12 & 0.11 & 23.00 \\
\hline 1992 & 16 & 16 & 73 & 0.13 & 0.10 & 25.00 \\
\hline 1992 & 16 & 17 & 61 & 0.11 & 0.10 & 22.00 \\
\hline 1992 & 16 & 18 & 54 & 0.10 & 0.10 & 22.00 \\
\hline 1992 & 16 & 19 & 67 & 0.13 & 0.13 & 24.00 \\
\hline 1992 & 16 & 20 & 68 & 0.13 & 0.15 & 25.00 \\
\hline 1992 & 16 & 21 & 68 & 0.12 & 0.10 & 25.00 \\
\hline 1992 & 16 & 22 & 71 & 0.12 & 0.12 & 23.00 \\
\hline
\end{tabular}




\begin{tabular}{|c|c|c|c|c|c|c|}
\hline 1992 & 16 & 23 & 68 & 0.14 & 0.12 & 24.00 \\
\hline 1992 & 16 & 24 & 67 & 0.12 & 0.14 & 22.00 \\
\hline 1992 & 16 & 25 & 68 & 0.13 & 0.11 & 25.00 \\
\hline 1992 & 16 & 26 & 68 & 0.13 & 0.12 & 25.00 \\
\hline 1992 & 16 & 27 & 65 & 0.13 & 0.11 & 23.00 \\
\hline 1992 & 16 & 28 & 57 & 0.11 & 0.10 & 20.00 \\
\hline 1992 & 16 & 29 & 65 & 0.13 & 0.11 & 22.00 \\
\hline 1992 & 17 & 1 & 50 & 0.09 & 0.03 & 19.00 \\
\hline 1992 & 17 & 2 & 69 & 0.14 & 0.12 & 22.00 \\
\hline 1992 & 17 & 3 & 57 & 0.11 & 0.10 & 21.00 \\
\hline 1992 & 17 & 4 & 52 & 0.10 & 0.12 & 22.00 \\
\hline 1992 & 17 & 5 & 66 & 0.13 & 0.10 & 24.00 \\
\hline 1992 & 17 & 6 & 61 & 0.12 & 0.09 & 19.50 \\
\hline 1992 & 17 & 7 & 57 & 0.11 & 0.12 & 21.20 \\
\hline 1992 & 17 & 8 & 58 & 0.10 & 0.12 & 21.00 \\
\hline 1992 & 17 & 9 & 65 & 0.14 & 0.09 & 23.10 \\
\hline 1992 & 17 & 10 & 54 & 0.12 & 0.09 & 20.00 \\
\hline 1992 & 17 & 11 & 61 & 0.12 & 0.08 & 23.00 \\
\hline 1992 & 17 & 12 & 61 & 0.13 & 0.08 & 24.50 \\
\hline 1992 & 17 & 13 & 66 & 0.13 & 0.13 & 21.00 \\
\hline 1992 & 17 & 14 & 67 & 0.13 & 0.10 & 25.00 \\
\hline 1992 & 17 & 15 & 58 & 0.11 & 0.10 & 18.00 \\
\hline 1992 & 17 & 16 & 58 & 0.12 & 0.08 & 24.00 \\
\hline 1992 & 17 & 17 & 73 & 0.15 & 0.12 & 24.00 \\
\hline 1992 & 17 & 18 & 81 & 0.16 & 0.15 & 31.20 \\
\hline 1992 & 17 & 19 & 64 & 0.12 & 0.11 & 22.80 \\
\hline 1992 & 17 & 20 & 64 & 0.14 & 0.10 & 21.00 \\
\hline 1992 & 17 & 21 & 70 & 0.13 & 0.15 & 23.00 \\
\hline 1992 & 17 & 22 & 58 & 0.11 & 0.08 & 19.00 \\
\hline 1992 & 17 & 23 & 57 & 0.10 & 0.09 & 24.00 \\
\hline 1992 & 17 & 24 & 73 & 0.14 & 0.16 & 26.00 \\
\hline 1992 & 17 & 25 & 52 & 0.09 & 0.10 & 21.00 \\
\hline 1992 & 17 & 26 & 62 & 0.13 & 0.10 & 24.00 \\
\hline 1992 & 17 & 27 & 72 & 0.14 & 0.12 & 28.00 \\
\hline 1992 & 17 & 28 & 41 & 0.08 & 0.05 & 17.00 \\
\hline 1992 & 17 & 29 & 49 & 0.08 & 0.09 & 20.00 \\
\hline 1992 & 17 & 30 & 51 & 0.09 & 0.10 & 20.00 \\
\hline 1992 & 17 & 31 & 65 & 0.13 & 0.10 & 25.00 \\
\hline 1992 & 17 & 32 & 48 & 0.10 & 0.10 & 20.00 \\
\hline 1992 & 17 & 33 & 55 & 0.11 & 0.10 & 19.50 \\
\hline 1992 & 17 & 34 & 59 & 0.12 & 0.10 & 20.00 \\
\hline 1992 & 17 & 35 & 58 & 0.09 & 0.10 & 17.00 \\
\hline 1992 & 17 & 36 & 48 & 0.09 & 0.10 & 12.00 \\
\hline 1992 & 17 & 37 & 57 & 0.11 & 0.09 & 18.00 \\
\hline 1992 & 17 & 38 & 47 & 0.07 & 0.06 & 18.00 \\
\hline 1992 & 17 & 39 & 46 & 0.08 & 0.09 & 16.00 \\
\hline
\end{tabular}




\begin{tabular}{|c|c|c|c|c|c|c|}
\hline 1992 & 17 & 40 & 57 & 0.11 & 0.09 & 17.00 \\
\hline 1992 & 17 & 41 & 57 & 0.10 & 0.09 & 17.00 \\
\hline 1992 & 17 & 42 & 39 & 0.06 & 0.08 & 15.00 \\
\hline 1992 & 17 & 43 & 46 & 0.08 & 0.08 & 16.00 \\
\hline 1992 & 17 & 44 & 10 & 0.02 & 0.01 & 6.00 \\
\hline 1992 & 17 & 45 & 40 & 0.06 & 0.05 & 15.00 \\
\hline 1992 & 18 & 1 & 48 & 0.10 & 0.13 & 18.00 \\
\hline 1992 & 18 & 2 & 38 & 0.08 & 0.06 & 14.00 \\
\hline 1992 & 18 & 3 & 93 & 0.18 & 0.16 & 28.00 \\
\hline 1992 & 18 & 4 & 27 & 0.06 & 0.05 & 13.00 \\
\hline 1992 & 18 & 5 & 74 & 0.15 & 0.11 & 29.00 \\
\hline 1992 & 18 & 6 & 57 & 0.10 & 0.14 & 23.00 \\
\hline 1992 & 18 & 7 & 101 & 0.20 & 0.18 & 33.00 \\
\hline 1992 & 18 & 8 & 82 & 0.14 & 0.12 & 26.00 \\
\hline 1992 & 18 & 9 & 76 & 0.17 & 0.12 & 28.00 \\
\hline 1992 & 18 & 10 & 88 & 0.15 & 0.15 & 26.00 \\
\hline 1992 & 18 & 11 & 100 & 0.19 & 0.16 & 32.00 \\
\hline 1992 & 18 & 12 & 65 & 0.12 & 0.12 & 24.00 \\
\hline 1992 & 18 & 13 & 77 & 0.15 & 0.14 & 23.00 \\
\hline 1992 & 18 & 14 & 77 & 0.16 & 0.11 & 26.00 \\
\hline 1992 & 18 & 15 & 99 & 0.19 & 0.19 & 36.00 \\
\hline 1992 & 18 & 16 & 98 & 0.18 & 0.19 & 33.00 \\
\hline 1992 & 18 & 17 & 69 & 0.12 & 0.13 & 28.00 \\
\hline 1992 & 18 & 18 & 85 & 0.16 & 0.13 & 28.00 \\
\hline 1992 & 18 & 19 & 96 & 0.18 & 0.15 & 27.00 \\
\hline 1992 & 18 & 20 & 81 & 0.14 & 0.11 & 25.00 \\
\hline 1992 & 18 & 21 & 105 & 0.20 & 0.18 & 33.00 \\
\hline 1992 & 18 & 22 & 21 & 0.04 & 0.04 & 10.00 \\
\hline 1992 & 18 & 23 & 74 & 0.15 & 0.10 & 25.00 \\
\hline 1992 & 18 & 24 & 69 & 0.14 & 0.13 & 22.00 \\
\hline 1992 & 18 & 25 & 24 & 0.04 & 0.04 & 13.00 \\
\hline 1992 & 18 & 26 & 55 & 0.12 & 0.14 & 20.00 \\
\hline 1992 & 18 & 27 & 81 & 0.15 & 0.12 & 27.00 \\
\hline 1992 & 18 & 28 & 118 & 0.22 & 0.16 & 35.00 \\
\hline 1992 & 18 & 29 & 101 & 0.19 & 0.17 & 34.00 \\
\hline 1992 & 18 & 30 & 80 & 0.16 & 0.19 & 29.00 \\
\hline 1992 & 18 & 31 & 74 & 0.14 & 0.16 & 28.00 \\
\hline 1992 & 18 & 32 & 97 & 0.18 & 0.17 & 30.00 \\
\hline 1992 & 18 & 33 & 86 & 0.16 & 0.15 & 34.50 \\
\hline 1992 & 18 & 34 & 64 & 0.13 & 0.16 & 23.00 \\
\hline 1992 & 18 & 35 & 83 & 0.15 & 0.10 & 25.00 \\
\hline 1992 & 18 & 36 & 100 & 0.18 & 0.18 & 34.50 \\
\hline 1992 & 18 & 37 & 67 & 0.15 & 0.18 & 26.00 \\
\hline 1992 & 18 & 38 & 83 & 0.16 & 0.12 & 27.00 \\
\hline 1992 & 18 & 39 & 83 & 0.17 & 0.11 & 30.00 \\
\hline 1992 & 18 & 40 & 36 & 0.08 & 0.11 & 15.00 \\
\hline
\end{tabular}


Appendix 1. Continued.

\begin{tabular}{|c|c|c|c|c|c|c|}
\hline 1992 & 18 & 41 & 69 & 0.12 & 0.09 & 23.00 \\
\hline 1992 & 18 & 42 & 38 & 0.10 & 0.09 & 18.00 \\
\hline 1992 & 18 & 43 & 38 & 0.08 & 0.07 & 12.00 \\
\hline 1992 & 18 & 44 & 26 & 0.06 & 0.09 & 12.00 \\
\hline 1992 & 18 & 45 & 22 & 0.07 & 0.03 & 10.00 \\
\hline 1992 & 18 & 46 & 24 & 0.04 & 0.02 & 7.00 \\
\hline 1992 & 18 & 47 & 18 & 0.07 & 0.05 & 6.00 \\
\hline 1992 & 18 & 48 & 67 & 0.15 & 0.13 & 27.00 \\
\hline 1992 & 18 & 49 & 102 & 0.18 & 0.12 & 29.00 \\
\hline 1992 & 19 & 1 & 112 & 0.26 & 0.27 & 31.00 \\
\hline 1992 & 19 & 2 & 103 & 0.22 & 0.21 & 30.00 \\
\hline 1992 & 19 & 3 & 119 & 0.26 & 0.22 & 29.00 \\
\hline 1992 & 19 & 4 & 115 & 0.25 & 0.26 & 29.00 \\
\hline 1992 & 19 & 5 & 108 & 0.23 & 0.16 & 29.00 \\
\hline 1992 & 19 & 6 & 78 & 0.18 & 0.18 & 23.00 \\
\hline 1992 & 19 & 7 & 124 & 0.30 & 0.29 & 32.00 \\
\hline 1992 & 19 & 8 & 117 & 0.26 & 0.29 & 30.00 \\
\hline 1992 & 19 & 9 & 84 & 0.18 & 0.18 & 25.00 \\
\hline 1992 & 19 & 10 & 91 & 0.19 & 0.20 & 24.00 \\
\hline 1992 & 19 & 11 & 95 & 0.20 & 0.20 & 27.00 \\
\hline 1992 & 19 & 12 & 96 & 0.20 & 0.20 & 27.00 \\
\hline 1992 & 19 & 13 & 85 & 0.19 & 0.18 & 27.00 \\
\hline 1992 & 19 & 14 & 95 & 0.21 & 0.20 & 26.00 \\
\hline 1992 & 19 & 15 & 92 & 0.19 & 0.16 & 25.00 \\
\hline 1992 & 19 & 16 & 48 & 0.11 & 0.18 & 14.00 \\
\hline 1992 & 19 & 17 & 98 & 0.21 & 0.20 & 28.00 \\
\hline 1992 & 19 & 18 & 101 & 0.22 & 0.16 & 29.00 \\
\hline 1992 & 19 & 19 & 92 & 0.20 & 0.20 & 28.00 \\
\hline 1992 & 19 & 20 & 81 & 0.18 & 0.18 & 23.00 \\
\hline 1992 & 19 & 21 & 100 & 0.21 & 0.20 & 30.00 \\
\hline 1992 & 19 & 22 & 65 & 0.14 & 0.14 & 18.00 \\
\hline 1992 & 19 & 23 & 91 & 0.19 & 0.21 & 27.00 \\
\hline 1992 & 19 & 24 & 101 & 0.21 & 0.18 & 28.00 \\
\hline 1992 & 19 & 25 & 96 & 0.18 & 0.26 & 28.00 \\
\hline 1992 & 19 & 26 & 82 & 0.18 & 0.20 & 23.00 \\
\hline 1992 & 19 & 27 & 96 & 0.20 & 0.20 & 29.00 \\
\hline 1992 & 19 & 28 & 96 & 0.20 & 0.18 & 27.00 \\
\hline 1992 & 19 & 29 & 83 & 0.17 & 0.14 & 24.00 \\
\hline 1992 & 19 & 30 & 76 & 0.17 & 0.16 & 23.00 \\
\hline 1992 & 19 & 31 & 83 & 0.17 & 0.13 & 24.00 \\
\hline 1992 & 19 & 32 & 91 & 0.18 & 0.19 & 27.00 \\
\hline 1992 & 19 & 33 & 100 & 0.20 & 0.20 & 28.00 \\
\hline 1992 & 19 & 34 & 86 & 0.18 & 0.17 & 24.00 \\
\hline 1992 & 19 & 35 & 93 & 0.19 & 0.18 & 28.50 \\
\hline 1992 & 19 & 36 & 82 & 0.16 & 0.16 & 24.00 \\
\hline 1992 & 19 & 37 & 69 & 0.15 & 0.14 & 21.00 \\
\hline
\end{tabular}


Appendix 1. Continued.

\begin{tabular}{|c|c|c|c|c|c|c|}
\hline 1992 & 19 & 38 & 73 & 0.15 & 0.16 & 24.50 \\
\hline 1992 & 19 & 39 & 71 & 0.14 & 0.14 & 26.00 \\
\hline 1992 & 19 & 40 & 75 & 0.15 & 0.10 & 25.00 \\
\hline 1992 & 19 & 41 & 86 & 0.18 & 0.19 & 25.00 \\
\hline 1992 & 19 & 42 & 84 & 0.16 & 0.16 & 23.00 \\
\hline 1992 & 19 & 43 & 75 & 0.15 & 0.11 & 21.00 \\
\hline 1992 & 19 & 44 & 84 & 0.18 & 0.20 & 23.00 \\
\hline 1992 & 19 & 45 & 76 & 0.16 & 0.10 & 20.00 \\
\hline 1992 & 19 & 46 & 70 & 0.14 & 0.12 & 21.00 \\
\hline 1992 & 19 & 47 & 84 & 0.18 & 0.18 & 19.00 \\
\hline 1992 & 19 & 48 & 72 & 0.15 & 0.16 & 23.00 \\
\hline 1992 & 19 & 49 & 81 & 0.15 & 0.14 & 22.00 \\
\hline 1992 & 19 & 50 & 75 & 0.16 & 0.10 & 19.00 \\
\hline 1992 & 19 & 51 & 74 & 0.14 & 0.12 & 18.00 \\
\hline 1992 & 19 & 52 & 70 & 0.15 & 0.12 & 22.00 \\
\hline 1992 & 19 & 53 & 90 & 0.19 & 0.16 & 23.00 \\
\hline 1992 & 19 & 54 & 62 & 0.11 & 0.13 & 18.00 \\
\hline 1992 & 20 & 1 & 139 & 0.31 & & 48.50 \\
\hline 1992 & 20 & 2 & 131 & 0.28 & 0.30 & 47.00 \\
\hline 1992 & 20 & 3 & 133 & 0.28 & 0.23 & 46.00 \\
\hline 1992 & 20 & 4. & 140 & 0.31 & 0.28 & 47.50 \\
\hline 1992 & 20 & 5 & 112 & 0.24 & 0.25 & 41.00 \\
\hline 1992 & 20 & 6 & 138 & 0.30 & 0.29 & 50.00 \\
\hline 1992 & 20 & 7 & 136 & 0.30 & 0.26 & 46.00 \\
\hline 1992 & 20 & 8 & 140 & 0.31 & 0.26 & 48.00 \\
\hline 1992 & 20 & 9 & 110 & 0.24 & 0.29 & 41.00 \\
\hline 1992 & 20 & 10 & 82 & 0.19 & 0.21 & 29.00 \\
\hline 1992 & 20 & 11 & 44 & 0.10 & 0.05 & 20.00 \\
\hline 1992 & 20 & 12 & 34 & 0.08 & 0.09 & 12.00 \\
\hline 1992 & 20 & 13 & 141 & 0.32 & 0.31 & 41.00 \\
\hline 1992 & 20 & 14 & 62 & 0.14 & 0.11 & 24.00 \\
\hline 1992 & 20 & 15 & 81 & 0.19 & 0.20 & 25.00 \\
\hline 1992 & 20 & 16 & 100 & 0.22 & 0.20 & 35.00 \\
\hline 1992 & 20 & 17 & 112 & 0.25 & 0.22 & 35.00 \\
\hline 1992 & 20 & 18 & 136 & 0.29 & 0.29 & 36.00 \\
\hline 1992 & 20 & 19 & 122 & 0.25 & 0.21 & 39.00 \\
\hline 1992 & 20 & 20 & 106 & 0.22 & 0.24 & 32.00 \\
\hline 1992 & 20 & 21 & 125 & 0.25 & 0.23 & 36.00 \\
\hline 1992 & 20 & 22 & 106 & 0.21 & 0.20 & 35.00 \\
\hline 1992 & 20 & 23 & 117 & 0.24 & 0.21 & 33.00 \\
\hline 1992 & 20 & 24 & 111 & 0.20 & 0.20 & 30.00 \\
\hline 1992 & 20 & 25 & 123 & 0.24 & 0.20 & 33.00 \\
\hline 1992 & 20 & 26 & 104 & 0.20 & 0.17 & 32.00 \\
\hline 1992 & 20 & 27 & 90 & 0.18 & 0.20 & 25.00 \\
\hline 1992 & 20 & 28 & 53 & 0.12 & 0.05 & 17.00 \\
\hline 1992 & 20 & 29 & 90 & 0.17 & 0.15 & 25.00 \\
\hline
\end{tabular}




\begin{tabular}{|c|c|c|c|c|c|c|}
\hline 1992 & 20 & 31 & 72 & 0.14 & 0.13 & 21.00 \\
\hline 1992 & 20 & 32 & 96 & 0.18 & 0.14 & 30.00 \\
\hline 1992 & 20 & 33 & 74 & 0.14 & 0.12 & 26.00 \\
\hline 1992 & 20 & 34 & 64 & 0.13 & 0.16 & 21.00 \\
\hline 1992 & 20 & $\begin{array}{l}34 \\
35\end{array}$ & 105 & 0.21 & 0.20 & 30.00 \\
\hline 1992 & 20 & & 96 & 0.18 & 0.20 & 26.00 \\
\hline 1992 & $\frac{20}{20}$ & $\frac{36}{37}$ & 91 & 0.18 & 0.16 & 25.00 \\
\hline 1992 & $\frac{<0}{20}$ & $\frac{37}{30}$ & 44 & 0.09 & 0.10 & 14.00 \\
\hline 1992 & $\frac{20}{20}$ & 38 & 99 & 0.18 & 0.20 & 30.00 \\
\hline 1992 & $\frac{20}{20}$ & 39 & 58 & 0.11 & 0.08 & 19.50 \\
\hline 1992 & 20 & 40 & 55 & 0.10 & 0.10 & 19.00 \\
\hline$\frac{1956}{1992}$ & 20 & 41 & 38 & 0.07 & 0.08 & 14.00 \\
\hline & 20 & 42 & 78 & 0.15 & 0.12 & 23.00 \\
\hline$\frac{1992}{1992}$ & 20 & 43 & 83 & 0.15 & 0.12 & 27.00 \\
\hline$\frac{1992}{1992}$ & 20 & 44 & 114 & 0.21 & 0.18 & 33.00 \\
\hline & 20 & 45 & 89 & 0.16 & 0.18 & 27.00 \\
\hline$\frac{1992}{1992}$ & 20 & 46 & 88 & 0.16 & 0.12 & 29.00 \\
\hline 1992 & 20 & 47 & 84 & 0.15 & 0.13 & 28.00 \\
\hline 1992 & 20 & 48 & 111 & 0.20 & 0.20 & 30.00 \\
\hline 1992 & 20 & 49 & 110 & 0.21 & 0.20 & 30.00 \\
\hline 1992 & 20 & 50 & 90 & 0.15 & 0.18 & 26.00 \\
\hline 1992 & 20 & 51 & 83 & 0.15 & 0.11 & 26.00 \\
\hline 1992 & 20 & 52 & 110 & 0.20 & 0.19 & 33.00 \\
\hline 1992 & 20 & 53 & 87 & 0.16 & 0.12 & 27.00 \\
\hline 1992 & 20 & 54 & 81 & 0.15 & 0.16 & 25.00 \\
\hline 1992 & 20 & 55 & 73 & 0.13 & 0.13 & 26.00 \\
\hline 1992 & 20 & 56 & 92 & 0.16 & 0.15 & 31.00 \\
\hline 1992 & 20 & 57 & 102 & 0.18 & 0.15 & 30.00 \\
\hline 1992 & 20 & 58 & 96 & 0.17 & 0.18 & 26.00 \\
\hline 1992 & 20 & 59 & 84 & 0.14 & 0.12 & 23.00 \\
\hline 1992 & 20 & 60 & 53 & 0.10 & 0.10 & 19.00 \\
\hline 1992 & 20 & 61 & 87 & 0.15 & 0.10 & 25.00 \\
\hline 1992 & 20 & 62 & 112 & 0.18 & 0.20 & 29.00 \\
\hline
\end{tabular}



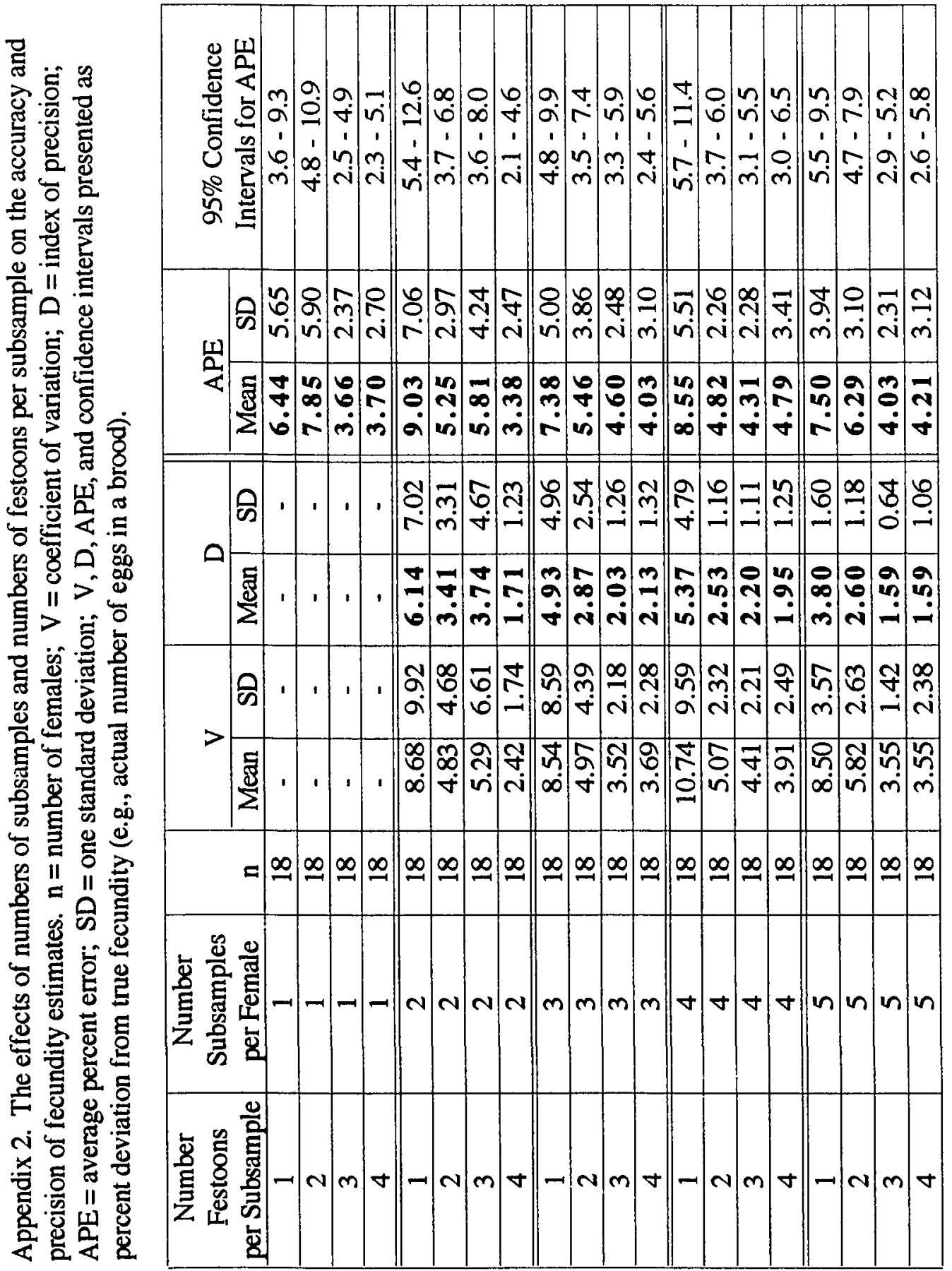